Report No: AUS0001368

Sri Lanka

PER for Nutrition in Sri Lanka

\title{
Assessing Public Financing for Nutrition in Sri Lanka (2014-2018)
}

February 2020

HNP

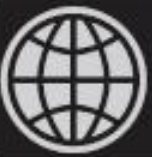

Document of the World Bank 


\section{Assessing Public Financing for Nutrition in Sri Lanka (2014-2018)}

February 2020

(4) THE WORLD BANK SAFA I SORLDANG GRoup 
(C) 2020 The World Bank

1818 H Street NW, Washington DC 20433

Telephone: 202-473-1000; Internet: www.worldbank.org

Some rights reserved

This work is a product of the staff of The World Bank. The findings, interpretations, and conclusions expressed in this work do not necessarily reflect the views of the Executive Directors of The World Bank or the governments they represent. The World Bank does not guarantee the accuracy of the data included in this work. The boundaries, colors, denominations, and other information shown on any map in this work do not imply any judgment on the part of The World Bank concerning the legal status of any territory or the endorsement or acceptance of such boundaries.

Rights and Permissions

The material in this work is subject to copyright. Because The World Bank encourages dissemination of its knowledge, this work may be reproduced, in whole or in part, for noncommercial purposes as long as full attribution to this work is given.

Attribution—please cite the work as follows: World Bank. 2020. Assessing Public Financing for Nutrition in Sri Lanka (20142018). World Bank.

All queries on rights and licenses, including subsidiary rights, should be addressed to World Bank Publications, The World Bank Group, 1818 H Street NW, Washington, DC 20433, USA; fax: 202-522-2625; e-mail: pubrights@ worldbank.org. 


\section{CONTENTS}

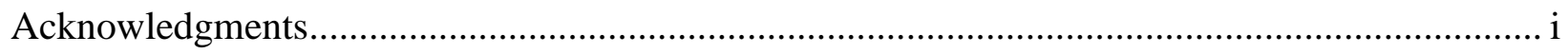

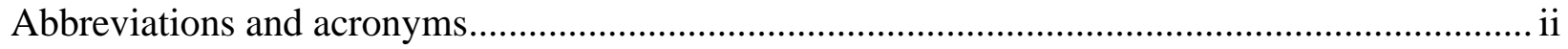

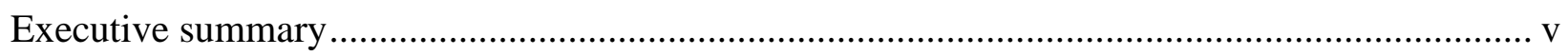

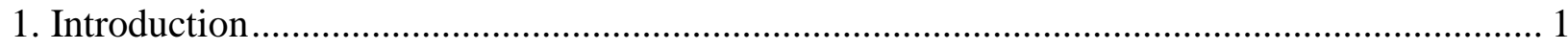

1.1 Rationale, purpose, and structure of the report …................................................... 1

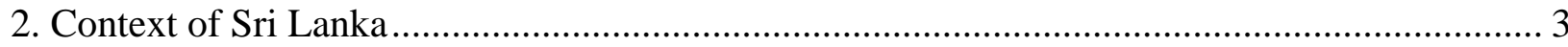

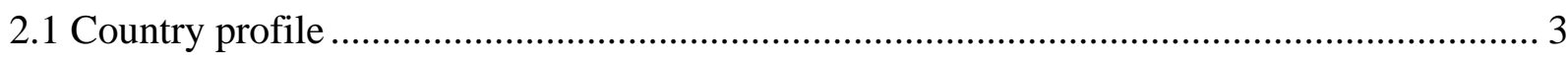

2.2 Health, health system, nutrition, and financing ..................................................... 4

3. Policies and interventions to address the problem of malnutrition in Sri Lanka ................... 11

3.1 Evidence-based nutrition interventions ................................................................. 11

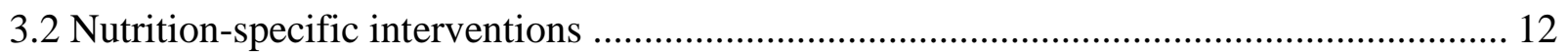

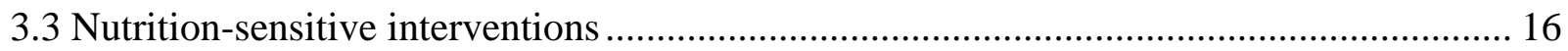

3.4 Nutrition-related policies in Sri Lanka................................................................. 17

3.5 Nutrition-specific interventions in Sri Lanka........................................................ 19

3.6 Nutrition-sensitive interventions in Sri Lanka ....................................................... 24

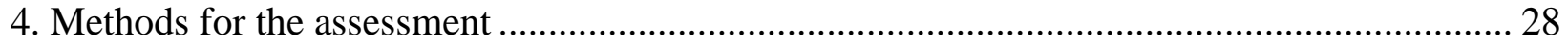

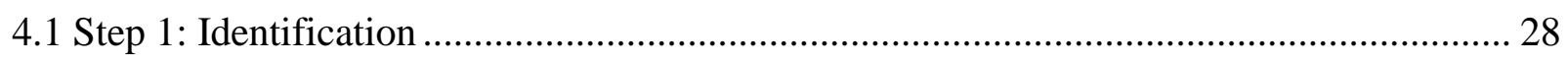

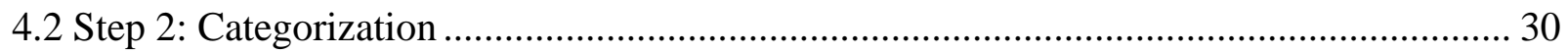

4.3 Step 3: Data collection and assignment of expenditure ............................................. 32

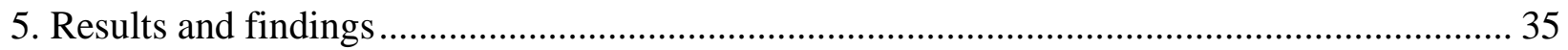

5.1 Public expenditure for nutrition interventions in Sri Lanka.......................................... 35

5.2 Public expenditure for nutrition-specific interventions .......................................... 38

5.3 Public expenditure for nutrition-sensitive interventions ........................................... 44

5.4 Provincial distribution of public expenditure for nutrition .......................................... 51

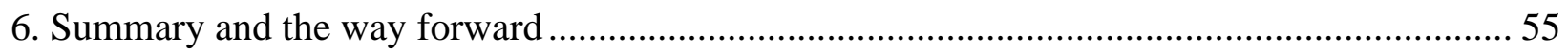

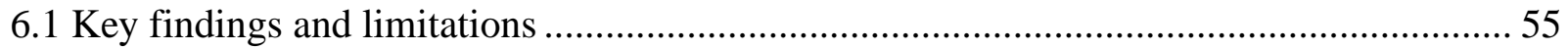

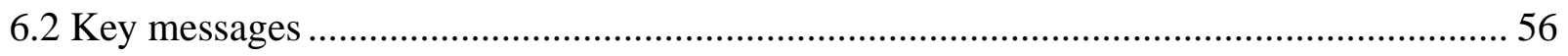


6.3 Challenges faced in tracking financial information ................................................ 57

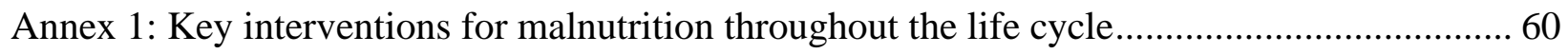

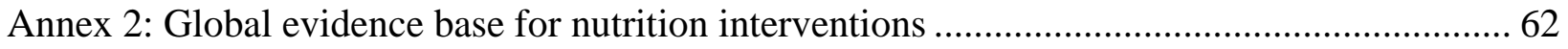

Annex 3: Program level Expenditure for Nutrition Interventions, 2018 ................................ 79

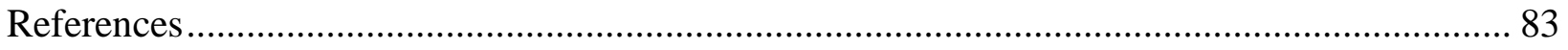

\section{TABLES}

Table 1: Ministries having significant responsibilities and programs related to nutrition ........... 29

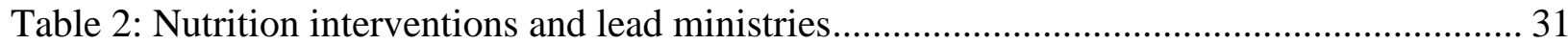

Table 3: Assumptions used for provincial allocation ........................................................... 33

Table 4: Public expenditure for nutrition interventions as a percentage of TPE ...................... 35

Table 5: Cost for scaling up nutrition-specific interventions per year globally ........................ 63

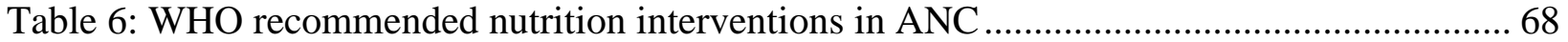

\section{FIGURES}

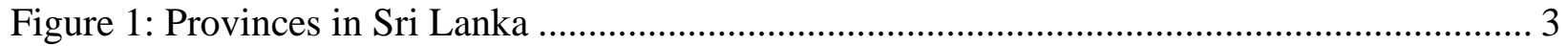

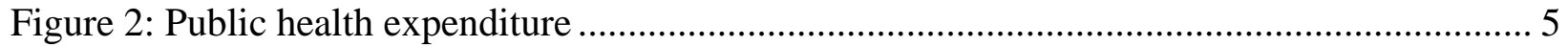

Figure 3: Trends in nutritional status of children under five in Sri Lanka ................................ 6

Figure 4: Fraction of DALYs attributable to key risk factors for under-five children, 2017 ........ 7

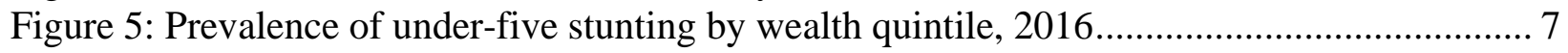

Figure 6: Geographic distribution of under-five stunting and wasting, 2016 ........................... 8

Figure 7: Fraction of DALYs attributable to key risk factors for all ages, 2017 ..................... 10

Figure 8: Lancet framework for actions to achieve optimum fetal and child nutrition and

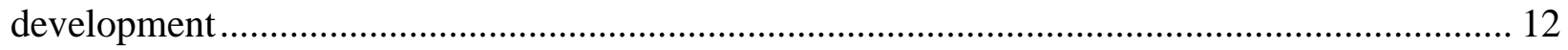

Figure 9: Improving nutrition around the life course.................................................... 13

Figure 10: Mainstreaming maternal nutrition intervention across life cycle and delivery platforms

Figure 11: Coverage of maternal nutrition intervention package through ANC Platforms......... 23

Figure 12: UNICEF conceptual framework of the determinants of child undernutrition............. 30

Figure 13: Nutrition expenditure as a percentage of TPE (unweighted) ................................. 35

Figure 14: Public expenditure on nutrition 2014-2018 ................................................. 36

Figure 15: Per capita public expenditure on nutrition 2014-2018 …....................................... 36

Figure 16: Public expenditure on nutrition-specific interventions .......................................... 39

Figure 17: Per capita public expenditure for key nutrition-specific interventions ..................... 39

Figure 18: Public expenditure on nutrition-specific interventions in the health sector .............. 40

Figure 19: Per-pregnant woman public expenditure for $\mathrm{MCH}$ medicine/supplements and Thriposha

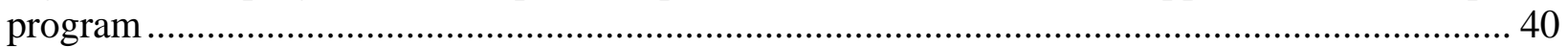

Figure 20: FHB supplements by $\mathrm{MCH}$ program............................................................... 41

Figure 21: Public expenditure on school and preschool nutritional programs .......................... 43 
Figure 22: Per child public expenditure for school and preschool nutritional program, 2018 .... 43

Figure 23: Coverage of schools under school meal program ............................................. 44

Figure 24: Allocation versus expenditure on school nutritional program ................................. 44

Figure 25: Public expenditure on nutrition-sensitive interventions .......................................... 45

Figure 26: Per capita public expenditure on nutrition-sensitive interventions ......................... 45

Figure 27: Public expenditure on cash assistance programs .................................................. 46

Figure 28: Food allowance for pregnant mothers (allocation versus expenditure) ................... 46

Figure 29: Public expenditure on agriculture sector nutrition-sensitive interventions ................ 47

Figure 30: Public expenditure on fisheries sector nutrition-sensitive interventions ................... 48

Figure 31: Public expenditure on livestock sector nutrition-sensitive interventions .................. 49

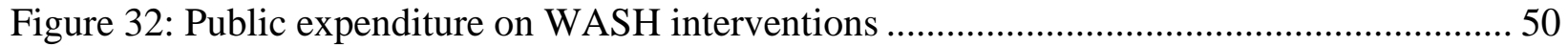

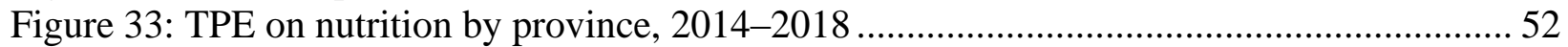

Figure 34: Per capita public expenditure for the DNAP program, 2018 ................................ 53

Figure 35: Percentage of preschool meal beneficiaries ...................................................... 53

Figure 36: Percentage of beneficiaries: Pregnant Mother's Food Allowance versus Samurdhi

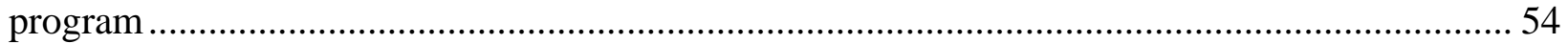

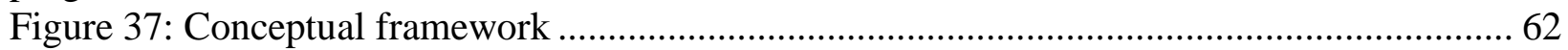

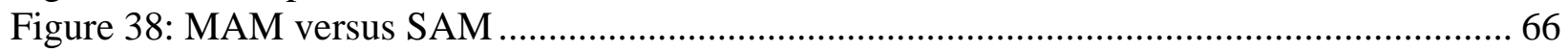

Figure 39: Supporting families for nurturing care and home visiting resource package............. 76

\section{BOXES}

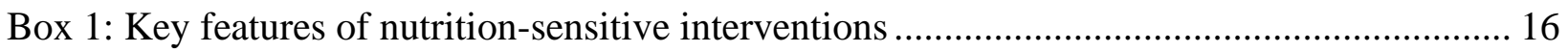

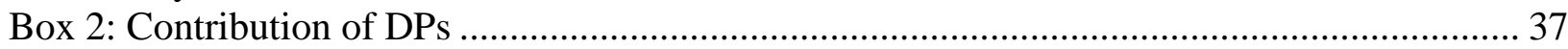

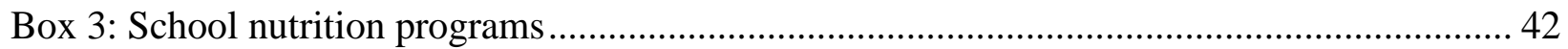

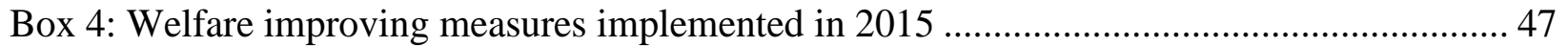

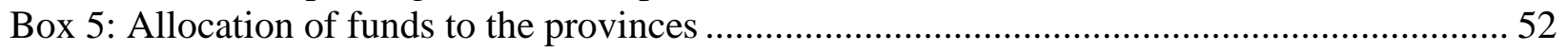

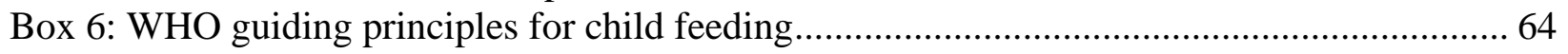

Box 7: Pathways by which agriculture can affect nutrition outcomes................................... 70

Box 8: Three milestones to be achieved for a successful biofortification program................... 71

Box 9: Pathways by which social protection can affect nutrition outcomes ............................ 74 


\section{ACKNOWLEDGMENTS}

This report was prepared by a joint team of the World Bank and the United Nations Children's Fund (UNICEF) consisting of Hideki Higashi, Senior Economist and Task Team Leader (World Bank); Priyanka Jayawardena, Consultant (World Bank); Louise Moreira Daniels, Chief of Social Policy (UNICEF); Suganya Yogeswaran, Research Assistant (World Bank); Upula Vishwamithra Amarasinghe, Research Assistant (World Bank); Safina Abdulloeva, CSD Program Manager (UNICEF); and Deepika Eranjanie Attygalle, Senior Health Specialist (World Bank) with technical support from Renuka Jayatissa (Medical Research Institute), Yi-Kyoung Lee, Senior Health Specialist (World Bank), and Ajay Tandon, Lead Economist (World Bank).

The report was reviewed by Malarmathy Gangatharan, Additional Director General (Department of National Planning); Chandrika Senanayake, Director (Department of National Planning); Gaya Adikari, Assistant Secretary to the President (Presidential Secretariat); Hiranya S. Jayawickrama, Consultant Community Physician (Family Health Bureau, Ministry of Health, Nutrition, and Indigenous Medicine); Anoma C. M. Basnayake, Consultant Community Physician (Nutrition Division, Ministry of Health, Nutrition, and Indigenous Medicine); Nayana Senaratne, Director (Children's Secretariat, Ministry of Women and Child Affairs); Ilija Talev, Policy Specialist (UNICEF); Sheila Murthy, Social Protection Consultant (UNICEF); Atif Khurshid, Policy Specialist (UNICEF); Harriet Torlesse, Regional Advisor Nutrition (UNICEF); and Deepika Nayar Chaudhery, Senior Health, Nutrition and Population Specialist (World Bank). We would like to express our appreciation for their valuable advice during the preparation of this report.

We wish to acknowledge the cooperation and support of the Government of Sri Lanka (GOSL), especially the Nutrition Technical Working Group chaired by the Department of National Planning with members from the Presidential Secretariat; Ministry of Health, Nutrition, and Indigenous Medicine; Ministry of Women and Child Affairs; Ministry of Education; Ministry of Agriculture, Rural Economic Affairs, Irrigation, and Fisheries and Aquatic Resources Development; Ministry of City Planning, Water Supply, and Higher Education; Ministry of Primary Industries and Social Empowerment; Ministry of Hill Country New Villages, Infrastructure, and Community Development; Ministry of Internal and Home Affairs and Provincial Councils and Local Government; Provincial Councils; Ministry of Finance; and Finance Commission, for their ideas and suggestions and for providing the information and data used in the preparation of this report. We would also like to thank the Development Partner Secretariat and Development Partners for contributing critical information and data.

This material has been funded thanks to the contributions of UK Aid from the UK government and the European Commission (EC) through the South Asia Food and Nutrition Security Initiative (SAFANSI), which is administered by the World Bank. The views expressed are entirely those of the authors and do not necessarily reflect the EC or UK government's official policies or the policies of the World Bank or UNICEF. 


\section{ABBREVIATIONS AND ACRONYMS}

ACCEND Assisting Communities in Creating Environmental and Nutritional Development

\begin{tabular}{|c|c|}
\hline $\mathrm{ADB}$ & Asian Development Bank \\
\hline $\mathrm{ANC}$ & Antenatal Care \\
\hline BMI & Body Mass Index \\
\hline $\mathrm{CCT}$ & Conditional Cash Transfer \\
\hline $\mathrm{CFC}$ & Ceylon Fisheries Corporation \\
\hline $\mathrm{CKDu}$ & Chronic Kidney Diseases of Unknown Etiology \\
\hline $\mathrm{CRC}$ & Convention on the Rights of the Child \\
\hline DALY & Disability-adjusted Life Year \\
\hline DAPH & Department of Animal Production and Health \\
\hline DFAR & Department of Fisheries \& Aquatic Resources \\
\hline DHS & Demographic and Health Survey \\
\hline DNCWS & Department of National Community Water Supply \\
\hline DNAP & District Nutrition Action Plan \\
\hline DP & Development Partner \\
\hline $\mathrm{EU}$ & European Union \\
\hline EU-SEM & European Union Support to Socio Economic Measures \\
\hline EU-SDDP & European Union Support to District Development \\
\hline $\mathrm{FAO}$ & Food and Agriculture Organization \\
\hline $\mathrm{FC}$ & Finance Commission \\
\hline FHB & Family Health Bureau \\
\hline FIRST & $\begin{array}{l}\text { Food and Nutrition Security Impact, Resilience, Sustainability, and } \\
\text { Transformation }\end{array}$ \\
\hline FPNP & Food Production National Program \\
\hline FSDD & Fisheries Social Development Division \\
\hline GDP & Gross Domestic Product \\
\hline GNI & Gross National Income \\
\hline GOSL & Government of Sri Lanka \\
\hline GPOBA & Global Partnership on Output-based Aid project \\
\hline $\mathrm{HCI}$ & Human Capital Index \\
\hline HPB & Health Promotion Bureau \\
\hline HR & Human Resource \\
\hline IDA & Iron Deficiency Anemia \\
\hline IEC & Information, Education, and Communication \\
\hline
\end{tabular}




\begin{tabular}{|c|c|}
\hline IMR & Infant Mortality Rate \\
\hline INMAS & Improving Nutrition through Modernizing Agriculture \\
\hline INPARD & Integrating Nutrition Promotion and Rural Development \\
\hline ISSA & International Step by Step Association \\
\hline IYCF & Infant and Young Child Feeding \\
\hline LB & Live Births \\
\hline LBW & Low Birth Weight \\
\hline LMIC & Low- and Middle-Income Country \\
\hline MAD & Minimal Acceptable Diet \\
\hline MAM & Moderate Acute Malnutrition \\
\hline $\mathrm{MCH}$ & Maternal and Child Health \\
\hline MCPWS & Ministry of City Planning, Water Supply, and Higher Education \\
\hline MDD & Minimally Diverse Diet \\
\hline MFARD & Ministry of Fisheries and Aquatic Resources Development \\
\hline MHC & $\begin{array}{l}\text { Ministry of Hill Country New Villages, Infrastructure, and Community } \\
\text { Development }\end{array}$ \\
\hline MLRD & Ministry of Livestock and Rural Community Development \\
\hline MMN & Multiple Micronutrient \\
\hline MNPEA & Ministry of National Policies and Economic Affairs \\
\hline MoA & Ministry of Agriculture \\
\hline MoE & Ministry of Education \\
\hline $\mathrm{MoF}$ & Ministry of Finance \\
\hline $\mathrm{MoH}$ & Ministry of Health, Nutrition, and Indigenous Medicine \\
\hline $\mathrm{MOH}$ & Medical Officer of Health \\
\hline MRI & Medical Research Institute \\
\hline MSAPN & Multi-sector Action Plan for Nutrition \\
\hline MPISE & Ministry of Primary Industry and Social Empowerment \\
\hline MWCA & Ministry of Women and Child Affairs \\
\hline NAQDA & National Aquaculture Development Authority \\
\hline NCD & Noncommunicable Disease \\
\hline ND & Nutrition Division \\
\hline NMR & Neonatal Mortality Rate \\
\hline NNP & National Nutritional Policy \\
\hline NPD & Department of National Planning \\
\hline NWSDB & National Water Supply and Drainage Board \\
\hline OOP & Out-of-Pocket \\
\hline ORS & Oral Rehydration Solution \\
\hline
\end{tabular}




$\begin{array}{ll}\text { PHE } & \text { Public Health Expenditure } \\ \text { PHM } & \text { Public Health Midwife } \\ \text { PNC } & \text { Postnatal Care } \\ \text { RMNCAYH } & \text { Reproductive, Maternal, Newborn, Child Adolescent, and Youth Health } \\ \text { RO } & \text { Reverse Osmosis } \\ \text { RUTF } & \text { Ready-to-Use Therapeutic Food } \\ \text { SAFANSI } & \text { South Asia Food and Nutrition Security Initiative } \\ \text { SAM } & \text { Severe Acute Malnutrition } \\ \text { SDG } & \text { Sustainable Development Goal } \\ \text { SHN } & \text { School Health and Nutrition } \\ \text { SUN } & \text { Scaling Up Nutrition } \\ \text { TPE } & \text { Total Public Expenditure } \\ \text { UN } & \text { United Nations } \\ \text { UNICEF } & \text { United Nations Children's Fund } \\ \text { WASH } & \text { Water, Sanitation, and Hygiene } \\ \text { WASSIP } & \text { Water Supply and Sanitation Improvement Project } \\ \text { WAZ } & \text { Weight-for-Age Z Score } \\ \text { WFP } & \text { World Food Programme } \\ \text { WHO } & \text { World Health Organization } \\ & \end{array}$




\section{EXECUTIVE SUMMARY}

For decades, Sri Lanka's health system has been known globally as one of the best performing in the world, having achieved 'good health at low cost'. Life expectancy at birth, which stood at 75 years as of 2016, was higher than the South Asian average of 69 years. In terms of maternal and child health $(\mathrm{MCH})$ indicators, Sri Lanka's neonatal, infant, and under-five mortality rates in 2018 were $6.5,9.1$, and 10.6 per 1,000 live births (LB), respectively, and the maternal mortality ratio was 39.3 per 100,000 LB in 2017. Nonetheless, issues remain.

Undernutrition is one such unfinished agenda that has not improved over the last decade. Stunting rate, which reflects chronic undernutrition in early life, remained unchanged at 17.3 percent between 2006 and 2016, neither did the rate of wasting change significantly. Particularly, the current wasting rate of 15.1 percent among children under five is considered 'very high' in the World Health Organization (WHO) benchmark. Undernutrition is the single dominant risk factor of burden of disease for children under five in Sri Lanka. In addition, there is a growing concern over the threat of noncommunicable diseases (NCDs). The share of NCDs in aggregate disabilityadjusted life years (DALYs) increased from 53 percent in 1990 to 77 percent in 2017, and the total DALYs from NCDs have increased by 36 percent. It is well regarded that overweight and obesity are critical risk factors for NCDs, and hence the country is in the midst of double burden of malnutrition.

Given the magnitude of burden of disease attributable to malnutrition in Sri Lanka, it is important to examine whether sufficient resources have been allocated for adequate nutrition activities. However, policy makers often do not have access to comprehensive data on nutrition expenditure. This is due to the characteristics of nutrition that is multisectoral in nature, and there is often no single database that compiles investments in nutrition programs. This study assesses the public financing for nutrition in Sri Lanka by reviewing the public expenditure utilized for nutrition programs and interventions over five years (2014-2018). The analytical method largely followed the standard three-step approach that has been proposed by the Scaling Up Nutrition (SUN) movement and used in multiple countries. The 'three steps' of the SUN approach are (a) identification of budget line items, (b) categorization of budget line items, and (c) weighting of budget line items (optional).

By reviewing key nutrition-related policy and program documents, nine line ministries were identified as having implemented nutrition-specific interventions (that is, addressing the immediate determinants of fetal and child nutrition and development) or nutrition-sensitive interventions (that is, addressing the underlying determinant of malnutrition). Over 80 nutritionrelated activities were identified. In 2018, the government spent approximately SL Rs 140 billion for nutrition-related activities, which was a 25 percent fall from SL Rs 188 billion in 2015 in real terms (2018 base). In all years, nutrition-sensitive programs accounted for over 90 percent of 
nutrition expenditure, a clear dominance over nutrition-specific programs. Per capita nutrition expenditure in 2018 was SL Rs 6,441 (approximately US\$39.6). The nutrition expenditure as share of gross domestic product (GDP) was 1.0 percent, which is equivalent to the level of Bhutan (1.0 percent). The share of nutrition in the total public expenditure (TPE) was 5.2 percent in 2018. This was higher than Bhutan (3 percent), yet substantially lower than other countries such as Nepal (23 percent) or Bangladesh (9 percent). Given the small share of nutrition-specific programs, they accounted for only 0.5 percent of TPE. Overall, the nutrition share of TPE has been gradually declining from the 2015 level (6.9 percent), indicating that nutrition has been given less attention in recent years. The largest nutrition-specific interventions were school meals and the Thriposha program that collectively accounted for over 80 percent of nutrition-specific expenditure. Among the nutrition-sensitive programs, the Samurdhi program; agriculture (particularly fertilizer subsidy); and water, sanitation, and hygiene (WASH) programs were the largest and accounted for over 90 percent of nutrition-sensitive expenditure.

It was noted that a significant share of resources has been used by a small number of programs that may or may not be the most effective interventions in reducing malnutrition. A rigorous prioritization exercise would be warranted by investigating the effectiveness, cost-effectiveness, and good practices of nutrition interventions, both nutrition-specific and nutrition-sensitive programs. Targeted programs are more cost-effective than blanket coverage provided that the targets are well selected. Weighted resource allocation has already been practiced by the government, though on a limited scale. There is a potential to gain some fiscal space by changing the supplementary feeding program, for pregnant and lactating women (Thriposha), to target atrisk pregnant women rather than all women. In this regard, the government has reviewed the design of supplementary feeding program for pregnant and lactating women, with possible change in targeting strategy from blanket to targeted provision in future.

The evidence of nutrition-specific interventions is generally more robust and they address the immediate determinants of malnutrition. More investment in nutrition-specific programs would be warranted given their current lower share compared to nutrition-sensitive programs. Nonetheless, the effects could be undermined if the underlying causes are not properly addressed. The difficulty in mobilizing resources for nutrition-sensitive programs rests with the fact that decisions are also guided by other agendas of the sectors. It is therefore important to mainstream nutrition in all sectors to have more voice in decision making. 


\section{INTRODUCTION}

\subsection{Rationale, purpose, and structure of the report}

Nutrition is a critical element that determines a country's stock of human capital. Early childhood undernutrition is associated with poor psychological functioning in late adolescence (Walker et al. 2007). In particular, undernutrition before the age of two predicts poorer cognitive and educational outcomes in later childhood and adolescence, which has significant educational and economic consequences at the individual, household, and community levels (WHO 2014a). Economists estimate that undernutrition can reduce a country's gross domestic product (GDP) by 7 percent and thus is an enormous drain on economic productivity and growth (Galasso and Wagstaff 2018). Conversely, overweight and obesity pose yet another challenge for human capital development due to the elevated risks of noncommunicable diseases (NCDs) in productive ages. Inadequate diet and high body mass index (BMI) have been key risk factors for the disease burden in high-income countries and are now rapidly growing in middle-income countries. ${ }^{1}$

Given the critical role nutrition plays for a country's human capital development, it is important to examine whether sufficient resources are allocated for adequate nutrition activities. However, policy makers often do not have access to comprehensive data on nutrition investments. This is chiefly due to the characteristics of nutrition that is multisectoral in nature, and there is often no single database that compiles expenditure on nutrition programs. Assessing the size of nutrition investments therefore requires careful investigation, identification of relevant line items, analysis, and some assumptions. Given the complexity involved, the Scaling Up Nutrition (SUN) movement has developed a standard approach to capture expenditure of nutrition programs from multiple sectors. The approach has enabled countries to investigate public financing for nutrition, albeit with various applications depending on each context.

This study aims to assess the public financing for nutrition in Sri Lanka. The primary purpose is to understand the size and share of public investments in nutrition relative to the overall level of public expenditure in the country. Second, it discusses whether the nutrition interventions in which the government budget is spent are in line with the global evidence base and priorities set out in national policies. It also provides some recommendations on how such assessments could be improved from challenges and difficulties faced in undertaking this exercise.

This report begins with background and contextual information of nutrition in Sri Lanka (Chapter 2). It then provides an overview of globally practiced nutrition interventions and policies and programs that have been implemented in the country (Chapter 3). Chapter 4 describes the approach

\footnotetext{
${ }^{1}$ IHME (Institute for Health Metrics and Evaluation). 2018. GBD Compare. https://vizhub.healthdata.org/gbd-compare/.
} 
used for the analysis followed by results and findings in Chapter 5. The report concludes with brief discussions on key findings, challenges, and recommendations in Chapter 6. 


\section{CONTEXT OF SRI LANKA}

\subsection{Country profile}

Sri Lanka lies in the southern tip of the Indian subcontinent with a population of approximately 21.7 million in 2018 (World Bank 2019a). The land area is 65,610 $\mathrm{km}^{2}$ with a relatively high population density of 346 per $\mathrm{km}^{2}$, similar to that of Japan or the Philippines (347 and 358 per $\mathrm{km}^{2}$, respectively). The population comprises multiple ethnicities: Sinhalese (75 percent), Tamils (15 percent), Moors ( 9 percent), and others (1 percent). Major religions include Buddhism (70 percent), Hinduism (13 percent), Islam (10 percent), Christianity (7 percent), and others. About 82 percent of the population resides in rural areas (World Bank 2019a). Administratively, the country is divided into nine provinces, 25 districts, 331 divisional secretary's divisions, and 14,022 Grama Niladhari divisions (Figure 1).

Figure 1: Provinces in Sri Lanka

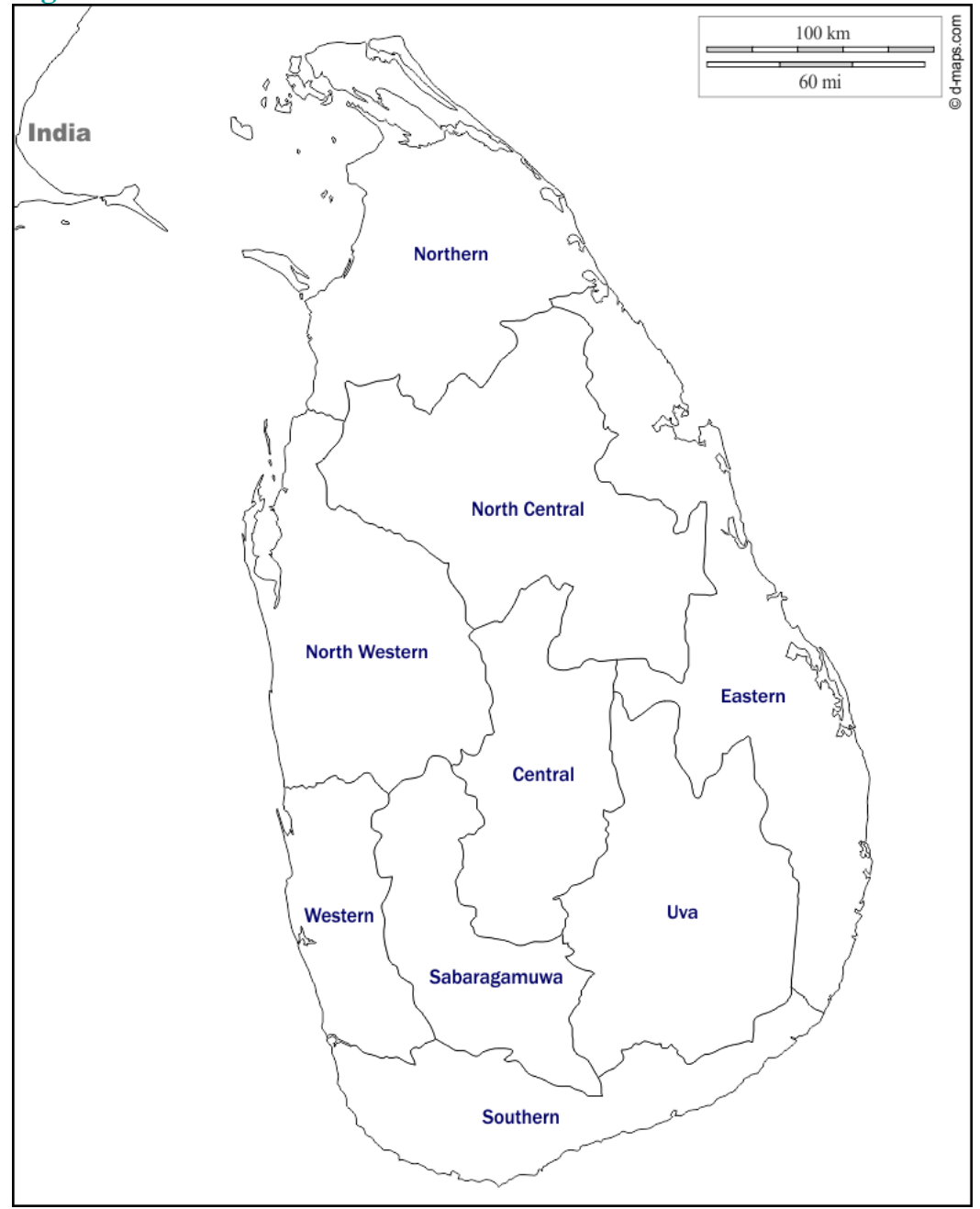

Source: https://d-maps.com/carte.php?num_car=617\&lang=en 
After the end of the war in 2009, economic growth picked up momentum, attaining what economists term as a 'peace dividend'. The annual GDP per capita growth rate averaged approximately 6 percent between 2008 and 2012 with a peak of 9 percent in 2012 (World Bank 2019a). Alongside the economic growth, poverty has declined significantly over the last decade. The national poverty headcount ratio decreased from 15 percent of the population in 2006 to 4 percent in 2016; 24 percent to 10 percent at I\$ 3.2 per day level, and 4 percent to 1 percent at I\$ 1.9 per day level during the same period (World Bank 2019a). The gross national income (GNI) per capita was US\$4,060 in 2018, which was similar to the size of the economy of Indonesia (US\$3,840) or Jordan (US\$4,210) (World Bank 2019a). The country has transitioned from a lower-middle-income country to an upper-middle-income country in July 2019 according to the World Bank classification. The dominant sector of the economy is the service sector that accommodates 46 percent of employment with a GDP share of 57 percent in 2018 (World Bank 2019a). The share of agriculture has continued to decline over decades and now accounts for only 8 percent of GDP albeit with a share of 26 percent of employment.

\subsection{Health, health system, nutrition, and financing}

Public health services in Sri Lanka are provided free of charge to the population at all levels with island-wide coverage. The country has achieved relatively strong health indicators at low health system costs. Life expectancy at birth, which stood at 77 years in 2017, was higher than the South Asian average of 69 years (World Bank 2019a). In terms of maternal and child health (MCH) indicators, Sri Lanka's neonatal, infant, and under-five mortality rates in 2018 were 6.5, 9.1, and 10.6 per 1,000 live births (LB), respectively, and the maternal mortality ratio was 39.3 per 100,000 LB in $2017 .{ }^{2}$ Public health care services are provided through a network of 1,118 government institutions operating at three levels. The primary level includes the primary medical care units and divisional hospitals; the secondary level includes the district general hospitals and base hospitals; and the tertiary level includes the National Hospital, teaching hospitals, and provincial general hospitals. Specialized care is provided by secondary and tertiary-level institutions. Despite the distinct levels of health institutions, the Sri Lankan health care system allows patients to bypass the primary-level institutions and obtain services directly from secondary and tertiary levels, which might increase the cost of health care provision since costs in secondary and tertiary institutions are usually higher, and this can potentially decrease the budget available for primary care/preventive health. The private sector is large in the country, particularly in providing outpatient care, outpatient drugs, and lab examination. Medical officers who practice in public facilities often provide private practice after hours. Even patients in the lowest wealth quintile seek private outpatient care due to inconvenient opening hours of public sector (close at 4 p.m.), less waiting time, and better personalized services.

${ }^{2}$ FHB. 2019. "Statistics." https://fhb.health.gov.lk/index.php/en/statistics. 
Although Sri Lanka has demonstrated strong performance in health indicators, particularly for $\mathrm{MCH}$, the government has been spending relatively less on health compared to its peers. Figure 2 provides Sri Lanka's public health expenditure (PHE) as share of GDP in comparison with its peers in Asia and the trend of PHE as share of total public expenditure (TPE). Sri Lanka's PHE share of GDP was 1.6 percent in 2017, which was comparable to countries such as Indonesia or the Philippines but significantly lower than many other countries (for example, about half of Thailand). Nonetheless, the PHE has been gradually increasing over years, and Sri Lanka's share of TPE in recent years is comparable to its peers (for example, Malaysia: 8.9 percent; Bhutan: 7.9 percent; Mongolia: 8.2 percent).

Figure 2: Public health expenditure

(a) PHE as share of GDP in comparison with peers in (b) PHE and its share of TPE over years Asia
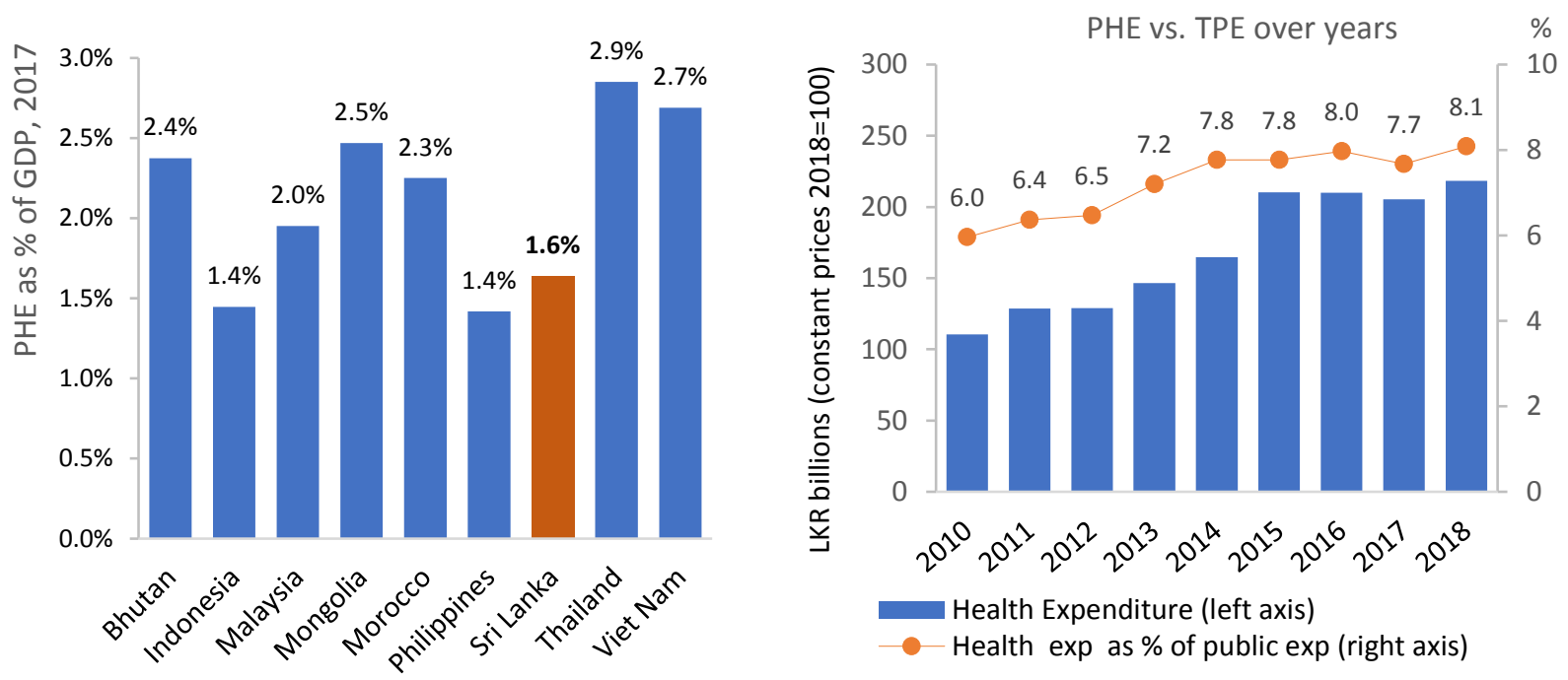

Source: CBSL 2019; WHO. 2020. "Global Health Expenditure Database." https://apps.who.int/nha/database/Home/Index/en.

The funding for the public health system is largely provided by the central government, which is managed by the Ministry of Health, Nutrition, and Indigenous Medicine (MoH) with allocation to its counterparts at the nine provinces. Government revenue in Sri Lanka is largely collected through the general tax system at the central level. In 2017, the central government collected a total revenue of 13.7 percent of GDP, about 12.5 percent of which was through general tax, primarily on imports, consumption, and income. This tax-GDP ratio, however, is one of the lowest in the world, especially for its income level (World Bank 2019a). The contribution of provincial revenue is even smaller, accounting for less than 0.5 percent of GDP. The major reasons for the low level of government revenues are a small tax base (less than 7 percent of the labor force and formal establishments pay income tax), reductions in statutory rates without commensurate efforts 
to expand the tax base, inefficiencies in administration, and numerous exemptions (World Bank 2017a). The low revenue base limits the more adequate investment in all sectors including health.

Despite the provision of free public health care, public spending on health constitutes less than half of the country's total health expenditure. In 2016, out-of-pocket (OOP) health payments constituted 50 percent of total health expenditure (WHO 2018), which is, for example, substantially higher than the corresponding figure for Thailand (12 percent). Nonetheless, the total health spending is still substantially lower (3.9 percent of GDP in 2016) than its comparator countries.

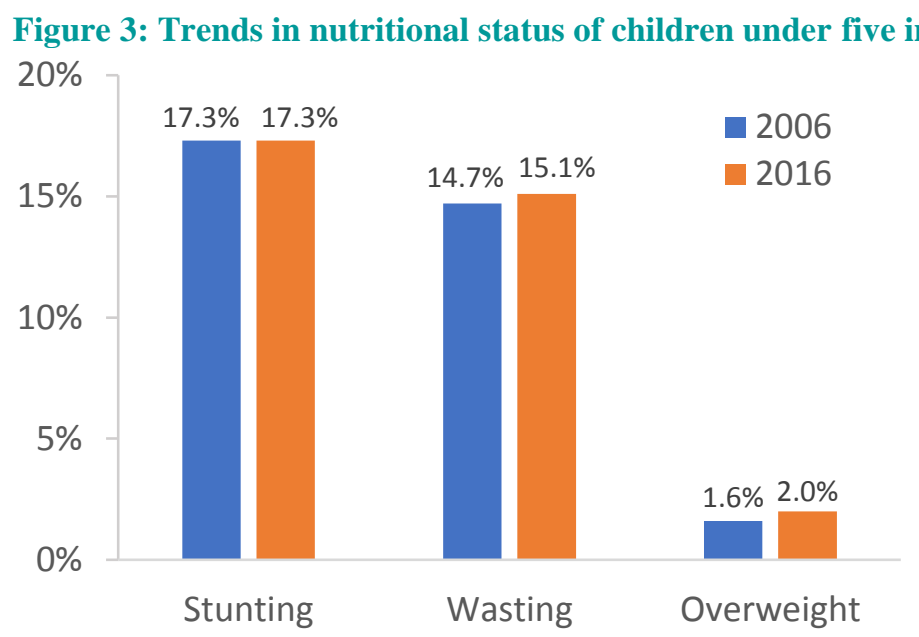

Source: DCS 2017.

Despite having achieved favorable health indicators at low cost, particularly in $\mathrm{MCH}$, issues remain. Undernutrition is one such unfinished agenda that has not improved over the last decade. Figure 3 provides the prevalence of malnutrition from three dimensions (stunting: height for age; wasting: weight for height; overweight: weight for height).

Prevalence of stunting, which reflects chronic undernutrition in early life, remained unchanged at 17.3 percent between 2006 and 2016 (DCS 2009, 2017), neither did the prevalence of wasting change significantly. It is noteworthy that the current prevalence of wasting is 15.1 percent among children under five (DCS 2017), which is considered 'very high' in the World Health Organization (WHO) benchmark. As per the new WHO categories, this 'very high' level of wasting places Sri Lanka among the top 10 high-burden low- and middle-income countries (LMIC). Wasting is highest among children ages 0-5 months (19 percent), while the lowest prevalence is observed among children ages 18-23 months (13 percent). Variations are observed in wasting prevalence rates across districts. Higher levels of wasting are observed in Monaragala (25 percent) and Mullaitivu and Hambantota (22 percent each), compared with Matale (10 percent) and Polonnaruwa (11 percent). However, the high wasting rate does not result in high mortality of children (see above $\mathrm{MCH}$ indicators) and neither does it lead to severe clinical forms such as 
Marasmus or Kwashiorkor. Overweight, on the other hand, is an emerging issue that is anticipated to increase in coming years in Sri Lanka, although the prevalence is not high among children yet.

Undernutrition is the single dominant risk factor of burden of disease for children under five years of age. Figure 4 provides the burden of disease attributable to different risk factors of children expressed in percentage of total disability-adjusted life years (DALYs). As is evident, nearly half the under-five DALYs are attributed to malnutrition, a significant factor that undermines the health and well-being of children and their adulthood. Further, there are substantial variations in the magnitude of undernutrition in Sri Lanka, in terms of both income levels and geographical locations.

Figure 5 provides the stunting prevalence by income levels in 2016. There is more than a twofold difference of stunting prevalence between the lowest and highest income quintiles, a clear indication of inequities in the prevalence of undernutrition by income levels, with some districts having alarming levels of wasting prevalence (for example, Monaragala at 25.4 percent, Hambantota at 21.8 percent). Figure 6 provides the geographic variations in stunting and wasting rates. For stunting, it is evident from the map that the rates are particularly high in the estate sector ${ }^{3}$ such as in Nuwara Eliya.

Figure 4: Fraction of DALYs attributable to key risk factors for under-five children, 2017

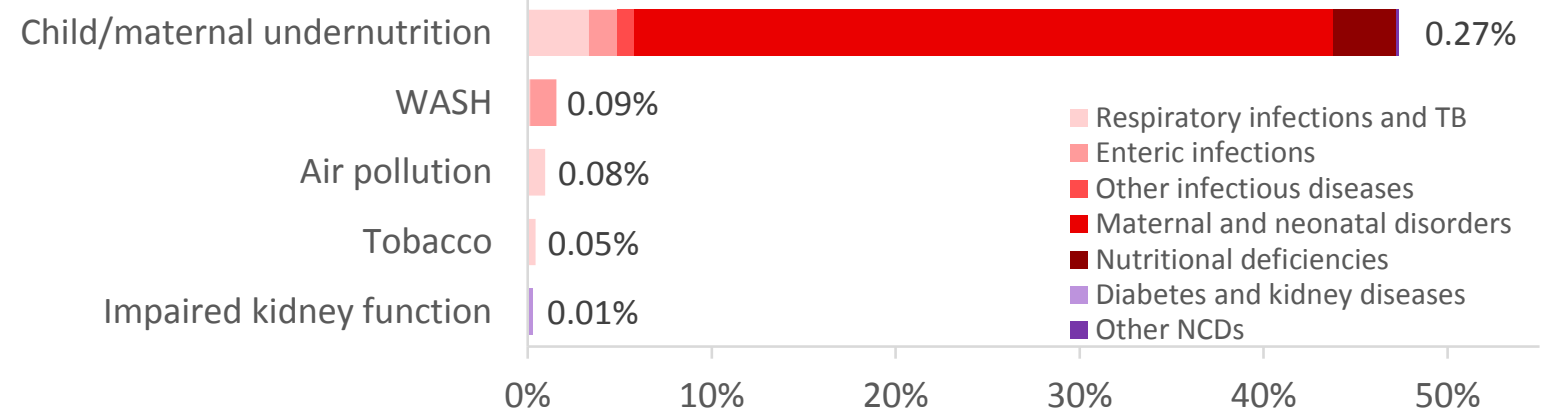

Source: IHME. 2018. GBD Compare. https://vizhub.healthdata.org/gbd-compare/.

Figure 5: Prevalence of under-five stunting by wealth quintile, 2016

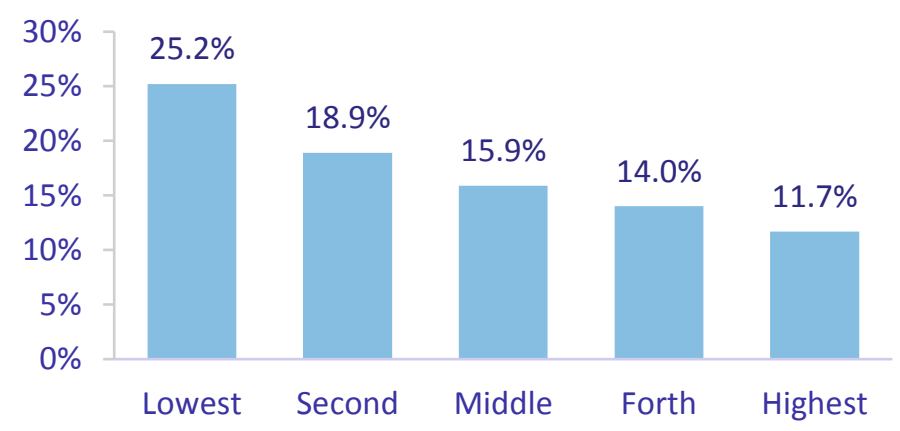

Source: DCS 2017.

\footnotetext{
${ }^{3}$ Estate sector refers to the large-scale tea and rubber plantations.
} 
Figure 6: Geographic distribution of under-five stunting and wasting, 2016

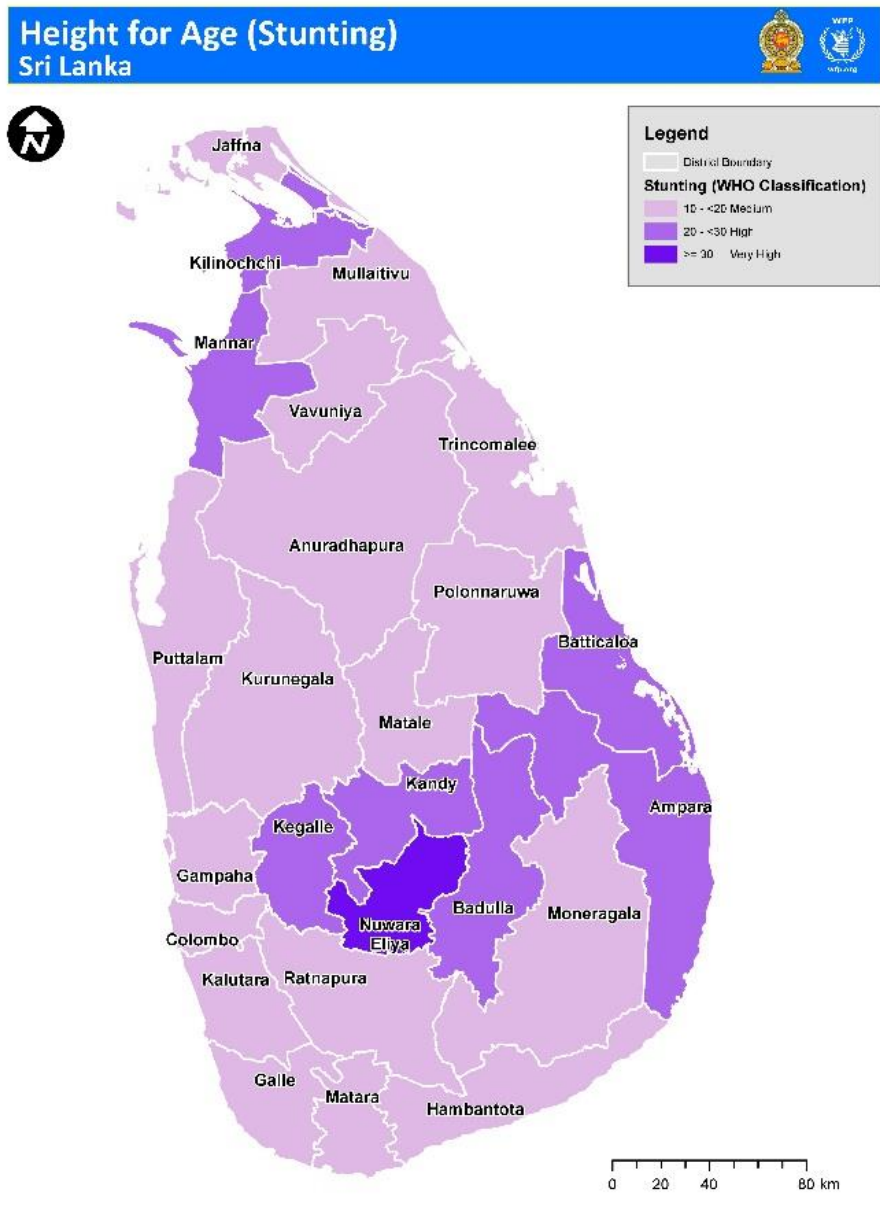

Map Produced on : 12 December 2019 | Data Source : Demographic and Health Survey Report - 2016

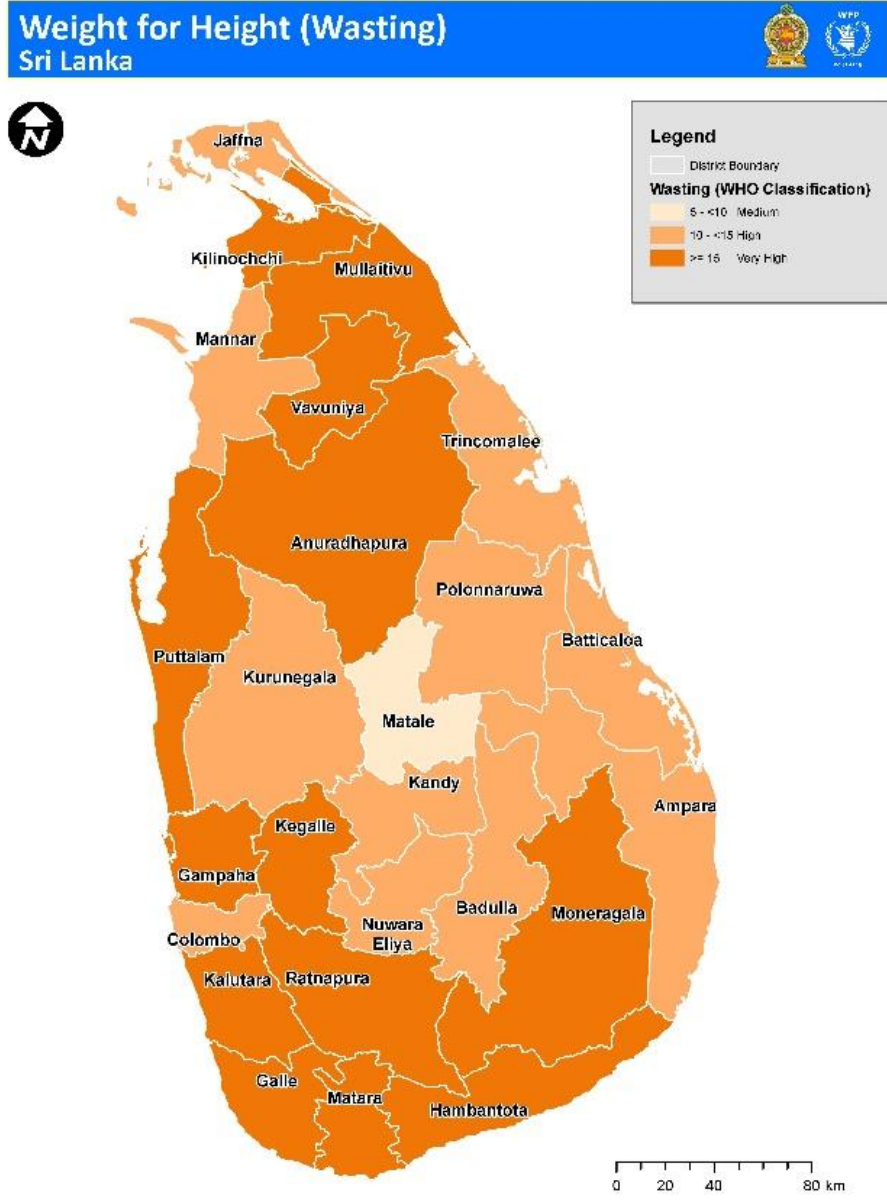

Map Produced on : 12 December 2019 | Data Source : Demographic and Health Survey Report - 2016

Source: DCS 2017. 
It is well recognized that exclusive breastfeeding reduces the neonatal mortality rates (NMRs) and infant mortality rates (IMRs). The infant and neonatal mortality rates have shown remarkable reductions during the last decade in Sri Lanka. IMR has reduced from 14.4 per 1,000 LB in 2000 to 10.9 per 1,000 LB in 2007 and to 8 per 1,000 LB in 2014. NMR has reduced from 10.1 per 1,000 LB in 2000 to 8.1 per 1,000 LB in 2007 and to 5.6 per 1,000 LB in 2014 (Registrar General). Early initiation of breastfeeding is reportedly culturally accepted and benefits 90.3 percent of infants in Sri Lanka. The proportion of infants in Sri Lanka ages less than six months who are exclusively breastfed is also the highest in the South Asia region (82 percent).

Conversely, two out of five (38 percent) of children ages 6-23 months do not receive a minimal acceptable diet (MAD) in terms of food diversity and meal frequency (DCS 2017). Dietary diversity is a larger problem than meal frequency. One out of four children ages 6-23 months do not consume a minimally diverse diet (MDD), and dietary diversity is particularly low among the youngest infants, especially those living in the estate sector and rural area (MDD is 52 percent among 6-8-month-old infants). It is of concern that these statistics may mask elements of poor feeding practices that are not picked up by these indicators (for example, insufficient quantities of diverse foods), given the critical level of wasting and persistent stunting. A multisectoral nutrition assessment in the estate sector suggested being a child of a working mother lowers dietary diversity and MAD (World Bank 2017b). This may partly explain the high malnutrition rate in the estate sector where a high proportion of mothers works (47.5 percent) compared to the national average of 36 percent, which further reduces for mothers with young children by 7.4 percentage point (World Bank 2017c). A subsequent study has shown that better nutrition could be achieved even in the estate sector by adopting positive behaviors such as adequate infant and young child feeding (exclusive breast feeding for six months, healthy complementary feeding practices, and adequate introduction of animal proteins), information and health service seeking behaviors, regular health service utilization, and father's involvement in feeding and child care (World Bank 2018).

In addition to the unfinished agenda of undernutrition, there is a growing concern over the threat of NCDs. Sri Lanka is in the midst of an epidemiological transition with a rapidly aging population and changing disease pattern toward high burden of NCDs. The share of NCDs in aggregate DALYs has risen from 53 percent in 1990 to 77 percent in 2017, and the total DALYs from NCDs have increased by 36 percent. ${ }^{4}$ A number of NCDs are known to be associated with lifestyles and behaviors such as smoking, alcohol consumption, and unhealthy diet. Figure 7 provides the fractions of risk factors associated with unhealthy diet. More than a quarter of disease burden of all ages can be attributed to nutrition-related risk factors such as dietary risks (13.5 percent), high BMI (7.7 percent), malnutrition (4.2 percent), and so on. Overweight is becoming a major threat to the health of population, especially for adults. About 45 percent of ever-married women in Sri Lanka are overweight or obese $\left(\mathrm{BMI} \geq 25 \mathrm{~kg} / \mathrm{m}^{2}\right)$, according to the latest Demographic and Health

\footnotetext{
${ }^{4}$ IHME. 2018. GBD Compare. https://vizhub.healthdata.org/gbd-compare/.
} 
Survey (DHS) 2016. It should be noted that childhood undernutrition not only affects the survival, health, growth, and development of a child but also increases the risk for NCDs in later life.

Figure 7: Fraction of DALYs attributable to key risk factors for all ages, 2017

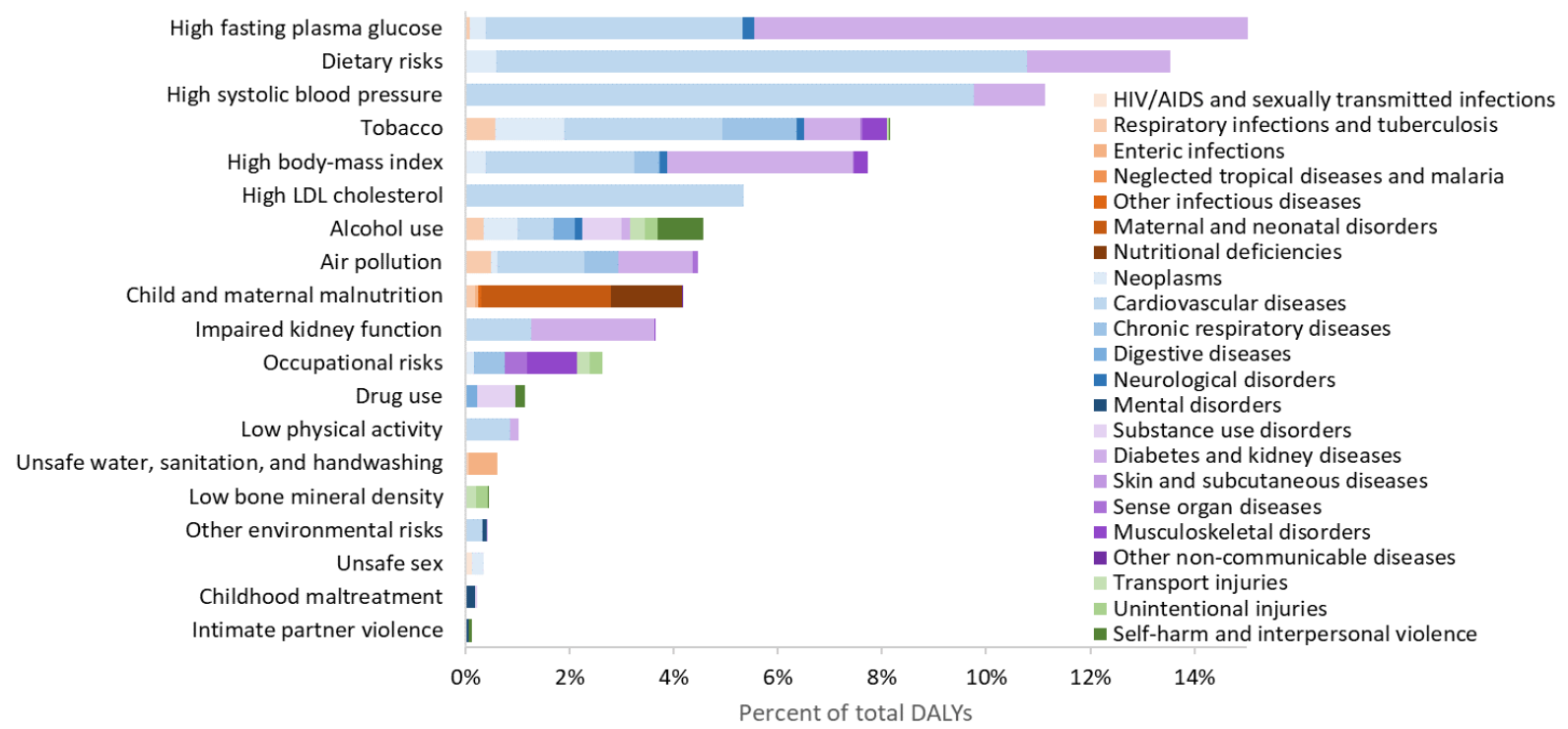

Source: IHME. 2018. GBD Compare. https://vizhub.healthdata.org/gbd-compare/.

Micronutrient deficiencies form the third arm of the triple burden of malnutrition alongside undernutrition and overweight. According to the micronutrient status survey conducted in 2012, the overall prevalence of iron deficiency anemia (IDA) among children ages 6-59 months was 7.4 percent. However, the highest level of IDA seen among children ages 6-23 months was 19.7 percent among children ages 6-11 months and 13.6 among children ages 12-23 months (MRI 2014).

The nutritional status of women in Sri Lanka poses a challenge in MCH due to the triple burden of malnutrition. The nutrition survey carried out in 2015 by the Medical Research Institute (MRI), found that one in three (31.8 percent) pregnant women was anemic $(\mathrm{Hb}<11 \mathrm{~g} / \mathrm{dL})$, with high inter-district variation in the prevalence of anemia, ranging from a low value of 14.6 percent in Badulla district to a high value of 62.6 percent in Ratnapura district. The results of the DHS 2016 showed that 9.1 percent of women ages 15-49 years were found to have a BMI less than 18.5 $\mathrm{kg} / \mathrm{m}^{2}$, while 31.9 percent of women were found to be overweight (BMI 25.0-29.9 kg/m²) and 13.3 percent of women were found to be obese $\left(\mathrm{BMI}>30 \mathrm{~kg} / \mathrm{m}^{2}\right)$, indicating the coexistence of undernutrition with overweight and obesity that poses a serious threat to the health and well-being of women and their infants. As for maternal nutrition, the prevalence of low BMI among pregnant women in their first trimester decreased from 23.8 percent in 2012 to 17.5 percent in 2017, with a parallel increase in overweight $\left(\mathrm{BMI} \geq 25 \mathrm{~kg} / \mathrm{m}^{2}\right.$ ) from 16.2 percent to 25.6 percent during the same period. 


\section{POLICIES AND INTERVENTIONS TO ADDRESS THE PROBLEM OF MALNUTRITION IN SRI LANKA}

\subsection{Evidence-based nutrition interventions}

South Asia bears the greatest share of all undernutrition and is home to almost 40 percent of all stunted children (59 million) and over half of all wasted children (26 million) in the world (UNICEF, WHO, and World Bank 2019). Malnutrition is often misunderstood by policy makers, and the public at large, in many ways: the image that most have of malnutrition is a picture of a dangerously thin child who is not receiving sufficient food. While that represents one type of malnutrition, this narrow understanding hinders comprehension of the broader problem, which is not only about lack of food but poor dietary practices in terms of both lack of nutritious food and excess consumption of unhealthy food. It also fails to account for the many different but interrelated factors that contribute to nutritional status, such as water and sanitation facilities, health status and health care services, care and feeding practices including personal hygiene, and so on.

Due to these varied and compounding determinants of malnutrition, the global scientific community concedes that maternal and child malnutrition is a complex public health issue that cannot be solved with simple one-dimensional solution by any sector alone. Various researchers, practitioners, and politicians have recognized that joint work across different sectors, systems, and disciplines under a shared framework is crucial to address this complex issue. The complexity of nutrition has been widely acknowledged by many specialists from academic and nonacademic disciplines who work together aiming to foster innovative solutions. Numerous scientific evidences show that malnutrition during the critical thousand days between conception and a child's second birthday can cause irreversible consequences to the brain and child's physical, cognitive, social, and emotional development.

Building on the nutritional framework of the United Nations Children's Fund (UNICEF), the 2013 Lancet series identified 10 high-impact nutrition-specific interventions and different nutritionsensitive interventions to improve maternal and child nutrition as provided in Figure 8. Nutritionspecific interventions are "interventions or programs that address the immediate determinants of fetal and child nutrition and development — adequate food and nutrient intake, feeding, caregiving and parenting practices, and low burden of infectious diseases" (Ruel, Alderman, and Maternal and Child Nutrition Study Group 2013). Nutrition-sensitive interventions are "interventions or program that address the underlying determinants of fetal and child nutrition and developmentfood security; adequate caregiving resources at the maternal, household and community levels; and access to health services and a safe and hygienic environment - and incorporate specific nutrition goals and actions" (Ruel, Alderman, and Maternal and Child Nutrition Study Group 2013). 
Figure 8: Lancet framework for actions to achieve optimum fetal and child nutrition and development

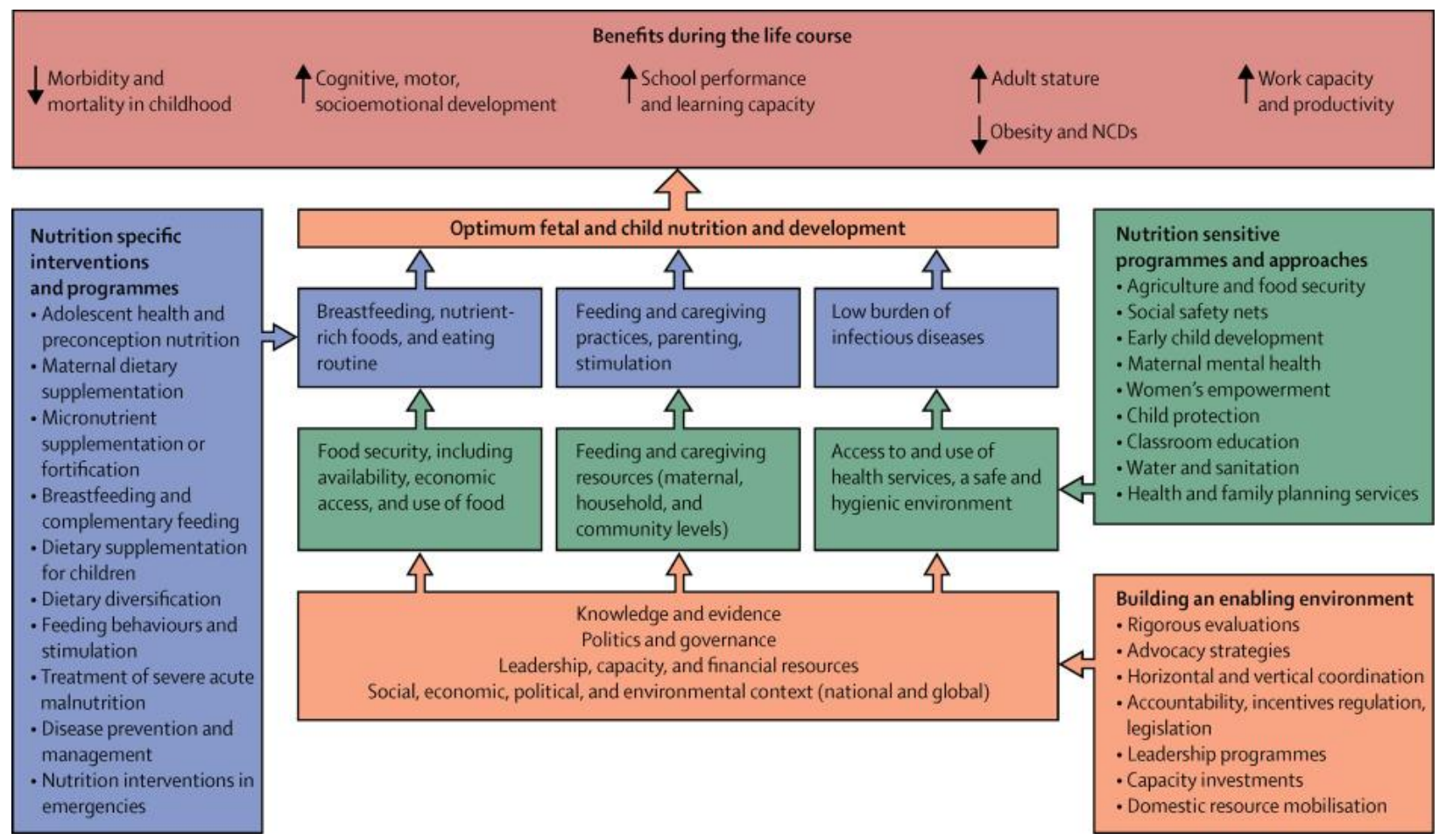

Source: Black et al. 2013.

\subsection{Nutrition-specific interventions}

There is a growing body of evidence that the nutritional status during the first 1,000 days of life since conception has life-long consequences on the child's development. Deficits acquired during this period are difficult to reverse later in life. Therefore, the period is perceived as a critical window of opportunity for fostering growth. As shown in Figure 8, the WHO and UNICEF recommend nutrition-specific interventions in prenatal period and early life as being essential in preventing growth failure. Recommended strategies for improving nutritional status and growth in children include interventions to improve nutrition of pregnant and lactating women; early initiation of breastfeeding; exclusive breastfeeding during the first six months; promotion, protection, and support of continued breastfeeding along with appropriate complementary feeding from six months up to two years and beyond; micronutrient supplementation, fortification, and supplementation; and the care of wasted and severely wasted children when needed. Further, the WHO and UNICEF recommend a series of evidence-based nutrition actions that are crucial in maintaining good nutritional status of mothers and children throughout their life courses, including during later childhood, adolescence, and pre-pregnancy (Figure 9). Details of the evidence of key nutrition-specific interventions are provided in Annex 2. 
Figure 9: Improving nutrition around the life course

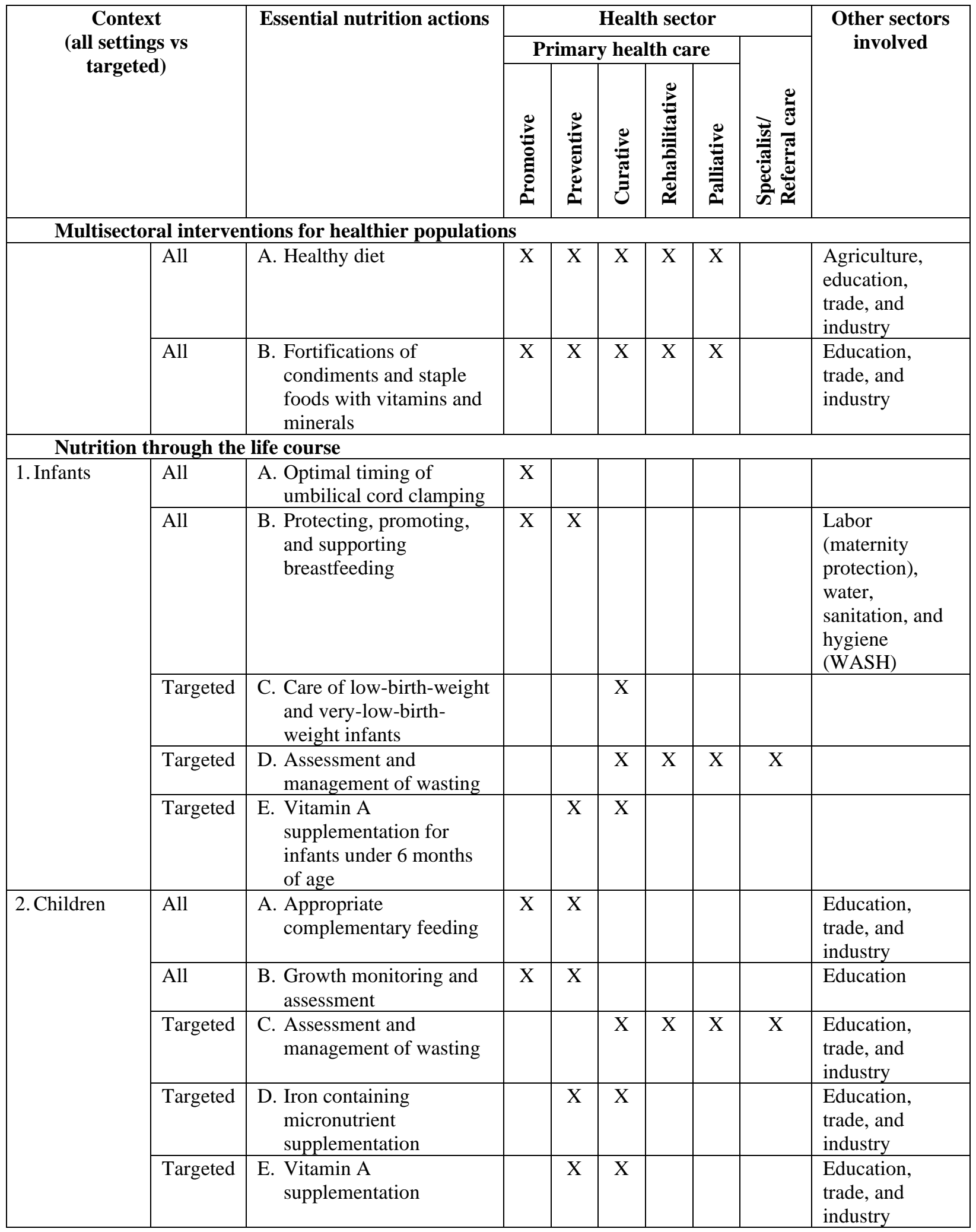




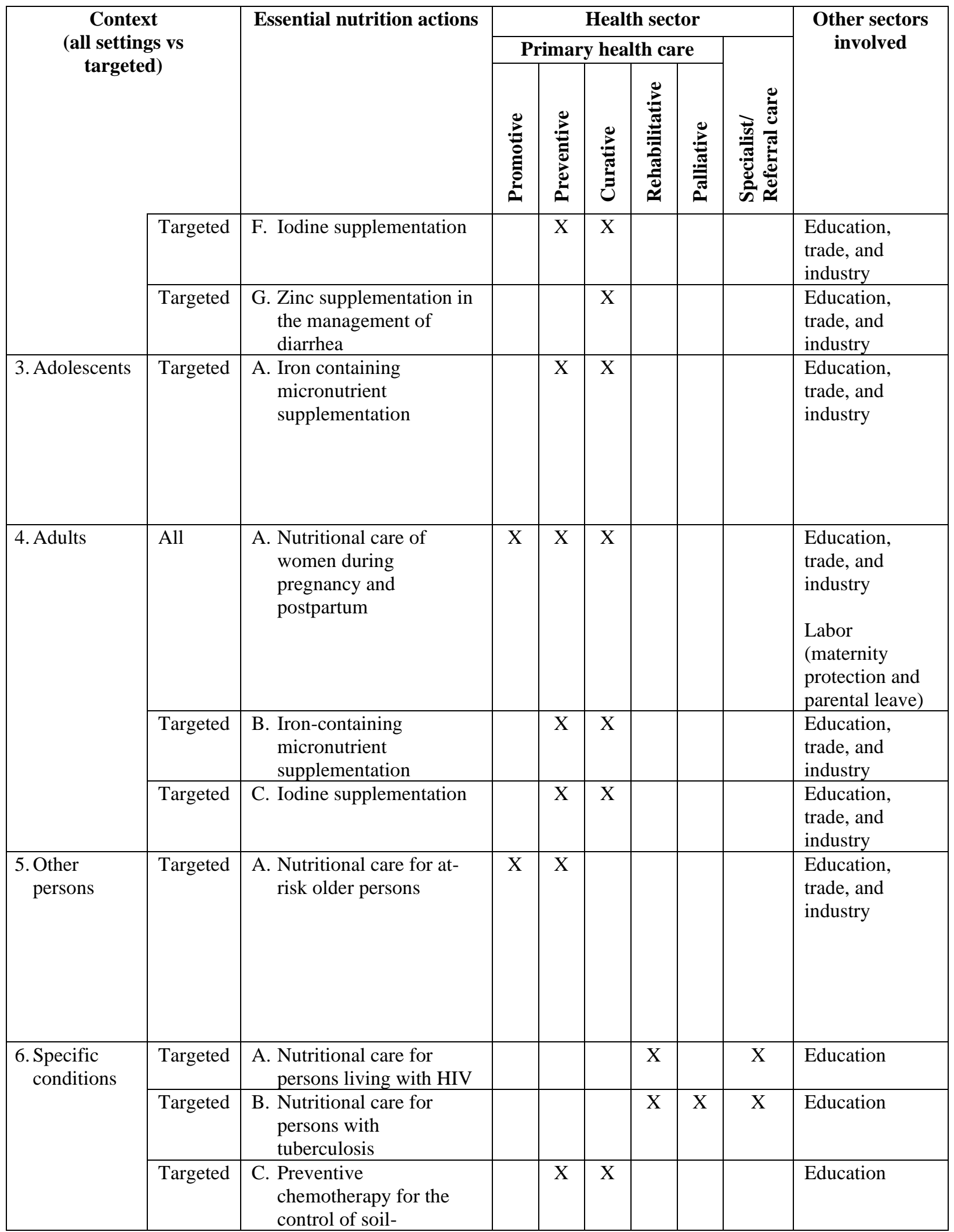




\begin{tabular}{|c|c|c|c|c|c|c|c|c|c|}
\hline \multirow{3}{*}{\multicolumn{2}{|c|}{$\begin{array}{c}\text { Context } \\
\text { (all settings vs } \\
\text { targeted) }\end{array}$}} & \multirow[t]{3}{*}{ Essential nutrition actions } & \multicolumn{6}{|c|}{ Health sector } & \multirow{3}{*}{$\begin{array}{l}\text { Other sectors } \\
\text { involved }\end{array}$} \\
\hline & & & \multicolumn{5}{|c|}{ Primary health care } & \multirow[b]{2}{*}{ 竎 } & \\
\hline & & & 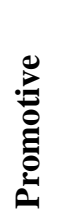 & 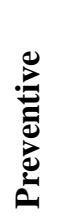 & 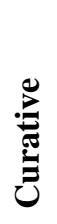 & : & : & & \\
\hline & & $\begin{array}{l}\text { transmitted helminth } \\
\text { infection (deworming) }\end{array}$ & & & & & & & \\
\hline & Targeted & $\begin{array}{l}\text { D. Nutritional care for } \\
\text { persons with Ebola } \\
\text { Virus disease }\end{array}$ & & $\mathrm{X}$ & & $\mathrm{X}$ & $\bar{X}$ & $\bar{X}$ & Education \\
\hline & Targeted & $\begin{array}{l}\text { E. Nutritional care for } \\
\text { persons with viral } \\
\text { hemorrhagic disease } \\
\text { (including Ebola, } \\
\text { Marburg Lassa and } \\
\text { Crimean Congo } \\
\text { hemorrhagic fever) }\end{array}$ & & $\mathrm{X}$ & & $\mathrm{X}$ & & $\bar{X}$ & Education \\
\hline & Targeted & $\begin{array}{l}\text { F. Nutritional care for } \\
\text { infants in the context for } \\
\text { ZIKA virus transmission }\end{array}$ & & $\mathrm{X}$ & & & $\mathrm{X}$ & $\mathrm{X}$ & Education \\
\hline & Targeted & $\begin{array}{l}\text { G. Feeding of infants of } \\
\text { mothers who are carriers } \\
\text { of chronic hepatitis B }\end{array}$ & & $\mathrm{X}$ & & $\mathrm{X}$ & & $\mathrm{X}$ & Education \\
\hline & Targeted & $\begin{array}{l}\text { H. Feeding of infants in } \\
\text { settings with an ongoing } \\
\text { pandemic of influenza A } \\
\text { (H1N1) virus } \\
\text { transmission } \\
\end{array}$ & & $\mathrm{X}$ & & & & & Education \\
\hline & Targeted & $\begin{array}{l}\text { I. Vitamin A } \\
\text { supplementation for } \\
\text { infants and children with } \\
\text { measles } \\
\end{array}$ & & & $\mathrm{X}$ & & & & Education \\
\hline \multicolumn{10}{|c|}{ Nutrition in emergencies } \\
\hline & All & $\begin{array}{l}\text { A. Infant and young child } \\
\text { feeding (IYCF) in } \\
\text { emergencies }\end{array}$ & $\mathrm{X}$ & $\mathrm{X}$ & & & & & All sectors \\
\hline & All & $\begin{array}{l}\text { B. Preventing and } \\
\text { controlling micronutrient } \\
\text { deficiencies in } \\
\text { emergencies }\end{array}$ & $X$ & $X$ & $\mathrm{X}$ & & & & All sectors \\
\hline
\end{tabular}

Source: WHO 2019.

Note: The interventions presented in the section are not exhaustive and other nutrition actions through the life course can be adapted, as needed, to emergency settings. 


\subsection{Nutrition-sensitive interventions}

Malnutrition is a multidimensional issue that goes beyond diet and disease and is a manifestation of socioeconomic, biological, and behavioral issues. No single intervention implemented in isolation will therefore be sufficient in reducing the burden of malnutrition. While nutritionspecific interventions are needed, evidence suggests that they are not sufficient on their own for rapidly reducing rates of undernutrition (Bhutta et al. 2008; Ruel, Alderman, and Maternal and Child Nutrition Study Group 2013), and recent nutrition success stories typically point to nutritionsensitive sectors as being the main drivers of nutritional change (Headey and Hoddinott 2015), pointing to the criticality of such interventions.

Nutrition-sensitive interventions or programs address underlying determinants of fetal and child nutrition-income and food security; adequate caregiving resources/practices at the maternal, household, and community levels; access to health services; and a safe and hygienic environment (Alderman 2015). They are thus drawn from complementary sectors, such as agriculture, health, social protection, early child development, education, and water and sanitation. By enhancing the household and community environments in which children develop and grow, nutrition-sensitive interventions are crucial to achieving accelerated results at scale, enhancing the effectiveness and coverage of nutrition-specific interventions.

Box 1: Key features of nutrition-sensitive interventions

Key features of nutrition-sensitive interventions that make them critical complements to nutrition-specific interventions are as follows:

1. They address crucial underlying determinants of nutrition.

2. They are often implemented at large scale, many times with well-established budgets.

3. They can be effective at reaching poor populations who have high malnutrition rates as negative consequences of food security threats and mitigate the effects of financial, man-made (conflicts, political issues, increased prices), and weather-related (natural disasters) shocks.

4. They can be leveraged to serve as delivery platforms for nutrition-specific interventions.

Source: Ruel, Alderman, and Maternal and Child Nutrition Study Group 2013.

However, evidence on the effectiveness of such interventions on nutritional outcomes is scarce, especially investments and policies in other sectors such as transport, communication, information technology, and trade, among others. For details of interventions that have some evidence based on nutritional outcomes, refer to Annex 2. 


\subsection{Nutrition-related policies in Sri Lanka}

\subsubsection{National Nutrition Policy}

Despite the efforts of the Government of Sri Lanka (GOSL) and other agencies to eliminate malnutrition, optimum results cannot be achieved unless all interventions are implemented based on a well-designed framework in a coordinated manner. Therefore, a solid nutrition policy is a prerequisite that has to be developed based on the situation on the ground and responsibilities of all relevant agencies. The first nutrition policy in Sri Lanka was developed in 1986 followed by several revisions, but its value has diminished over years for several reasons: limited inter-sectoral coordination, changes in government priorities, and the policies not having been updated along the rapid socioeconomic and demographic changes.

Given the situation, the Ministry of Healthcare and Nutrition (current $\mathrm{MoH}$ ) developed the National Nutrition Policy (NNP) in 2010 (MoH 2010). Based on this document, a strategic plan and action plans have subsequently been developed. The NNP was designed to be implemented by the strategies and action plans while incorporating existing relevant policies. The NNP was prepared assuming a strong inter-sectoral collaboration as the platform to improve nutritional status of the population and hence include a wide range of sectors such as planning, health, agriculture, fisheries, livestock, education, social services, and poverty alleviation, among others.

The NNP has six key objectives:

(a) To ensure optimal nutrition throughout the life cycle

(b) To enhance capacity to deliver effective and appropriate interventions

(c) To ensure effective management of adequate nutrition to vulnerable populations

(d) To ensure food and nutrition security for all citizens

(e) To strengthen research, monitoring, and evaluation

Accordingly, the NNP has focused its attention on optimum nutrition throughout the life cycle by reducing the intergenerational transmission of malnutrition. The NNP has recognized the importance of targeting nutritional interventions to underserved areas, the plantation community, urban poor, and conflict-affected areas. Further, it has identified the necessity to promote behavioral change among the people, enabling them to make appropriate food choices and care practices. The NNP, which is in the process of revision for 2020-2030, reflects the malnutrition in all stages of life, including presently neglected nutrition among elders. It is expected to place greater emphasis on multisectoral coordination and partnership while increasing the coverage of nutrition-specific interventions at the primary health care level. 


\subsubsection{Multi-sector Action Plan for Nutrition}

In Sri Lanka, successive governments have taken several measures to enhance the nutrition situation through a multisectoral approach. The first Multi-sector Action Plan for Nutrition (MSAPN) 2013-2016 set the platform through multisector partnerships within the government, cutting across sectors, for targeted action on the nutrition agenda to reduce malnutrition in the country (GOSL 2013). The MSAPN was built upon existing interventions and operationalizes the framework laid out in the NNP by enhancing the synergies between institutions - ministries, provincial offices, and divisional secretariats together with development partners (DPs) toward a common nutrition goal. This effort is aligned with the global SUN movement that strongly advocates the adoption of a multisectoral approach. Building on the lessons learned from the implementation of the first MSAPN 2013-2016, the second MSAPN 2018-2025 (in draft) further aims to improve the multisectoral collaboration and coordination (GOSL 2019). Especially, the MSAPN 2018-2025 aims to increase the momentum toward improving the nutritional status of the population in line with the Sustainable Development Goals (SDGs) related to nutrition.

\subsubsection{Maternal and Child Health Policy}

In line with the WHO recommended actions, the Reproductive, Maternal, Newborn, Child, Adolescent, and Youth Health (RMNCAYH) program is a collection of evidence-based interventions implemented by the $\mathrm{MoH}$ to improve maternal and child health and nutrition. This RMNCAYH program provides the most wide-spread community-based health care services implemented through 354 Medical Officer of Health (MOH) areas. The Family Health Bureau (FHB) is the central-level institution in the $\mathrm{MoH}$ that is responsible for planning, implementing, monitoring, and evaluating the RMNCAYH program.

The RMNCAYH program encompasses interventions for preconception care; care during pregnancy and lactation; services for children under five years, school children, and adolescents; and women's health. This broad package includes nutrition assessment (during antenatal care [ANC] visits, child's growth monitoring), provision of micronutrient supplements (iron, folic acid, calcium, and vitamin C) during pregnancy and first six months of lactation, provision of supplementary food Thriposha (throughout pregnancy, six months of lactation, and undernourished children under five years of age), vitamin A supplementation, and deworming treatment (children ages 18 months and above up to grade 10 at school with higher intensity in the estate sector), and zinc supplementation for children with diarrhea. To combat anemia among infants and young children, the multiple micronutrient (MMN) supplementation program has been implemented island wide from 2017, based on a national compliance study conducted by the MRI and UNICEF.

The target population of the RMNCAYH program, or 'Eligible Family', is defined as a family with either a married (or living together) female ages between 15 and 49 years or having a child 
under five years of age. Further, a family with a pregnant woman (irrespective of marital status and age) and previously married women (widowed, divorced, separated) are also considered Eligible Family. The Eligible Families are identified by public health midwives (PHMs) in communities and are registered in the Eligible Family registers. Further, according to the RMNCAYH eligibility criteria, it is estimated that 18.5 percent of the population is covered under this program.

Many services of the integrated package are offered through $\mathrm{MCH}$ clinics from the time expectant mothers are registered to the monitoring of the child up to five years of age. Nutrition education is presently implemented mainly at $\mathrm{MCH}$ clinics and field weighing posts by the PHMs and during their home visits. The health and nutrition education cover breastfeeding, complementary feeding, and health promotion among children under five years of age and nutrition of other target groups including pregnant women and school children. Further, special nutrition clinics have been established in the field to implement targeted interventions to malnourished mothers and children. District-level trainers were also trained on the new WHO growth standards and growth monitoring and promotion and IYCF counseling.

\subsection{Nutrition-specific interventions in Sri Lanka}

\subsubsection{Infant and young child feeding and care in the first two years of life}

Breastfeeding promotion (including support for early initiation and exclusive breastfeeding) is advocated following the 10 steps of the Baby Friendly Hospital Initiative. Capacity building on breastfeeding for the health staff in maternal and child care was introduced in 1995 using the 40hour Breastfeeding Counselling Course. Exclusive breastfeeding rates have since improved, with exclusive breastfeeding rate going up from 19 percent in 1993, 52 percent in 2000, and 76 percent in 2006 to 82 percent in 2016 (DHS).

However, the DHS 2016 data revealed that while 93.4 percent of infants ages $0-1$ months were exclusively breastfed, only 87.2 percent of infants ages 2-3 months and 63.8 percent of infants ages 4-5 months exclusively breastfed. The average duration of exclusive breastfeeding was 4.4 months. It is also interesting to note that within the 4-5 months age group, 7.7 percent of children were given other milk and 12.5 percent of children were given plain water. This may indicate that some mothers face difficulties and challenges in exclusively breastfeeding their infants for six months.

Complementary feeding refers to the timely introduction of safe and nutrient-rich foods, in addition to breastmilk, that are typically provided during 6-23 months of age. Age-appropriate complementary foods, which is adequate in terms of frequency, density, and diversity for children in the first two years of life, are promoted through the primary health care system and community health workers. Complementary feeding practices are context specific and influenced by cultural, 
geographic, social, economic, gender, and other family and community factors. A more in-depth analysis of the practices and their driving factors is required.

\subsubsection{Micronutrient supplementation programs for young children}

The following micronutrient supplementation interventions are being implemented island wide:

\section{Vitamin A high-dose supplementation}

Vitamin A is an essential micronutrient that helps in maintaining healthy vision, growth, and development of a child. The program has been designed for infants and children ages 6-59 months, who are given a vitamin A mega dose every six months. Currently, the coverage of vitamin A supplementation is 86.1 percent at 18 months and 92.9 percent at 3 years. ${ }^{5}$

\section{MMN supplementation}

Iron is an important micronutrient for a child's brain development and for transportation of oxygen to the body tissues. Globally, IDA is a major public health concern. In Sri Lanka, MMN is given to children at the age of 6,12 , and 18 months on a daily basis for two consecutive months as a means to prevent anemia.

\section{Zinc supplementation}

It is given for managing diarrhea along with oral rehydration solution (ORS) among children under five years of age. According to the current $\mathrm{MoH}$ protocols, all children with diarrhea are given zinc tablets for 10-14 days from the onset of diarrhea.

\subsubsection{Treatment and management of infants and young children with severe or moderate acute malnutrition (SAM/MAM)}

Under the national growth monitoring program, all children under five years are periodically measured at child welfare clinics, field weighing posts, and well-baby clinics in curative establishments. According to $\mathrm{MoH}$ recommendations, the weight-for-age of children under two is assessed monthly and thereafter once every three months up to the age of five years if the child is growing normally. However, if a child is having any nutritional problems, irrespective of age, monthly weighing is recommended. The length-for-age is measured at birth, 4, 9, and 18 months, and for children with nutritional problems it is measured every two months up to two years of age. The height-for-age is assessed every six months from two years of age up to five years, and for children with nutritional problems, it is measured every three months from two to five years.

\footnotetext{
${ }^{5}$ FHB. 2019. “Statistics.” https://fhb.health.gov.lk/index.php/en/statistics.
} 
Children whose weight for age lies below -2SD receive locally produced fortified food supplement, Thriposha, at the primary health care level. Although there are potential benefits of Thriposha, it has not led to positive changes in the prevalence of acute malnutrition. This was affirmed by a World Food Programme (WFP) technical mission in 2016 and 2017, which cited several reasons for this, including sharing of the product at the household level, indicating a need for effective and targeted social and behavior change communication, plus issues with supply management.

The children with SAM receive BP 100, ready-to-use therapeutic food (RUTF) only after confirmation of the diagnosis by a pediatrician at the district hospital level or above. At present, the coverage of services is suboptimal as inpatient and outpatient care and treatment services are currently available only at the district hospital level and above. Outpatient care for severe wasting without medical complications has not been decentralized to the divisional hospitals in line with other primary health care interventions that are provided at the lower levels of the district health system.

However, service coverage is still limited because of low demand of services from the population, lack of active case identification, and poor geographical access to services in some provinces. Lastly, there are no data available on the performance of existing services to treat SAM/MAM (for example, coverage and treatment outcomes), making it difficult to assess whether children are being reached and successfully treated.

\subsubsection{Women's nutrition}

In Sri Lanka, the interventions around women's nutrition target the pre-pregnancy, pregnancy, and postpartum periods as shown in Figure 10.

Figure 10: Mainstreaming maternal nutrition intervention across life cycle and delivery platforms

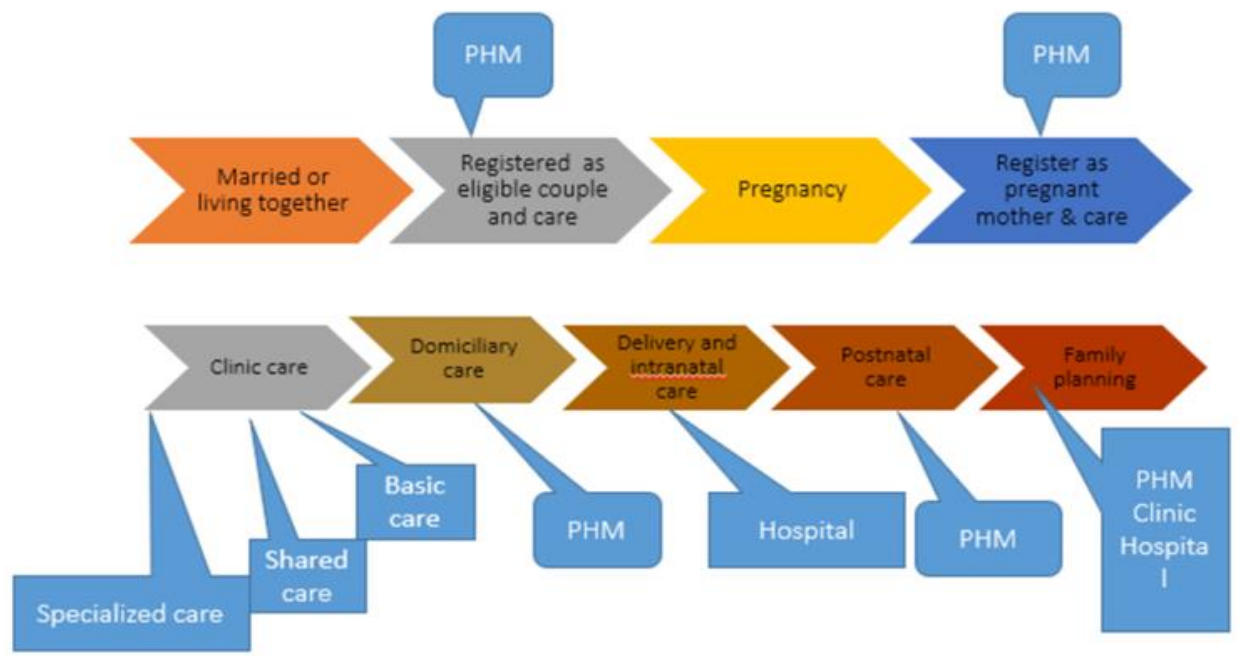

Source: FHB 2018. 


\section{Preconception nutrition}

As part of a preventative approach, newly married couples are invited to a pre-pregnancy care program when they first register their marriage. Preconception care is defined as a set of interventions that aim to identify and modify biomedical, behavioral, and social risks to couples before conception occurs, including education on achieving a healthy weight through diet and exercise before becoming pregnant. Coverage for the initiative is currently at 50 percent across the country, but it is being scaled up and there are plans to extend the program to include interpregnancy counseling.

\section{Nutritional care during pregnancy}

The nutritional status of women at the time of conception and during pregnancy plays a vital role in determining the health of the mother and for ensuring healthy fetal growth and development. The maternal nutrition program is mainly run by the MoH, Sri Lanka, through ANC and postnatal care (PNC) platforms. The coverage reached through these platforms are presented in Figure 11. In addition, there is a cash allowance program for pregnant and lactating women run through a social protection program by the Ministry of Women and Child Affairs (MWCA).

The maternal care package includes

1. Anthropometric assessment at the first visit through measuring height and weight and calculating BMI, as well as monitoring weight gain during pregnancy;

2. Universal screening of pregnant women for blood sugar levels (part of the maternal care package since 2014) as hyperglycemia in pregnancy (including both chronic diabetes and gestational diabetes mellitus) is an emerging issue in Sri Lanka;

3. Screening for anemia, with full blood count and management of identified cases, including referrals;

4. Micronutrient supplementation (iron, folic acid, calcium, vitamin C) for all pregnant women and deworming for pregnant women (until 2018) when required (Mebendazole 100 $\mathrm{mg}$ twice a day for 3 days); and

5. Dietary supplementation for all pregnant and lactating women along with nutrition counseling:

- Thriposha supplementation, two packets per month and

- Cash allowance to buy nutritious food-SL Rs 2,000 per month for 10 months. 
Figure 11: Coverage of maternal nutrition intervention package through ANC Platforms

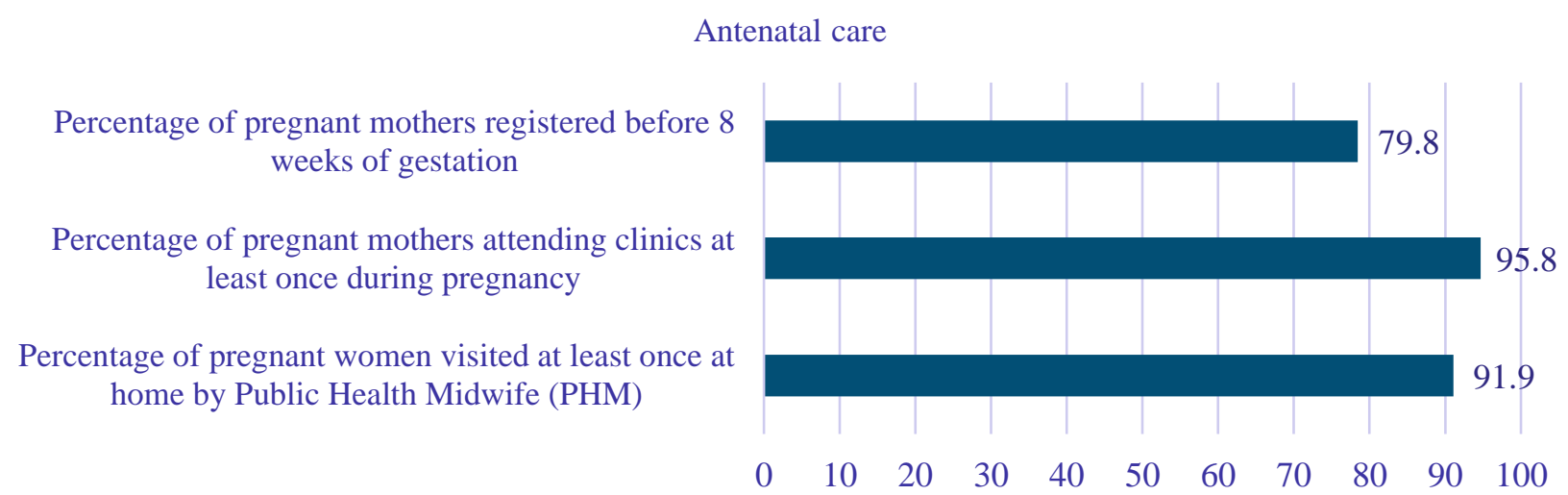

Source: FHB 2019. https://fhb.health.gov.lk/index.php/en/statistics.

During the postpartum period, micronutrient and food supplementation continues for six months after delivery, together with appropriate nutrition counseling. Home visits by the public health staff, postnatal clinics, and family planning clinics are used to deliver nutritional services for women after delivery and Well Woman Clinics later on.

High coverage of ANC and PNC interventions to all pregnant women, starting in early pregnancy, reduced the levels of anemia and undernutrition over the last decades. Nearly four in five pregnant mothers are registered for ANC before 8 weeks of pregnancy and more than 95 percent are registered before 12 weeks. In 2018, the average number of field clinic visits was 6.5 per pregnant woman. However, with a shift in the epidemiological situation and increasing levels of maternal overweight and obesity, the existing food supplementation programs, which target all pregnant and lactating women, pose a critical question around the efficiency of blanket supplementation. Currently, Thriposha supplementation and cash allowance program for pregnant and lactating women (for essential food commodities) account for 60 percent of the budget for nutrition-specific interventions. According to the National Nutrition and Micronutrient Survey of Pregnant Women in Sri Lanka (MRI 2013), 91 percent of pregnant mothers had received Thriposha, but only 11 percent of them had consumed it as prescribed. To improve the cost efficiency and costeffectiveness of the Thriposha program, there is a need to reconsider the targeting of food supplementation.

\subsubsection{School health program}

Health of school children can play a major role in determining the successful development of a nation. Schools serve as an ideal setting to positively affect children's health because they reach young people at a critical stage of development. To activate a school to achieve its potential to improve health, it is essential for the community to understand the importance and feasibility of improving health through schools. Several school health interventions are implemented in Sri 
Lanka to enhance the health and nutritional status of school children such as school medical inspection and follow-up, immunization, weekly iron folate supplementation, and so on.

\subsubsection{School meal program}

In Sri Lanka, there have been three modalities for school meal programs. The first one is the government cash-based catering modality and the second is the school milk modality. Combined, these target more than 1.1 million school students island wide and they are fully funded by the government. The budget allocation for these programs has been steadily increasing each year and currently stands at approximately US\$6 billion per year. The third modality is the in-kind school meal program, which was implemented by the WFP in the Northern Province until December 2017. However, the availability of unhealthy food in school canteens is a constraint for nutrition among school children in spite of availability of school canteen guidelines. Proper monitoring of school canteens with a regulatory mechanism is needed to improve this situation.

\subsubsection{Preschool meal program}

Following the same concept, Sri Lanka's preschool meal programs are also considered as nutritionspecific interventions. At present, there are two preschool meal programs: preschool meal program administered by the MWCA and 'Tikiri Shakthi', a high protein nutrient bar for the plantation sector children ages 3-5 years, administered by the Ministry of Hill Country New Villages, Infrastructure, and Community Development (MHC).

\subsection{Nutrition-sensitive interventions in Sri Lanka}

A multisectoral approach that combines nutrition-specific and nutrition-sensitive interventions is vital for a holistic and sustainable approach to address malnutrition. Nutrition sensitiveinterventions include actions from a range of sectors such as health, agriculture and food systems, WASH, education, and social protection.

\subsubsection{Agriculture sector food security interventions}

Historically, Sri Lanka has been self-sufficient and has been regarded as the 'Granary in the East' due to the abundant food the country produced and exported. Sri Lanka has traditionally been an agriculture/farming-oriented society, although agriculture contributes to only about 8 percent of the national GDP today (CBSL 2019). Rice is the staple food and rice cultivation/farming is the most important economic activity for the majority of the population in rural areas. During recent years, the paddy sector has grown rapidly due to the extended cultivation of land areas and improved productivity due to the adoption of modern technologies. The modernization of farming, such as the use of high-yielding seeds, new machineries and equipment, and chemical fertilizers, has led to the increased production of rice. 
The main objectives of the Food Crop Production and Improvement Program are to make Sri Lanka self-sufficient in rice production and enhance production and productivity of vegetables and fruits through improved agricultural methods; water management system; pest control; and use of fertilizer, equipment, and technology. Strategies to enhance production of several crops at a mass scale include the following: (a) adopt novel technologies, (b) mechanize to raise productivity, (c) expand national productions and decrease import, (d) increase the efficiency of fertilizer by new technologies, (e) extend cultivation areas, (f) maintain production availability during nonseasonal period, and (g) increase high-quality seeds and self-generated seed production.

\section{Home Gardening Promotion}

The Home Gardening Promotion aims to make Sri Lanka a self-sufficient nation while fulfilling the family's food and nutritional requirements. To attract communities to home gardening, the government has sponsored providing a few fruit plants without any costs to families, introducing related training programs, and providing home garden development handbooks.

\section{Fertilizer subsidy}

One of the largest subsidy programs provided by the GOSL is for fertilizer, which aims to provide farmers with adequate fertilizer at reduced costs, especially for rice production. Around 1.5 million farmers benefit from this program. With the current policy the subsidized price of a $50 \mathrm{~kg}$ bag of fertilizer used for cultivating paddy fields has been fixed at SL Rs 500, regardless of the global market price.

\section{Food Production National Program}

The Food Production National Program (FPNP) was introduced in 2015 to develop the Sri Lankan economy through promoting agriculture and a healthy diet among the population. To achieve the goal of the program, several ministries including the Ministry of Agriculture (MoA), Ministry of Rural Economy, Ministry of Fisheries and Aquatic Resources Development (MFARD), and Ministry of Plantation Industries had been collaborating with several other authorities. There were multiple objectives: (a) make the country self-sufficient in traditional local foods and thereby save the sum of food imports; (b) ensure availability of high-quality food items through adopting environment friendly food production methods while minimizing the use of chemicals fertilizer and pesticides; (c) ensure food security by proper management of available food stocks; (d) introduce a crop production program based on agro-ecological zones; (e) increase productivity by promoting suitable methodologies in food crop production; (f) maintain proper coordination with all the institutions involved in local food production and joining the program with the normal daily routine of school community, civil society, and general public; (g) provide high-quality inputs in food production and create formal procedures for their production; and (h) build a healthy nation. 


\subsubsection{Fisheries sector programs}

Fish is the most important source of animal protein consumed in Sri Lanka. Fish provides more than 60 percent of animal protein requirement of the country and is the cheapest source of protein (MFARD 2016). Domestic marine and fresh water fish products are critical in improving the food security of the country. Marine fish production accounts for around 85 percent of the total fish production in the country and the rest from inland and aquaculture. There are 15 fishery districts in the country. However, Sri Lanka imports fish and fishery products to cater for the excess demand. To facilitate effective distribution of fish without decreasing its nutritional value, retail outlets of the Ceylon Fisheries Corporation (CFC) have been established island wide, and new outlets are proposed to be established in 20 more cities. The CFC operates as a public-private joint venture, aiming to provide its services efficiently through digitization of its financial and sales divisions. Awareness-raising programs for fishers are ongoing to minimize post-harvest losses and to improve facilities for ice production and cold rooms and supply of clean water for harbors and anchorages. Canned fish, which enables storing of fish, also contributes immensely to the per capita fish consumption. The GOSL is now producing canned fish domestically with support from the private sector.

\subsubsection{Livestock sector programs}

Livestock sector is also playing a vital role in the local economy to enhance food security. The Livestock Development Division under the Department of Animal Production and Health (DAPH) implements various programs and projects with the aim of meeting the increasing demand through healthy and quality animal products. At present, around 1 million families are engaged in dairy, goat, poultry, and swine farming, the majority of whom represent the rural sector.

\subsubsection{Food security cash assistance programs}

In Sri Lanka, the need to protect the most vulnerable population has been well recognized and successive governments have been supporting the poor through food subsidization and income supplementation programs. In 1978, the 'Food Stamp' scheme was introduced to low-income groups, a cash subsidy in the form of food stamps to procure a basket of nutritious food commodities (rice, flour/cereal, sugar, infant milk foods, dried fish, and pulses). In 1989, the food stamp scheme was replaced by the national poverty alleviation program 'Janasaviya'. In 1995, after the change of government, the Janasaviya program was amended as the 'Samurdhi' program.

Further, a nutrition food package for pregnant mothers was introduced in 2006 with the aim of enhancing the nutritional status of pregnant and lactating mothers of low-income families. The eligible criteria included those registered in an $\mathrm{MOH}$ living in a Samurdhi beneficiary family. Under this program, the beneficiary received a nutrition relief card to obtain a 'Nutrition Food Package' worth of SL Rs 500 for 20 months. In 2015, when the new government took office, the 
program was expanded to a universal program where all $\mathrm{MOH}$-registered pregnant mothers became entitled for the food allowance. Benefits were also increased to SL Rs 2,000 per month for 10 months, amounting to a total of SL Rs 20,000 per beneficiary.

\subsubsection{Water and sanitation programs}

The Ministry of City Planning, Water Supply, and Higher Education (MCPWS) administers access to safe drinking water and ensures sanitation facilities island wide. The GOSL has taken several measures to improve the capacity, quality, and distribution of water supply and sanitation facilities. At present, 90.6 percent of the population has access to safe drinking water and safe piped water coverage is 50.5 percent (MCPWS 2018). The National Water Supply and Drainage Board (NWSDB) and the Department of National Community Water Supply (DNCWS) play key roles in launching projects and programs in the urban and rural areas, respectively.

There are large-scale projects, such as the Water Supply and Sanitation Improvement Project (WASSIP) 2016-2020 implemented with support from the World Bank in seven districts around the country and the Asian Development Bank (ADB) Dry Zone Urban Water and Sanitation Project. Also, there are special programs implemented that aim to prevent chronic kidney diseases of unknown etiology (CKDu). 


\section{METHODS FOR THE ASSESSMENT}

This study largely followed the three-step approach that has been proposed by the SUN movement and used in multiple countries (Fracassi et al. 2017). The 'three steps' of the SUN approach are (a) identification of budget line items, (b) categorization of budget line items, and (c) weighting of budget line items (optional) (Fracassi et al. 2017). The following sections provide details of the approaches that this study has employed.

\subsection{Step 1: Identification}

\subsubsection{Desk review and search to identify nutrition programs and interventions}

Following the SUN approach, we first reviewed various government documents to identify nutrition programs and interventions that have been implemented in recent years. We initiated this process by searching the reports from the Ministry of Finance (MoF) using key words recommended by the SUN approach (Fracassi et al. 2017). While this approach yielded some information, it has soon become apparent that the line items were largely input based and provided little to no information on program and activity-wise budget allocation and expenditure that was needed for this exercise. We then shifted the approach to review key nutrition-related documents including the NNP 2010, MSAPN Vision 2016, MSAPN 2018-2025 (in draft), and National Strategic Review of Food Security and Nutrition: Towards Zero Hunger (WFP 2017). This strategy provided the necessary information, and all programs and interventions that were covered in those documents were extracted and listed, which formed the basis of the exercise.

\subsubsection{Consultation with government stakeholders through working group}

Although we obtained a reasonable list of nutrition programs and interventions from the desk review, there was a critical drawback that little to no information on budget or expenditure was obtained from the available documents at the granularity required for the analysis. This implied that we needed to obtain the budget allocation and expenditure data from each ministry, department, and province manually. To obtain support from the government and facilitate this process, a working group was formed comprising key ministries and government agencies. We identified the key ministries and relevant departments from the list of programs developed through desk review that are summarized in Table 1. 
Table 1: Ministries having significant responsibilities and programs related to nutrition

\begin{tabular}{|c|c|}
\hline Ministry & Implementing agencies/departments \\
\hline $\mathrm{MoH}$ & $\begin{array}{l}\text { Nutrition Division (ND); FHB; Health Promotion Bureau } \\
\text { (HPB); MRI; Estate and Urban Health Unit; NCD Unit; } \\
\text { Environmental, Occupational Health, and Food Safety Unit }\end{array}$ \\
\hline MWCA & Children's Secretariat; Women Development \\
\hline Ministry of Education (MoE) & School Health and Nutrition (SHN) Division \\
\hline Ministry of Agriculture (MoA) & Department of Agriculture, National Food Promotion Board \\
\hline MFARD & $\begin{array}{l}\text { National Aquaculture Development Authority (NAQDA); } \\
\text { Fisheries Social Development Division (FSDD); Department } \\
\text { of Fisheries \& Aquatic Resources (DFAR); Ceylon Fisheries } \\
\text { Corporation (CFC) }\end{array}$ \\
\hline $\begin{array}{l}\text { Ministry of Livestock and Rural Community } \\
\text { Development (MLRD) }\end{array}$ & Livestock Development; DAPH \\
\hline $\mathrm{MHC}$ & $\begin{array}{l}\text { Plantation Human Development Trust; District/ Divisional } \\
\text { Secretariats }\end{array}$ \\
\hline MCPWS & $\begin{array}{l}\text { National Water Supply \& Drainage Board; Department of } \\
\text { National Community Water Supply }\end{array}$ \\
\hline $\begin{array}{l}\text { Ministry of Primary Industry and Social } \\
\text { Empowerment (MPISE) }\end{array}$ & Department of Divineguma \\
\hline
\end{tabular}

The Department of National Planning (NPD) agreed to chair the working group that comprises delegates from each of the identified key ministries and departments. Additionally, the Presidential Secretariat, MoF, and the Ministry of Internal and Home Affairs and Provincial Council and Local Government were invited to the working group. Before initiating data collection, a workshop of the working group was organized to confirm and agree if all nutrition programs and interventions had been included in the list, to discuss the most appropriate data sources to obtain budget allocation and expenditure data, and to request support in the administrative procedures needed for collecting data from each program.

\subsubsection{Scope of the exercise}

\section{Central and provincial funding}

The scope of this exercise focused on the state-sponsored or development-partner-funded nutrition programs. The government funds are channeled through two systems: more than 90 percent of the funds are dispensed through the central line ministries and the remainder through the provincial ministries. As such, this study aimed to capture the public funding at both central and provincial levels that are assisted by the GOSL.

\section{Capital expenditure}

Some of the expenditure items involve capital assets that are sectorwide in nature (for example, warehouse, rural infrastructures) and are shared with other programs that have very different objectives. It was often problematic to work out the portion of contribution of such capital assets to nutrition. Therefore, we excluded such capital expenditure from the analysis following the SUN 
guideline. However, recognizing the importance of some capital assets that are exclusively used for nutrition-specific or nutrition-sensitive programs, such as equipment for nutrition clinics, WASH interventions, and capital assets related to Thriposha program, was included in this analysis.

\subsection{Step 2: Categorization}

Following the Lancet definition, this study defines nutrition-specific actions as "interventions and programs which address the immediate determinants of fetal and child nutrition and development - adequate food and nutrient intake, feeding, caregiving and parenting practices, and low burden of infectious diseases" (Fracassi et al. 2017). Nutrition-sensitive interventions refer to "interventions and programs that address the underlying determinant of malnutrition as originally set out in the UNICEF conceptual framework" (see Figure 12). They include actions from a range of sectors including health, agriculture, and food systems; promotion of WASH; education; and social protection. Key practices, services, and policy interventions for preventing and treating stunting and other forms of undernutrition and overweight and obesity throughout the life cycle are detailed in Annex 1.

Figure 12: UNICEF conceptual framework of the determinants of child undernutrition

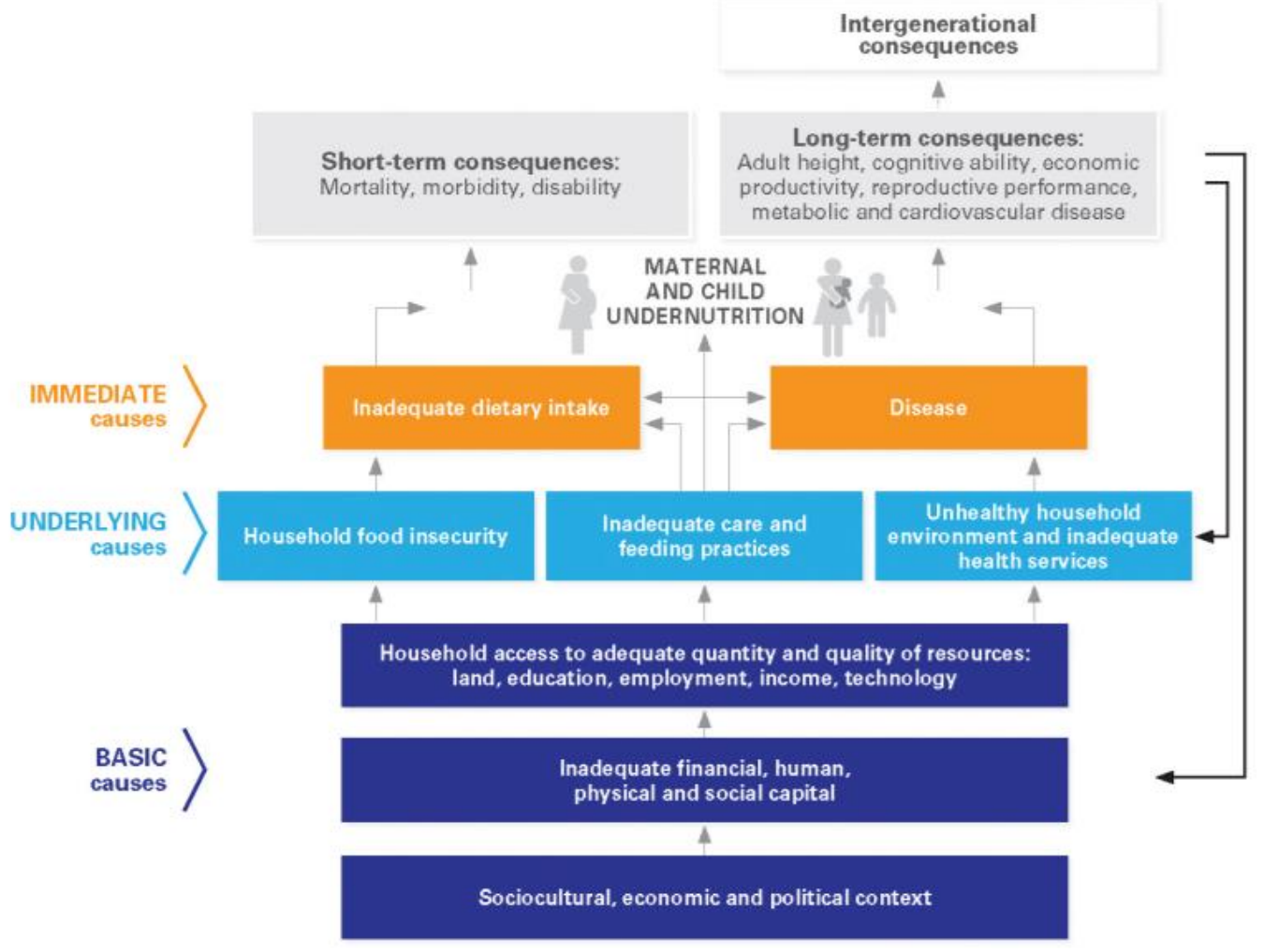

UNICEF 2015.

Source: 
As provided in Table 2, the categorization of nutrition programs into specific and sensitive interventions was performed in line with the global definition, albeit with a few exceptions (UNICEF 2015). According to global literature, school feeding programs are classified as nutrition-sensitive interventions whereas in Sri Lanka school feeding and preschool feeding programs were classified as nutrition-specific interventions. This deviation from the global definition was discussed and agreed at one of the working group workshops conducted during the exercise, considering the general recognition in Sri Lanka of the school meal program as being nutrition specific (MoE 2017). Likewise, two preschool meal programs administered by the MWCA and MHC were also classified as nutrition-specific interventions.

Table 2: Nutrition interventions and lead ministries

\begin{tabular}{|c|c|c|c|}
\hline Ministry & Program/Activity & $\begin{array}{l}\text { Specific/ } \\
\text { Sensitive }\end{array}$ & Program description \\
\hline \multirow[t]{10}{*}{$\mathrm{MoH}$} & $\begin{array}{l}\text { Micro-nutrient supplementation } \\
\text { programs }\end{array}$ & Specific & $\begin{array}{l}\text { Micronutrient supplementation (iron, } \\
\text { folic acid, vitamin C, and calcium) for } \\
\text { pregnant women and lactating } \\
\text { mothers; vitamin A mega dose for } \\
\text { children (ages } 6 \text { months to 5years); } \\
\text { MMN supplementation ( } 6 \text { months to } \\
18 \text { months); iron, folic acid, vitamin C } \\
\text { for school children (grades } 1-13 \text { ) and } \\
\text { vitamin A mega dose supplementation } \\
\text { at grades } 1,4 \text {, and } 7\end{array}$ \\
\hline & $\begin{array}{l}\text { Multivitamin drops, iron, folic acid } \\
\text { for preterm and low birth weight } \\
\text { (LBW) children }\end{array}$ & Specific & $\begin{array}{l}\text { Starting soon after birth continue till } \\
\text { completion of } 2 \text { years }\end{array}$ \\
\hline & Therapeutic food (BP 100) & Specific & Children with SAM \\
\hline & $\begin{array}{l}\text { Zinc supplementation for children } \\
\text { with diarrhea }\end{array}$ & Specific & $\begin{array}{l}\text { Starting with onset of diarrhea and } \\
\text { continued for } 10-14 \text { days }\end{array}$ \\
\hline & Deworming treatment & Sensitive & $\begin{array}{l}\text { Children at ages } 18 \text { months, } 2,3,4,5 \\
\text { years; all school children and pregnant } \\
\text { mothers }\end{array}$ \\
\hline & Thriposha program & Specific & $\begin{array}{l}\text { Pregnant women and lactating } \\
\text { mothers (for up to } 6 \text { months post- } \\
\text { delivery) and undernourished children } \\
\text { ages 6-59 months }\end{array}$ \\
\hline & $\begin{array}{l}\text { Promote optimal maternal nutrition } \\
\text { and IYCF practices }\end{array}$ & Specific & Nutrition counseling \\
\hline & $\begin{array}{l}\text { Capacity building of relevant health } \\
\text { staff in maternal nutrition and IYCF } \\
\text { counseling; growth monitoring and } \\
\text { promotion }\end{array}$ & Specific & Nutrition counseling \\
\hline & $\begin{array}{l}\text { Information, education, and } \\
\text { communication (IEC) material - } \\
\text { breastfeeding, IYCF }\end{array}$ & Specific & Nutrition counseling \\
\hline & $\begin{array}{l}\text { Printing of growth monitoring } \\
\text { materials - child health } \\
\text { development record, pregnancy } \\
\text { records }\end{array}$ & Sensitive & Growth assessment \\
\hline
\end{tabular}




\begin{tabular}{|c|c|c|c|}
\hline Ministry & Program/Activity & $\begin{array}{l}\text { Specific/ } \\
\text { Sensitive }\end{array}$ & Program description \\
\hline & $\begin{array}{l}\text { Health awareness programs - family } \\
\text { planning, NCDs, healthy lifestyles }\end{array}$ & Sensitive & Health awareness programs \\
\hline & $\begin{array}{l}\text { District Nutrition Action Plan } \\
\text { (DNAP) - for vulnerable population, } \\
\text { estate sector }\end{array}$ & Specific & Behavioral and social change \\
\hline & $\begin{array}{l}\text { Recommended instruments for } \\
\text { MCH clinics }\end{array}$ & Specific & Growth assessment \\
\hline & School health program & Sensitive & $\begin{array}{l}\text { Growth assessment and nutrition } \\
\text { counseling for children }\end{array}$ \\
\hline & $\begin{array}{l}\text { Equipment for school health } \\
\text { program }\end{array}$ & Sensitive & Growth assessment \\
\hline \multirow[t]{4}{*}{ MWCA } & $\begin{array}{l}\text { Morning meal/fresh milk for } \\
\text { preschool children (ages } 2-5 \text { years) }\end{array}$ & Specific & $\begin{array}{l}\text { Preschool children (ages } 2-5 \text { years) in } \\
\text { remote areas }\end{array}$ \\
\hline & $\begin{array}{l}\text { Food allowance for pregnant } \\
\text { mothers }\end{array}$ & Sensitive & All MOH-registered pregnant women \\
\hline & $\begin{array}{l}\text { Poshana Manpetha - Food and } \\
\text { Nutrition Awareness Program }\end{array}$ & Specific & Nutrition counseling \\
\hline & Cash assistance at the birth of twins & Sensitive & Safety nets \\
\hline \multirow[t]{4}{*}{$\mathrm{MoE}$} & School meal program & Specific & School children in grades $1-5$ \\
\hline & Glass of milk for school children & Specific & School children in grades $1-5$ \\
\hline & Food for Education Program (WFP) & Specific & School children in grades $1-9$ \\
\hline & School WASH & Sensitive & $\begin{array}{l}\text { School water sanitation and hygiene } \\
\text { (WASH) }\end{array}$ \\
\hline \multirow[t]{4}{*}{ MHC } & $\begin{array}{l}\text { Tikiri Shakthi - high-protein } \\
\text { nutrient bar }\end{array}$ & Specific & $\begin{array}{l}\text { Nutrition food supplementation } \\
\text { children (ages 3-5 years) thrice per } \\
\text { week }\end{array}$ \\
\hline & Estate sector WASH & Sensitive & $\begin{array}{l}\text { Improve safe drinking water and } \\
\text { sanitation facilities }\end{array}$ \\
\hline & Home gardening (Hill country) & Sensitive & Food availability \\
\hline & Upgrade child development centers & Sensitive & Early childhood development \\
\hline MoA & Nutrition-related interventions & Sensitive & Food availability \\
\hline MLRD & Nutrition-related interventions & Sensitive & Food availability \\
\hline MFARD & Nutrition-related interventions & Sensitive & Food availability \\
\hline MCPWS & National WASH program & Sensitive & Improve water and sanitation \\
\hline MPISE & Samurdhi welfare & Sensitive & Safety net program \\
\hline
\end{tabular}

\subsection{Step 3: Data collection and assignment of expenditure}

\subsubsection{Data collection}

As described in Section 4.2, there were limited budget line data from government documents that capture and isolate nutrition budget and expenditure from others. Budget line items were available for very few nutrition interventions such as school meal and Thriposha programs. Therefore, information collection of this study was based on documentation analysis and in-depth visits to ministries and department that were involved in delivery of nutrition interventions.

Once the programs and interventions to be included in the exercises were agreed by the stakeholders, the study team followed a program-level primary data collection exercise, both at 
central and provincial levels. Initially it was attempted to collect data from 2010 to 2018, but older data were not available for many programs and sectors. Eventually, this exercise was limited to the most recent five years between 2014 and 2018. At the central level, the study team visited all government offices and institutes that were identified in Table 2, and regional-level data were collected through the provincial ministries. The team prepared an Excel-based template to guide the data collection exercise. Also, the data collection template was designed to allow for identifying information for each program by funding source to avoid duplications. Finally, the information collected through central and provincial levels were checked for any duplications. Further, DP off-budget funding was also considered wherever possible. For instance, UNICEF and WHO off-budget funding for FHB programs was extracted from FHB finance data.

\subsubsection{Assignment of human resource expenditure}

Assigning expenditure of human resource (HR) for nutrition was problematic as most provincial staff were engaged in multiple tasks, including those other than nutrition. Therefore, we resorted to some assumptions in assigning the HR expenditure to each program. For instance, for each ministry/department that implements nutrition interventions, we estimated the ratio of total HR costs with respect to total non-HR costs and applied the same ratio of HR cost for all nutritionrelated expenditure by each ministry. However, there were two exceptions: (a) for school programs, we excluded the teachers' salary (about 80 percent of total HR expenditure) from the assigned HR costs, and (b) for national WASH programs, HR costs were not added as those are large-scale projects that are outsourced to firms and labor costs are largely covered by the project costs.

\subsubsection{Provincial distribution}

Information on the provincial distribution was not available for some centrally procured program items. Further, data on provincial distributions of some nutrition-specific interventions (FHB medicine/supplementation programs and Thriposha program) as well as most of the nutritionsensitive interventions (programs under MoA, MFARD, DAPH and National Water and Sanitation programs) were not available. In those cases, we have assigned expenditure to provinces proportionally using assumptions provide in Table 3.

Table 3: Assumptions used for provincial allocation

\begin{tabular}{|l|l|}
\multicolumn{1}{|c|}{ Program } & \multicolumn{1}{c|}{ Provincial allocation is based on } \\
\hline FHB program and Thriposha program & Proportion to registered pregnant mothers \\
\hline FHB school health program & Proportion to number of school children \\
\hline School WASH & Proportion to number of schools \\
\hline Agriculture programs & Proportion to population \\
\hline Fisheries programs & Proportion to population \\
\hline DAPH programs & Proportion to population \\
\hline National WASH & Proportion to population \\
\hline
\end{tabular}




\subsubsection{Weighting}

We did not attempt to weight the nutrition-sensitive programs. In the SUN guideline, weighting is suggested as optional. The assignment of weights largely relies on expert opinions or rudimentary assumptions, which are highly prone to subjectivity. Although we clearly acknowledge the value of weights for nutrition-sensitive interventions, a robust scientific method is yet to be developed to derive the weights. For this reason, we did not assign weights for the sensitive interventions. Therefore, the findings of the investments in nutrition-sensitive interventions must be interpreted accordingly with cautions.

\subsubsection{Inflation adjustment}

For this study, we adjusted for inflation by using a GDP deflator. Accordingly, unless otherwise mentioned hereafter, figures are presented in constant market prices with base year 2018 . 


\section{RESULTS AND FINDINGS}

\subsection{Public expenditure for nutrition interventions in Sri Lanka}

\subsubsection{Overview}

Despite the existing budgetary constraints, Sri Lanka has maintained a relatively stable level of investments in nutrition over years. During 2014-2018, the country's annual public investment in nutrition was roughly around 5-6 percent of the total government expenditure. This is relatively smaller compared to the levels of other countries in the region, although there are countries that spend even less (Figure 13). To make the investments in nutrition effective, it is important to identify which nutrition interventions deserve further investments to maximize the nutrition outcomes to reach the country's targets. Investments in both nutrition-specific and nutritionsensitive interventions are fundamental for countries to improve food security and nutrition. However, Sri Lanka currently spends only a small portion of its nutrition expenditure on nutritionspecific interventions (see Table 4). Given the strong evidence of nutrition-specific interventions and their role in addressing the immediate determinants of nutrition, the balance of expenditure deserves due attention.

Table 4: Public expenditure for nutrition interventions as a percentage of TPE

\begin{tabular}{|l|c|c|c|c|c|}
\hline & 2014 & 2015 & 2016 & 2017 & 2018 \\
\hline Nutrition-specific interventions & 0.54 & 0.49 & 0.45 & 0.42 & 0.49 \\
\hline Nutrition-sensitive interventions & 4.96 & 6.44 & 6.43 & 6.11 & 4.67 \\
\hline Total & 5.50 & 6.93 & 6.88 & 6.53 & 5.16 \\
\hline
\end{tabular}

Figure 13: Nutrition expenditure as a percentage of TPE (unweighted)

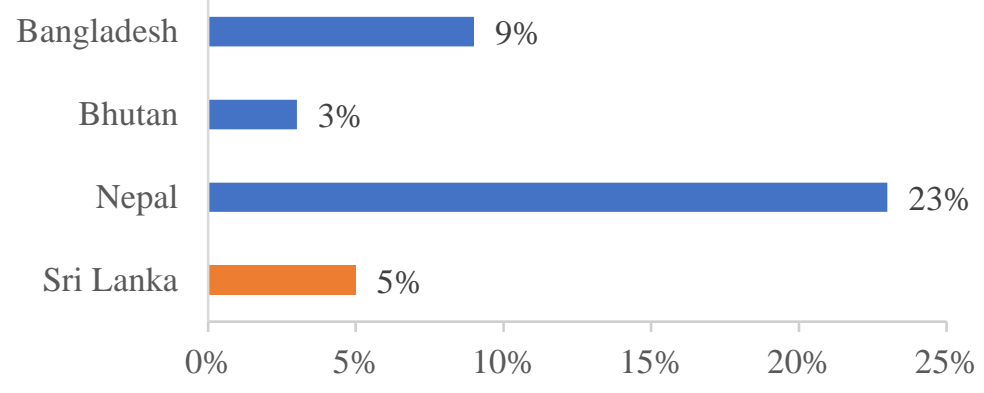

Source: Bangladesh Finance Division and UNICEF 2019; World Bank 2019b; World Bank 2019c.

\subsubsection{Trends in public expenditure on nutrition (specific and sensitive)}

Sri Lanka's investments in nutrition interventions are dominated by nutrition-sensitive interventions at 90 percent (Figure 14). On average, the GOSL annually spends around SL Rs 5,000-8,000 per capita for nutrition-sensitive interventions as against SL Rs 550-600 per capita 
for nutrition-specific interventions (Figure 15). It is noteworthy, however, that expenditure on nutrition-specific interventions continued to increase despite a substantial drop in nutritionsensitive investments in 2018.

Over the last five years, the most remarkable increase in expenditure on nutrition-sensitive interventions was observed in 2015, a 60 percent increase from 2014. This increase was largely due to the changes in the policies and priorities and introduction of new programs and reforms of existing programs in 2015. Some existing programs such as the Samurdhi welfare program and food allowance for pregnant mothers received substantially more resources and expanded while some new programs such as the FPNP were initiated. However, the overall expenditure on nutrition has seen a gradual decline in subsequent years with a clear drop in 2018. This drop was caused primarily by some nutrition-sensitive interventions such as the fertilizer subsidy and WASH programs which are discussed in detail later in section 5.3.

Figure 14: Public expenditure on nutrition 2014-2018

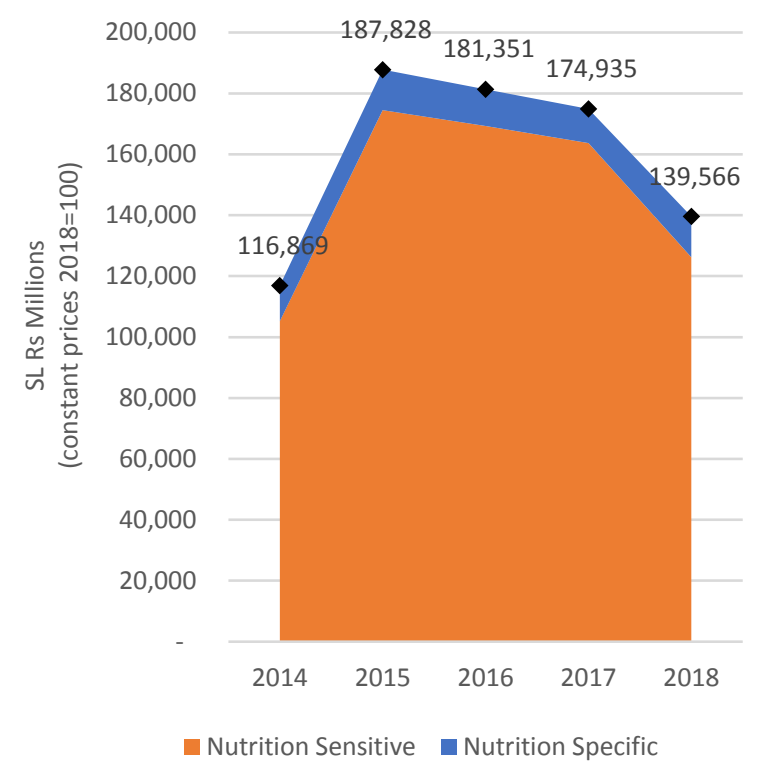

Figure 15: Per capita public expenditure on nutrition 2014-2018

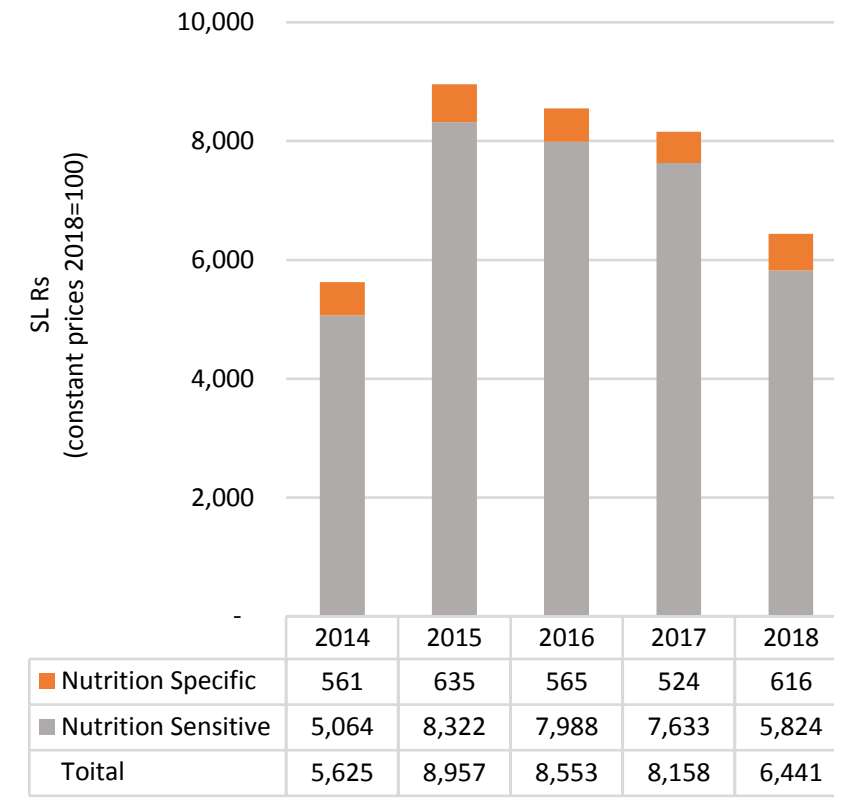

\subsubsection{Nutrition programs financed by DPs}

In Sri Lanka, a number of DPs are funding nutrition programs either through the government treasury (on-budget) or direct financing (off-budget). Nutrition programs that are financed onbudget appear in the government system and hence have been captured through different line ministries and provinces. On the other hand, off-budget financing is managed by each DP and hence needed to be obtained individually from each agency. However, despite the official request made to all registered DPs through the DP Coordination Secretariat, response remained minimal due to difficulties faced by the DPs in isolating and compiling their contributions to nutrition. 
However, we obtained some information from the government offices on off-budget donor-funded programs that are implemented by the ministry or provinces. We included those programs in the analysis after confirming that they were identified in Step 1 of the process. Nonetheless, the contribution of DPs in Sri Lanka is small in general compared to the TPE, and given that on-budget support is captured on the government side, the incomplete information on off-budget contributions would not make a major difference at the overall investment level. Box 2 provides a summary of key contributions from the DPs. ${ }^{6}$

Box 2: Contribution of DPS

Every year, various nutrition-specific and nutrition-sensitive interventions are funded through different DP organizations. A summary of their contributions is as follows:

- UNICEF, the WHO, and the WFP are the main DPs aiding financial support to implement nutritionspecific interventions in Sri Lanka, island wide through the FHB, Nutrition Coordination Division, and HPB.

- UNICEF contributes to policy development, evidence generation, IYCF promotion, capacity building, and advocacy programs on maternal and child nutrition, to buy required equipment for the $\mathrm{MCH}$ clinics in certain situations (that is, disaster), and programs such as early childhood development, national nutritional month, and health and nutrition (by a mix of own fund and grants from other DPs).

- Funds from the WHO are mainly utilized to conduct training and advocacy programs on nutrition, including promotion of IYCF and breastfeeding practices, as well as for the printing of certain materials such as preterm growth charts and leaflets only at the inception of a program. In addition, WHO funds are used for programs under the National Nutrition Surveillance System.

- There are other DPs such as the WFP, Food and Agriculture Organization (FAO), Global Affairs Canada, and EU-Aid majorly funding to implement different nutrition-sensitive programs in Sri Lanka.

- Improving the nutritional status of pregnant and lactating women and undernourished children is funded by the WFP and FAO, using SUN through multisectoral approach programs.

- The FAO further funds the Northern, Eastern, and Central Provinces to improve the nutritional status of vulnerable families in post-war-affected and flood-affected areas.

- The FAO also funds agricultural and agroeconomic development programs, which are implemented through the MoA and MPISE.

- The Ministry of Fisheries is funded by the FAO for programs such as fish handling, reduction of postharvest loses in tsunami-affected areas, restoration and improving fish landing sites, construction of ponds to cultivate fresh water fish, preparation of the inland fisheries sector development program and implementation strategy, and aquaculture industry improvement.

- $\quad$ EuropeAid supports the estates and surrounding communities to provide equitable WASH for improved health and nutrition and Assisting Communities in Creating Environmental and Nutritional Development (ACCEND) in the most vulnerable districts of the Central and Uva Provinces through the Integrated Rural Development program.

\footnotetext{
${ }^{6}$ The share of foreign financing in public expenditure is generally small in Sri Lanka. In 2016, the TPE was SL Rs 3,106 billion, of which the share of foreign financing was 7 percent (SL Rs 216 billion). In the health sector, the share of external health expenditure is even smaller and accounted for just 0.9 percent of PHE in 2016.
} 
- Further EU-Aid-funded programs include EU Support to Socio Economic Measures in North and East Sri Lanka (EU-SEM); EU Support to District Development (EU-SDDP); Food and Nutrition Security Impact, Resilience, Sustainability, and Transformation (FIRST); and South Asia Food and Nutrition Security Initiative (SAFANSI), in partnership with the World Bank.

- EU-Aid programs mainly focus on implementing activities such as Building Effective Nutrition Communication through Partnerships: Addressing Estate Sector Nutrition Issues in Sri Lanka, Integrating Nutrition Promotion and Rural Development (INPARD), Improving Nutrition through Modernizing Agriculture (INMAS), and Learning from 'Champions': Qualitative study on infant and young child feeding and caring practices in Sri Lanka's estate sector.

- Global Affairs Canada funds through Bilateral Aid Disbursements for Nutrition and Related Sectors in Sri Lanka for programs such as school feeding program in partnership with the WFP, other programs plantation communities project, International Development Research Centre-Canadian food security, Volunteer Cooperation Program Uniterra (World University Service of Canada-Centre for International Studies and Cooperation) (basic nutritional programs), and other agricultural research programs.

\subsection{Public expenditure for nutrition-specific interventions}

\subsubsection{Overview}

Nutrition-specific interventions largely fall under the mandate of the MoH. Many of the nutritionspecific interventions are provided primarily through the existing public health systems, involving a wide network of health institutions. This broad network has contributed to develop a solid infrastructure to provide effective health services throughout the country. In addition to the $\mathrm{MoH}$, the MWCA and MoE are the key ministries that implement nutrition-specific interventions, particularly targeting the preschool and school children. As discussed earlier in this report, considering the general recognition of the school meal program as being nutrition specific in Sri Lanka, school feeding and preschool feeding programs were classified as nutrition-specific interventions. 
Figure 16: Public expenditure on nutrition-specific interventions

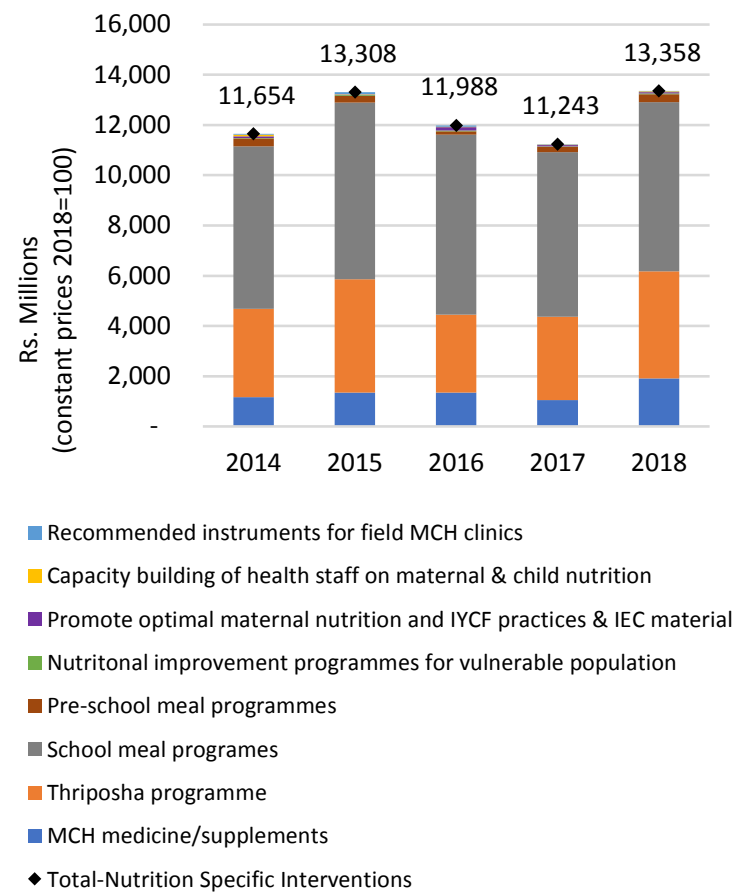

Figure 17: Per capita public expenditure for key nutrition-specific interventions

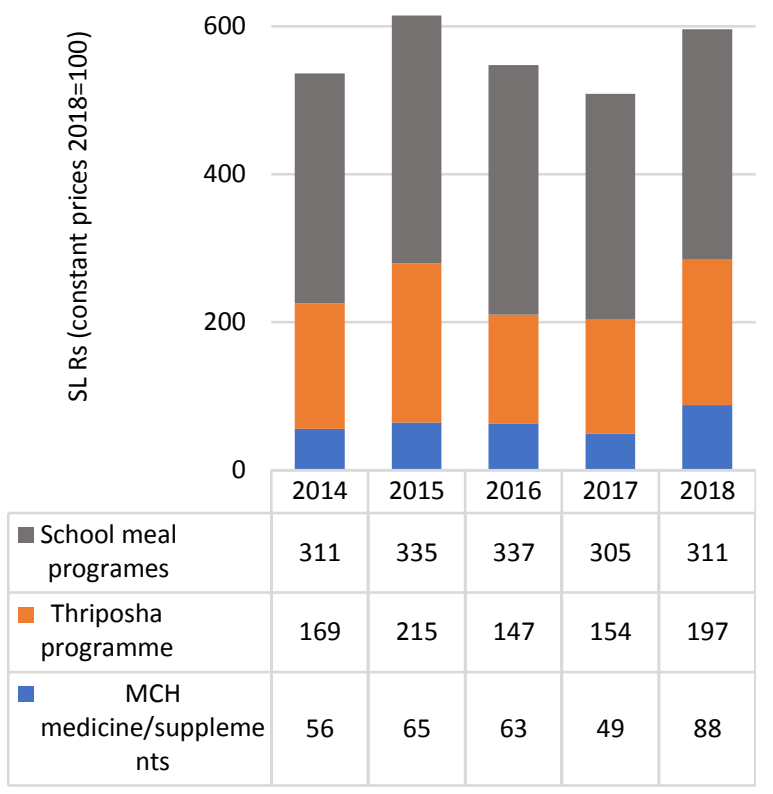

Key nutrition-specific interventions in Sri Lanka include medicine and supplements provided through the national $\mathrm{MCH}$ program of the $\mathrm{FHB},{ }^{7}$ Thriposha program, and school meal program. These three programs account for 96.7 percent of the expenditure on nutrition-specific interventions (Figure 16). In 2018, 50.5 percent of the total expenditure on nutrition-specific programs was spent by the school meal program followed by the Thriposha program (31.9 percent), and FHB medicine and supplements in $\mathrm{MCH}$ program accounted for only 14.3 percent of the nutrition-specific investments. Further, in 2018 the GOSL spent around SL Rs 300 per capita for school meal program, followed by the Thriposha program (SL Rs 200 per capita) and MCH program (SL Rs 90 per capita) (Figure 17). Also, it is worth noting that the bulk of 'nutritionspecific' expenditure is on school meals for children ages 5-10 years, which is outside the first 1,000-day window when nutrition interventions are most effective. Investments in nutritionspecific interventions have risen in 2015 driven by the increased expenditure on the Thriposha program. Public expenditure on nutrition-specific interventions again increased in 2018 driven by the change in some $\mathrm{MCH}$ programs, which is discussed in detail under the FHB programs.

\footnotetext{
7 The MCH program includes a collection of evidence-based interventions to improve nutrition of reproductive, maternal, newborn, child adolescent, and youth health.
} 


\subsubsection{Nutrition specific interventions: $\mathrm{MoH}$}

Figure 18: Public expenditure on nutrition-specific interventions in the health sector

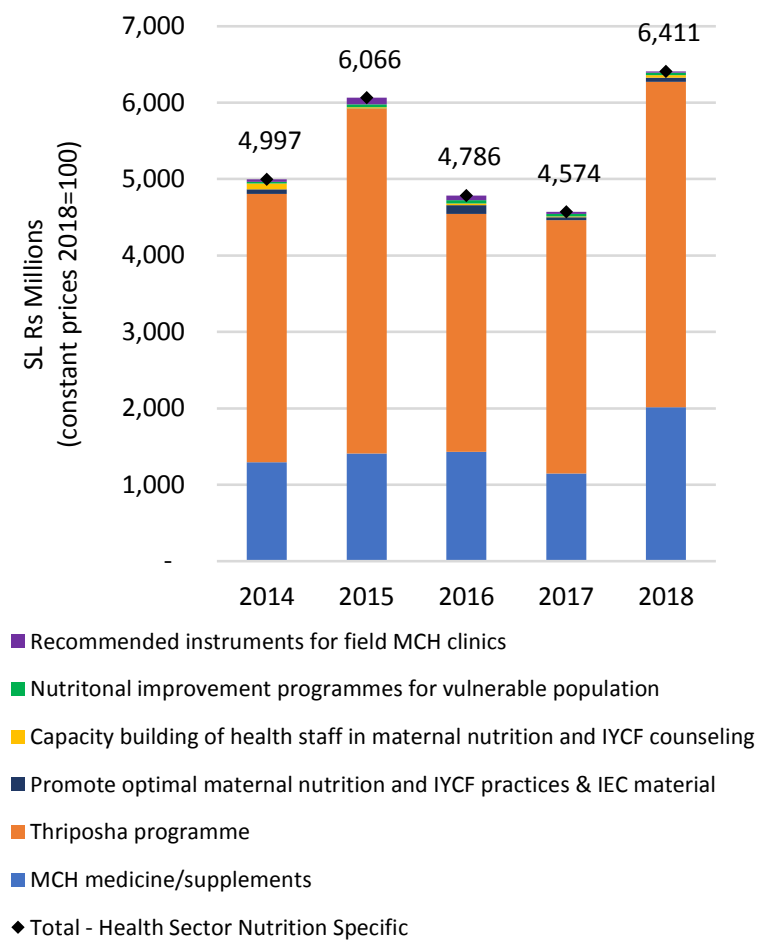

Figure 19: Per-pregnant woman public expenditure for MCH medicine/supplements and Thriposha program

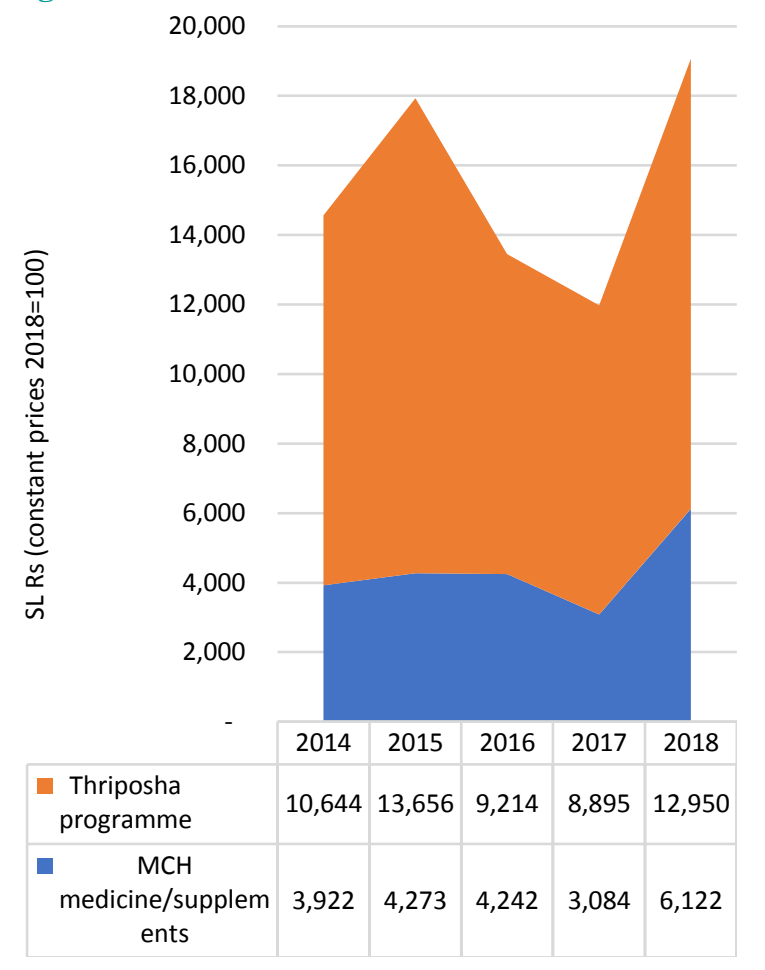

Almost all nutrition-related resources under the $\mathrm{MoH}$ are absorbed by the maternal and child micronutrient supplementation program and the supplementary feeding program. The government spends around SL Rs 5-6 billion for $\mathrm{MoH}$ nutrition interventions annually (Figure 18). Out of the $\mathrm{MoH}$ nutrition expenditure, 96 percent is spent on two key programs: $\mathrm{MCH}$ medicine/supplementation program and Thriposha. FHB medicine/supplements in $\mathrm{MCH}$ program is a collection of evidence-based interventions that target nutrition of RMNCAYH, while the Thriposha program ${ }^{8}$ is a supplementary feeding program for pregnant and lactating mothers and undernourished children under five years. It is noteworthy that investment in the Thriposha program is almost double the amount of the FHB medicine and supplements in MCH programs. Figure 19 shows the public expenditure per pregnant woman on key $\mathrm{MCH}$ programs. The $\mathrm{MoH}$ spent around SL Rs 6,000 per pregnant woman for FHB supplements for MCH programs in 2018 while around SL Rs 13,000 per pregnant woman was spent for Thriposha, although both programs have wider beneficiaries. However, as discussed earlier in this report, the potential benefit of Thriposha has not been explored in reducing acute malnutrition.

\footnotetext{
${ }^{8}$ Thriposha is a precooked blend of corn and soya fortified with minerals and vitamins. It is designed to supplement energy, protein, and micronutrients.
} 
Of the total nutrition-specific expenditure, only 1.8 percent accounted for awareness-raising programs on nutrition practices such as IYCF with related IEC materials and staff training programs and nutritional improvement programs for vulnerable population. Nutrition education is provided primarily by the PHMs at $\mathrm{MCH}$ clinics, at field weighing posts, and during home visits to pregnant and lactating mothers and infants. Additionally, the ND of the $\mathrm{MoH}$ provides nutritional improvement programs at the regional level, which accounts for around SL Rs 30 million annual public expenditure, including HR costs.

\subsubsection{FHB medicine/supplements in the MCH program}

As shown in Figure 20, public expenditure on FHB medicine/supplements in MCH program sharply increased in 2018, chiefly due to the change in the micronutrient supplementation. Under the maternal care program, iron, folic acid, calcium, and vitamin $\mathrm{C}$ are provided through the ANC package. As a measure of improving quality of the product and compliance of the maternal care program, ferrous fumarate + folic Acid tablets $(182.4 \mathrm{mg}+400 \mathrm{mcg})$ was introduced in the form of blister packs in 2018 in place of the previously used ferrous sulphate tablets and folic acid tablets, which added to the expenditure under the $\mathrm{MCH}$ program.

Figure 20: FHB supplements by MCH program

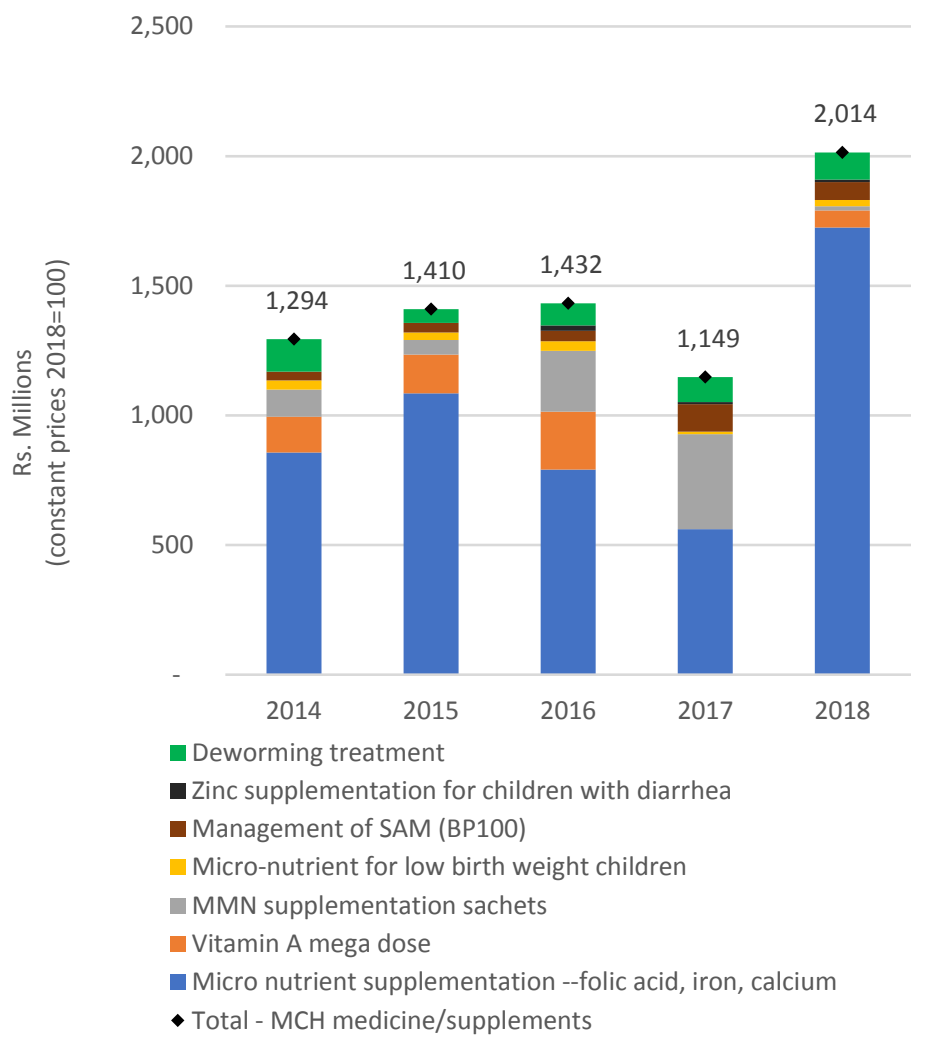


With the aim of preventing iron deficiency among children ages 6 to 23 months, the MMN supplementation program was expanded island wide since 2017. MMN supplementation ${ }^{9}$ for children was introduced in 2007, with the support of UNICEF, on a pilot basis in four most nutritionally vulnerable districts. Subsequently the program was expanded and implemented in 13 selected districts. Based on the findings from a national compliance study conducted by the MRI and UNICEF, the MMN program was expanded to the entire island in 2017. Given the expansion, expenditure on MMN has increased to around SL Rs 370 million in 2017, which dropped in 2018 due to the balance left from the 2017 procurement.

BP 100, a RUTF, has been used in Sri Lanka for the treatment of SAM, which absorbed SL Rs 70 million in 2018. To ensure the availability of SAM treatment, procurement of BP 100 was increased during 2016-2018. The annual usage during this period was around 2,700-3,800 cartons, which was around 2,000 cartoons during 2014-2015.

\subsubsection{Public expenditure of school nutritional program}

There are three kinds of 'school nutrition programs' implemented by the MoE: government school meal program; 'Food for Education' Program jointly implemented by the Ministry of National Policies and Economic Affairs (MNPEA) and WFP; and the glass of fresh milk/milk packets program (see Box 3).

Box 3: School nutrition programs

\section{Government school meal program}

Schools to conduct the school meal program are selected based upon 3 criteria:

- All the students of schools with total number of students less than 100

- Students from grades 1-5 of selected schools

- Students of the special education unit

SL Rs 28.00 is allocated for one meal for one student a day. The meals should be provided according to the approved menus. The recommended time to provide meals is 7.30 to $8.30 \mathrm{a} . \mathrm{m}$.

\section{Food for Education Program}

The program is jointly implemented by the MNPEA and WFP:

- Implemented in the schools of the Northern Province

- Students of grades 1-9 from selected schools

The MNPEA provides rice, oil, dhal, and canned fish for this program through district secretariat and additional fund to purchase greenery. This greenery fund is provided based on the daily attendance of students on meal serving days. The per student allocation for a meal range from SL Rs 3.50 to SL Rs 7.00 based on the number of the students in the school.

\footnotetext{
${ }^{9} \mathrm{MMN}$ powder sachets (containing 15 vitamins and minerals, including iron, zinc, and vitamin A).
} 


\section{Glass of fresh milk/milk packets program}

This program is funded by the government:

- Students from grades 1-5 of selected schools are included in this project.

- A $150 \mathrm{ml}$ milk packet is provided to a student 5 days in a week.

The government school meal program dominates among the school and preschool meal programs. The GOSL annually spends around SL Rs 5-6 billion for the government school meal program (Figure 21).

This program has been implemented in almost 80 percent of all government schools with 1 million beneficiaries among grade 1-5 school children. Conversely, the glass of fresh milk/milk packets program is implemented in only around 10 percent of schools, which are not covered under the school meal program. The GOSL spent around SL Rs 6,000 per child for the school meal program in 2018 while around SL Rs 3,500 per child was spent on the preschool meal program (Figure 22).

Figure 21: Public expenditure on school and preschool nutritional programs

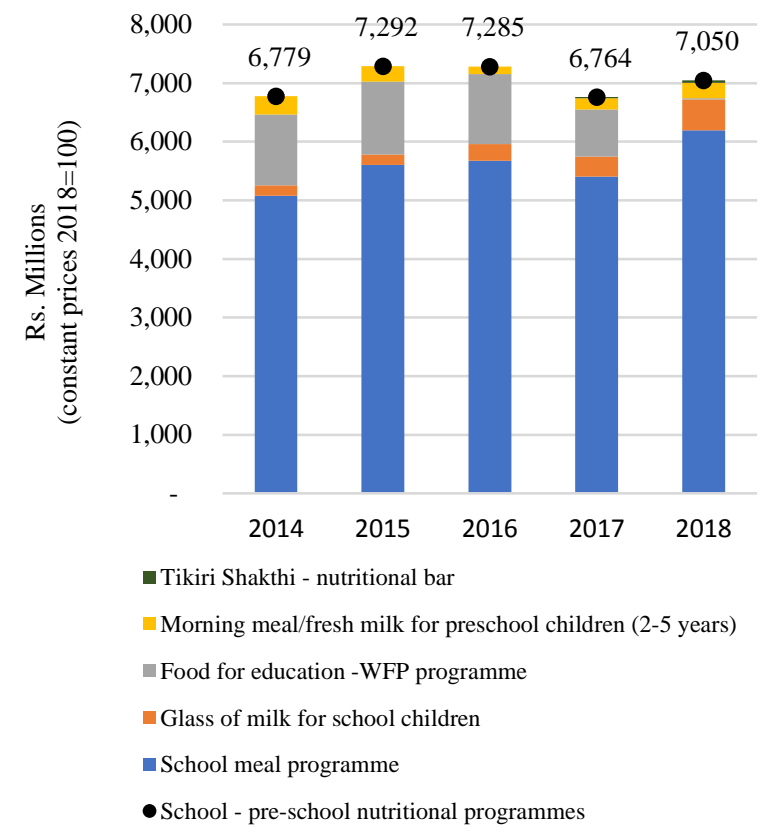

Figure 22: Per child public expenditure for school and preschool nutritional program, 2018

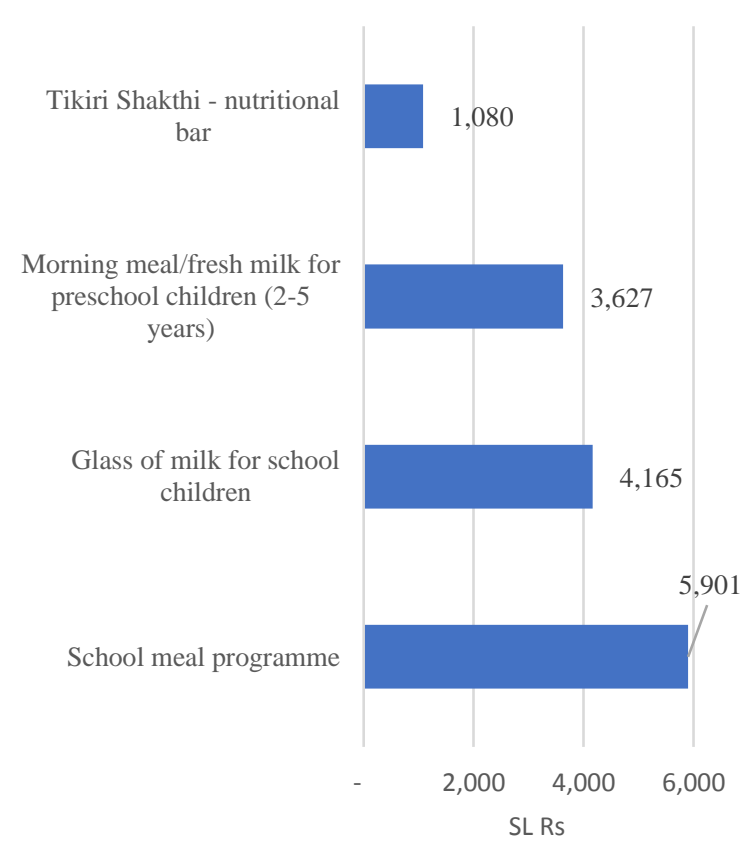

It is also noteworthy that the government school meal program places higher priority on marginalized regions. For instance, more than 85 percent of schools have the meal program in North Central and Uva Provinces, while only 60 percent of schools in the Western Province are covered by the program (see Figure 23). As the WFP-funded 'Food for Education' Program that was implemented in the Northern Province closed in 2017, the government school meal program was expanded to the Northern Province. With this expansion, public expenditure for the school 
meal program increased by around SL Rs 1 billion in 2018. However, as shown in Figure 24, budgetary allocation for the school meal program has continued to expand over the last five years. On the other hand, underutilization of budget has become evident since 2016.

Figure 23: Coverage of schools under school meal program

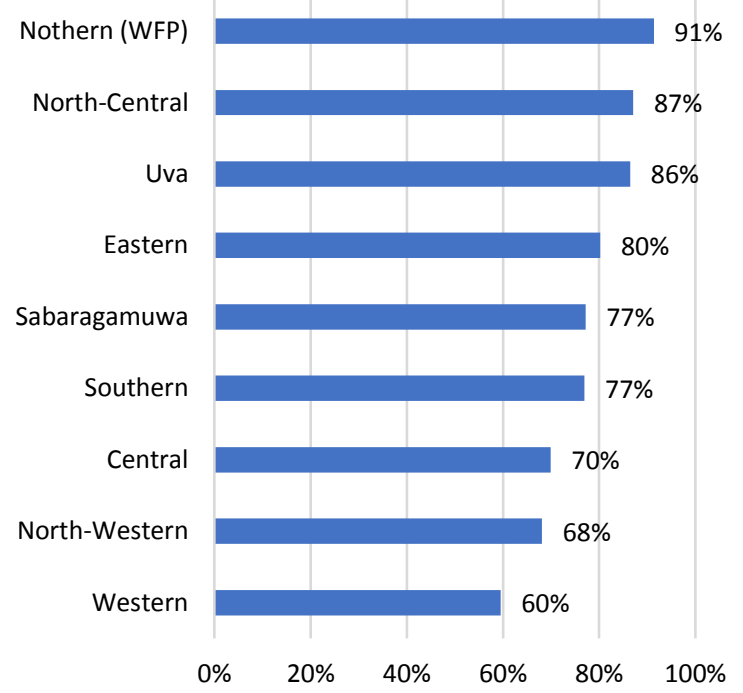

Figure 24: Allocation versus expenditure on school nutritional program

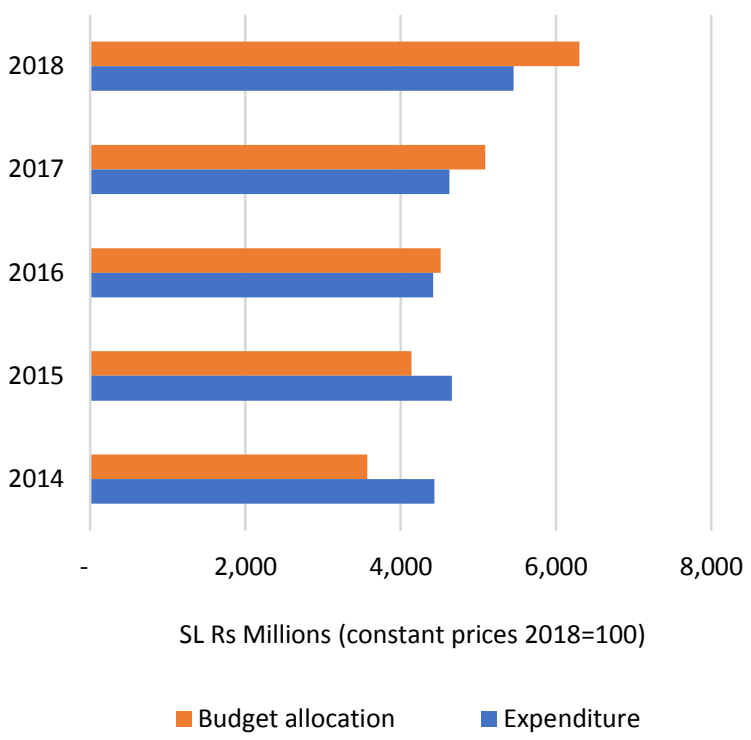

Note: HR cost was not incorporated in Figure 24.

Both of the preschool nutrition programs aim to improve the nutritional status of preschool-age children in vulnerable areas. Since 2017, preschool children are provided morning meal, which replaced the previously provided glass of fresh milk. In 2018, around SL Rs 260 million was spent for this program with 72,450 preschool children from 2,500 preschools in 217 divisional secretary divisions benefiting from this program. The MHC has been providing 'Tikiri Shakthi', a highprotein nutrient bar, since 2017, with the aim of improving nutrition of children in child development centers of the plantation sector where malnutrition is highly prevalent. This nutrient bar is given thrice per week under the supervision of Child Development Officers in the plantations. The GOSL invested around SL Rs 43 million for this program in 2018, whereas around 42,000 children benefitted from the program in 2017.

\subsection{Public expenditure for nutrition-sensitive interventions}

\subsubsection{Overview}

The amount of government investments in nutrition-sensitive interventions is almost 10 times as high as that for nutrition-specific interventions. Annually, the GOSL finances around SL Rs 125170 billion for nutrition-sensitive interventions, which accounts for around 5-6 percent of the GGE (Figure 25). As discussed earlier in this report, public expenditure on nutrition significantly 
increased in 2015 largely due to the introduction of new programs and reforms of existing programs. Particularly, public expenditure on nutrition-sensitive interventions has increased by 65 percent, mostly due to the expansion of various welfare benefits such as the Samurdhi allowances for the poor families, food allowance for pregnant mothers, and new programs such as the FPNP.

Figure 25: Public expenditure on nutrition-sensitive interventions

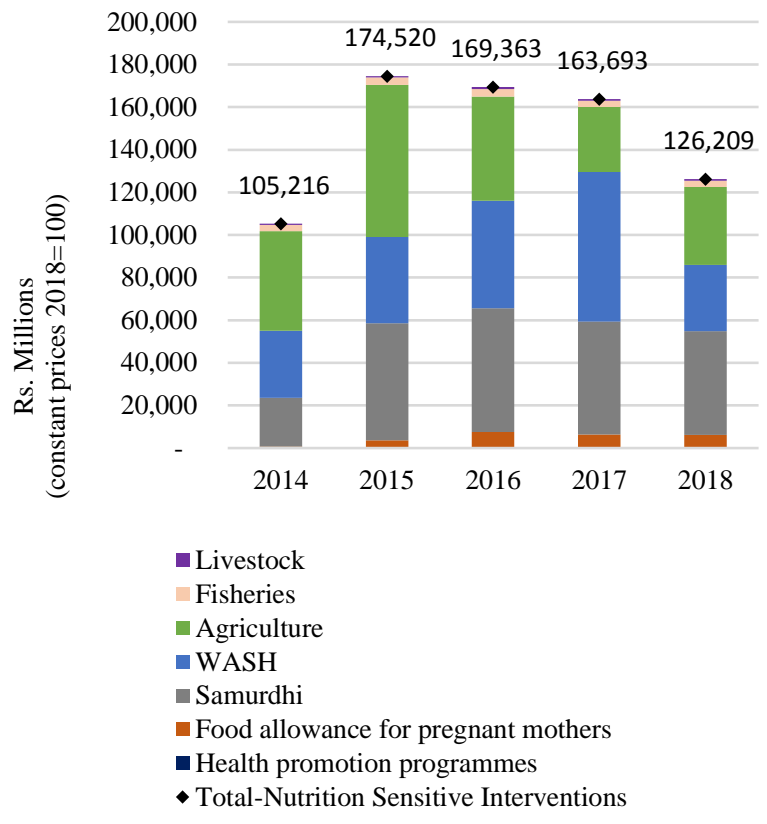

Figure 26: Per capita public expenditure on nutrition-sensitive interventions

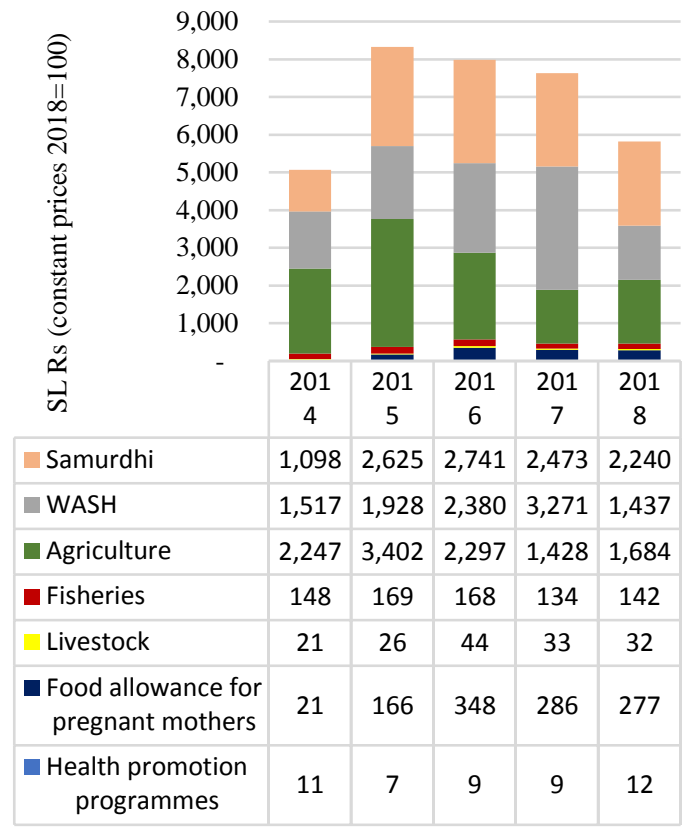

About 92 percent of the investment in nutrition-sensitive programs was allocated to three sectors: Samurdhi welfare program, WASH, and the agriculture sector. The GOSL is committed to ensuring that social welfare, such as Samurdhi and fertilizer subsidy, continues to reach the marginalized segment of the population. In 2018, the Samurdhi program absorbed the highest proportion of expenditure on nutrition-sensitive programs ( 39 percent), followed by the agriculture sector food security programs (28.9 percent) and WASH (24.7 percent), leaving only a share of 7.8 percent for other nutrition-sensitive programs such as food allowance for pregnant mothers, health promotion programs, and fisheries and livestock food security programs. The GOSL annually spends around SL Rs 2,500 per capita for the Samurdhi welfare program, followed by agriculture sector nutrition interventions (SL Rs 1,700 per capita) and WASH programs (SL Rs 1,400 per capita expenditure) (Figure 26).

\subsubsection{Public expenditure for food security cash assistance programs}

The government has spent around SL Rs 55 billion annually for cash assistance programs since 2015, of which the Samurdhi program accounted for 89 percent of the total expenditure for cash assistance programs (see Figure 27). 
Figure 27: Public expenditure on cash assistance programs

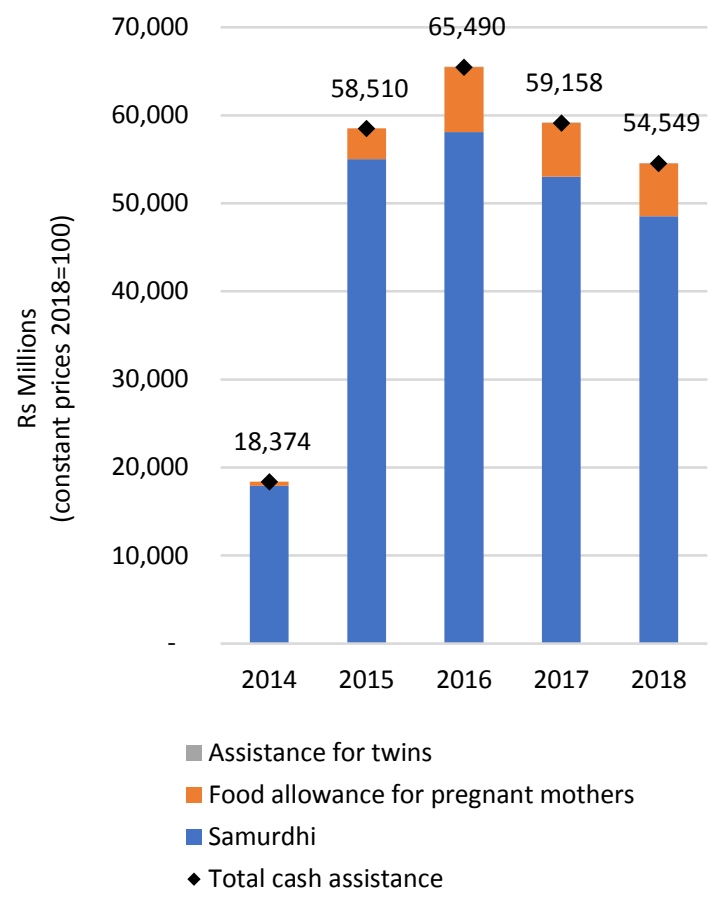

Figure 28: Food allowance for pregnant mothers (allocation versus expenditure)

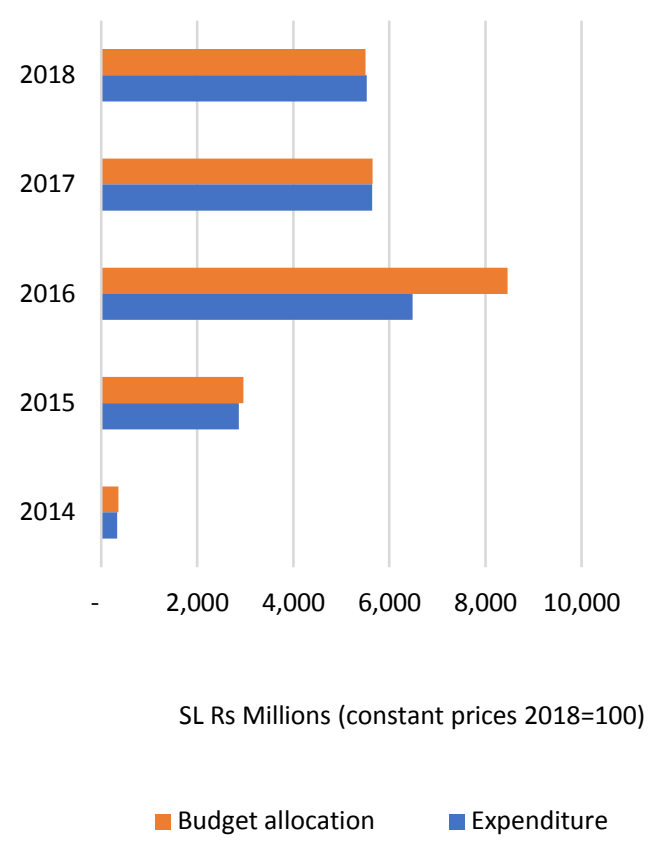

Note: HR cost was not included in Figure 28.

Among the safety net programs, the Samurdhi transfer program provides the largest amount of social welfare with a total of 1.4 million beneficiary families in 2018 . The total amount invested in the Samurdhi program was around SL Rs 39 billion (without including the HR expenditure), which accounted for 1.5 percent of the TPE. In 2015, the amount of the Samurdhi program increased significantly from SL Rs 15 billion in 2014 to SL Rs 37 billion (without HR expenditure). This is likely due to reforms of the Samurdhi program in 2015, whereas the Samurdhi monthly allowance was doubled to a maximum of SL Rs 3,500 per beneficiary (see Box 4 for comparisons between pre- and post-2015 benefits). The level of Samurdhi continued to be high in subsequent years although the amount was reduced to SL Rs 48.5 billion in 2018, including HR cost.

Expansion of food assistance for pregnant mothers from a targeted to a universal program can be very expensive. There were around 330,000-370,000 beneficiaries per year during 2016-2018. The total expenditure on food allowance for pregnant mothers was SL Rs 6 billion in 2018, which was an increase of SL Rs 5.6 billion from SL Rs 0.4 billion in 2014 (1,250 percent). It is worth noting that expenditure on this program is roughly equal to the total expenditure on nutritionspecific interventions implemented by the $\mathrm{MoH}$. On the budget execution, no major underspending or overspending has been observed in recent years (except for 2016), which may not be surprising as the government allocates budget for the food allowance based on the estimated number of pregnant mothers in the year (Figure 28). 
Box 4: Welfare improving measures implemented in 2015

Samurdhi monthly allowance, per beneficiary (SL Rs)

\begin{tabular}{|l|c|c|}
\hline \multicolumn{1}{|c|}{ Beneficiary categories } & $\mathbf{2 0 1 2 - 2 0 1 4}$ & $\mathbf{2 0 1 5}$ \\
\hline Less than 3 members & $\mathbf{7 5 0}$ & 1,500 \\
\hline 3 members & 1,200 & 2,500 \\
\hline 4 or more members & 1,500 & 3,500 \\
\hline Empowered families & 210 & 420 \\
\hline
\end{tabular}

Pregnant mother's food assistance program

\begin{tabular}{|l|l|l|}
\hline Food allowance & \multicolumn{1}{|c|}{ 2009-2014 Rs 500 for 20 months } & \multicolumn{1}{c|}{2015} \\
\hline Target group & $\begin{array}{l}\text { Pregnant mothers who are living in Samurdhi } \\
\text { beneficiary family registered at the MOH }\end{array}$ & $\begin{array}{l}\text { All pregnant mothers who are } \\
\text { registered at the MOH }\end{array}$ \\
\hline
\end{tabular}

\subsubsection{Public expenditure for nutrition-sensitive interventions in the agriculture sector}

Fertilizer subsidy dominates the expenditure on nutrition - in the agriculture sector, accounting for 89 percent of the sector's expenditure on nutrition (Figure 29). The GOSL spent SL Rs 32.3 billion on fertilizer subsidy in 2018 to enhance paddy production. Other long-standing nutrition-sensitive interventions in the agriculture sector, such as minor irrigation programs, accounted for an expenditure of approximately SL Rs 2.5 billion in 2018, while the food crop production and improvement program accounted for around SL Rs 200 million.

Figure 29: Public expenditure on agriculture sector nutrition-sensitive interventions

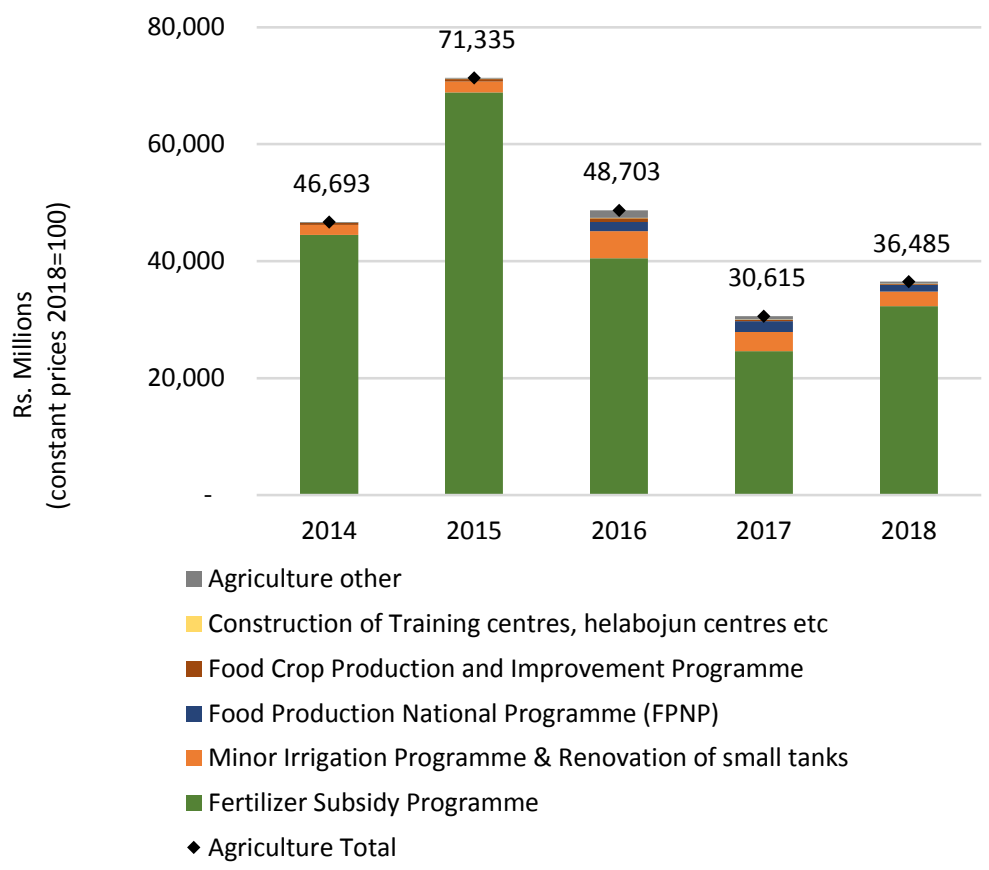


Further, there are some more recent programs that increase domestic agricultural production to ensure food and nutrition security. The FPNP, introduced in 2015, aims to transform Sri Lanka to be 'self-sustained' in food supply and promote healthy diet. The home gardening promotion aims to improve food availability while fulfilling food and nutrition requirements at the household level. The GOSL has spent around SL Rs 1 billion to implement the FPNP, while home gardening accounted for around SL Rs 200 million in recent years.

\subsubsection{Public expenditure for fisheries sector nutrition-sensitive interventions}

Figure 30: Public expenditure on fisheries sector nutrition-sensitive interventions

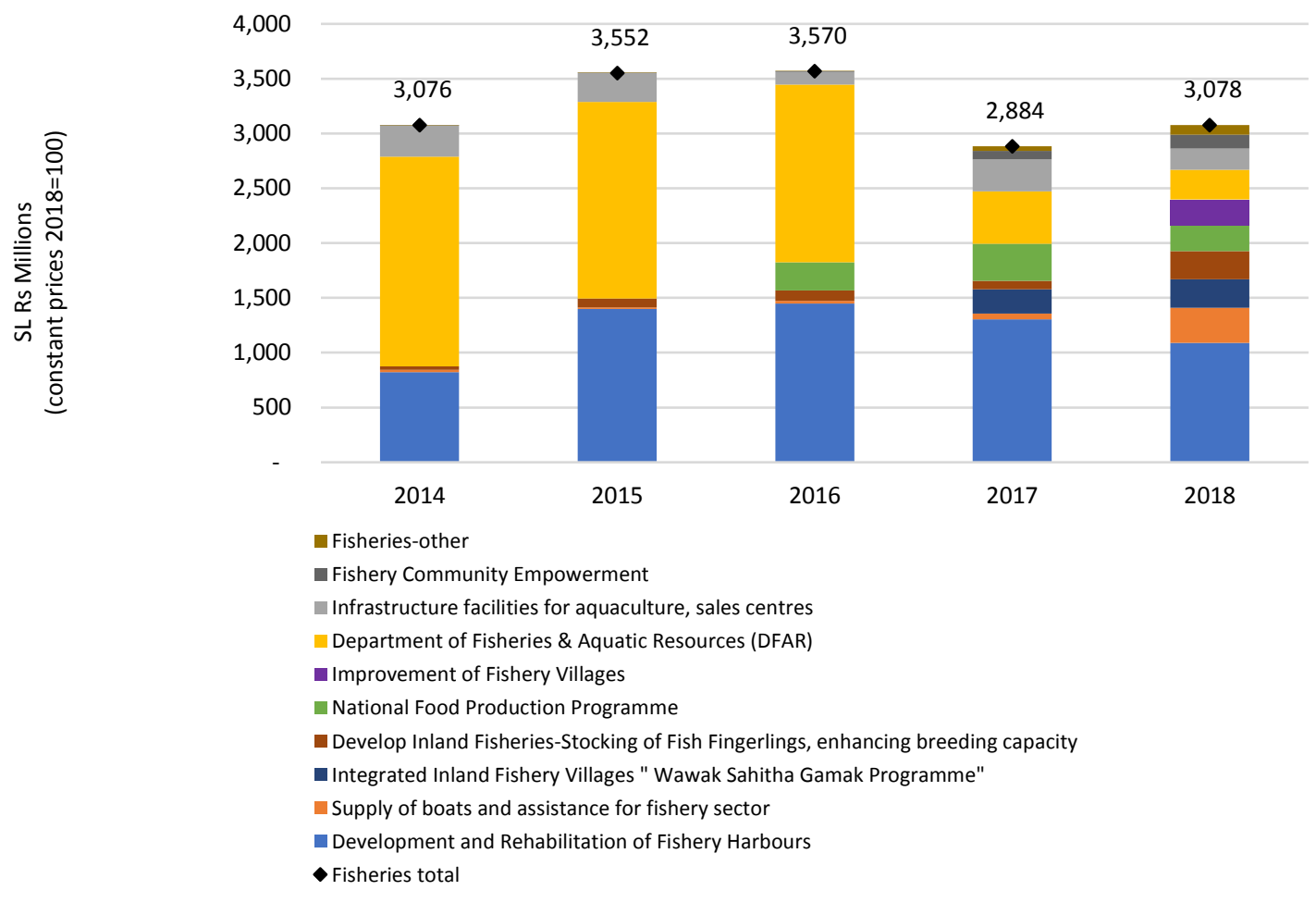

Every year, the GOSL finances around SL Rs 3.0-3.5 billion on nutrition-sensitive programs in the fisheries sector (Figure 30). Among various investments related to nutrition, nearly a third of the total amount accounted for investment in the development and rehabilitation of fishery harbors.

In recent years, many projects and programs have been implemented to enhance fish productions, particularly focusing on developing inland and aquaculture fish productions. In 2016, the FPNP was initiated by the NAQDA to promote fish consumption through increased access to fish diet. In 2018, the GOSL financed around SL Rs 240 million for the fisheries sector FPNP program. The growth of expenditure in inland and aquaculture fish production was mainly driven by the increased stocking of fingerlings in inland water bodies. In 2018, the GOSL financed around SL Rs 250 million to develop inland fisheries stocking of fish fingerlings and to enhance the breeding 
capacity. Further, in 2016, the MFARD initiated and integrated inland fishery villages under the 'Wewak Sahitha Gamak Program' (that is, a village with a tank) for the development of the fisheries sector and socioeconomic enhancement of fishers' community.

\subsubsection{Public expenditure for nutrition-sensitive interventions in the livestock sector}

Government expenditure on the livestock sector increased sharply in 2016 (over SL Rs 900 million), which now stands at around SL Rs 700 million in more recent years (see Figure 31). Among various nutrition programs in this sector, the DAPH livestock sector development program accounts for almost half of the expenditure on nutrition interventions in the livestock sector. The DAPH is the main state organization responsible for livestock development in Sri Lanka. Main functions of the DAPH include research and development pertaining to the sector, provision of technical leadership, expertise and backup services for animal production and healthy livestock, HR development pertaining to livestock development, and project preparation for the development of the livestock industry.

Figure 31: Public expenditure on livestock sector nutrition-sensitive interventions

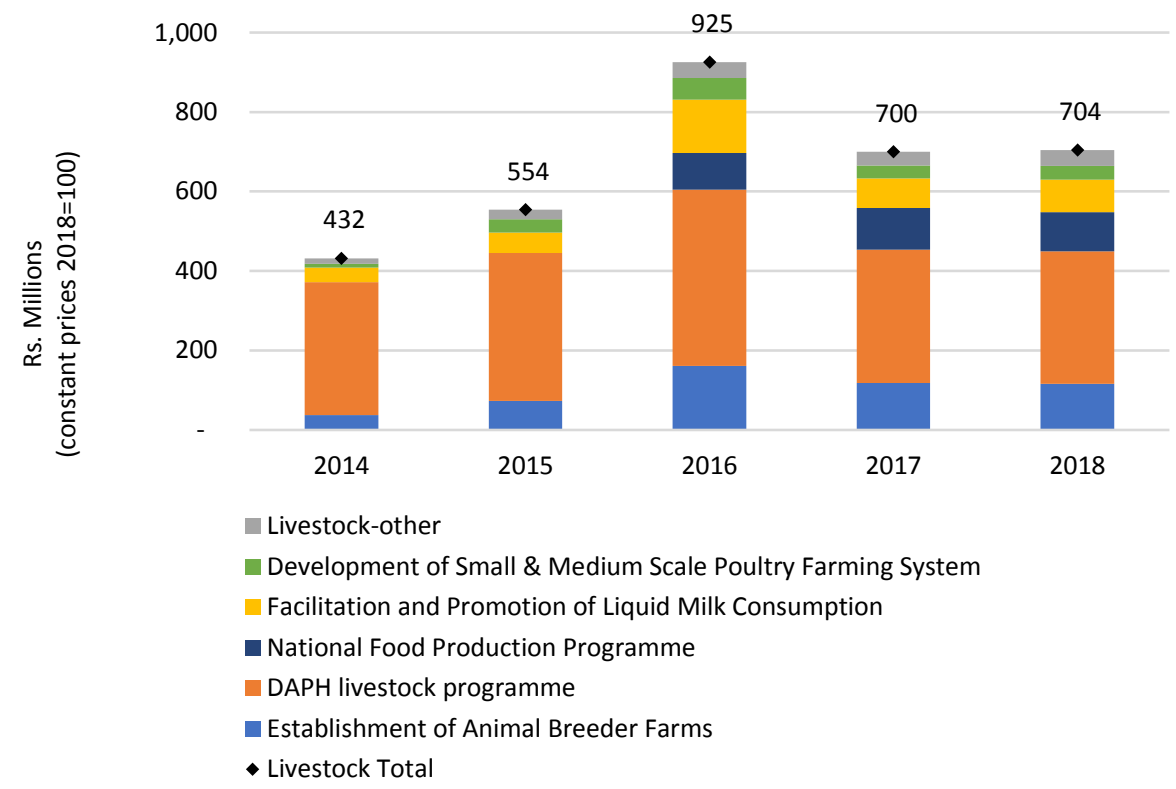

Similar to the agriculture and fisheries sector, the livestock sector is also part of the FPNP with the aim of enhancing food security of the country. Under the FPNP, small-scale dairies and goat and poultry farmers were empowered to enhance the production of milk and meat to improve the nutrition of the population. During 2016-2018, the GOSL spent around 100 million on the livestock sector as part of the FPNP. 
More resources have been spent on the facilitation and promotion of the liquid milk consumption program, especially targeting the school children. Several other programs have been in place to enhance the milk production including improvement of hygiene conditions for milk produce in dairy farms, development of small-scale dairy farms, and provision of cows to female-headed households. The government has also enhanced financing to support establish breeder farms. Breeder farms were established island wide at the provincial level with the aim of minimizing the shortage of dairy cows. Further, several programs are under way to enhance the poultry industry including distributing chicks, establishing mini feed mills, and enhancing household backyard poultry programs.

\subsubsection{Public expenditure for water and sanitation programs}

Figure 32: Public expenditure on WASH interventions

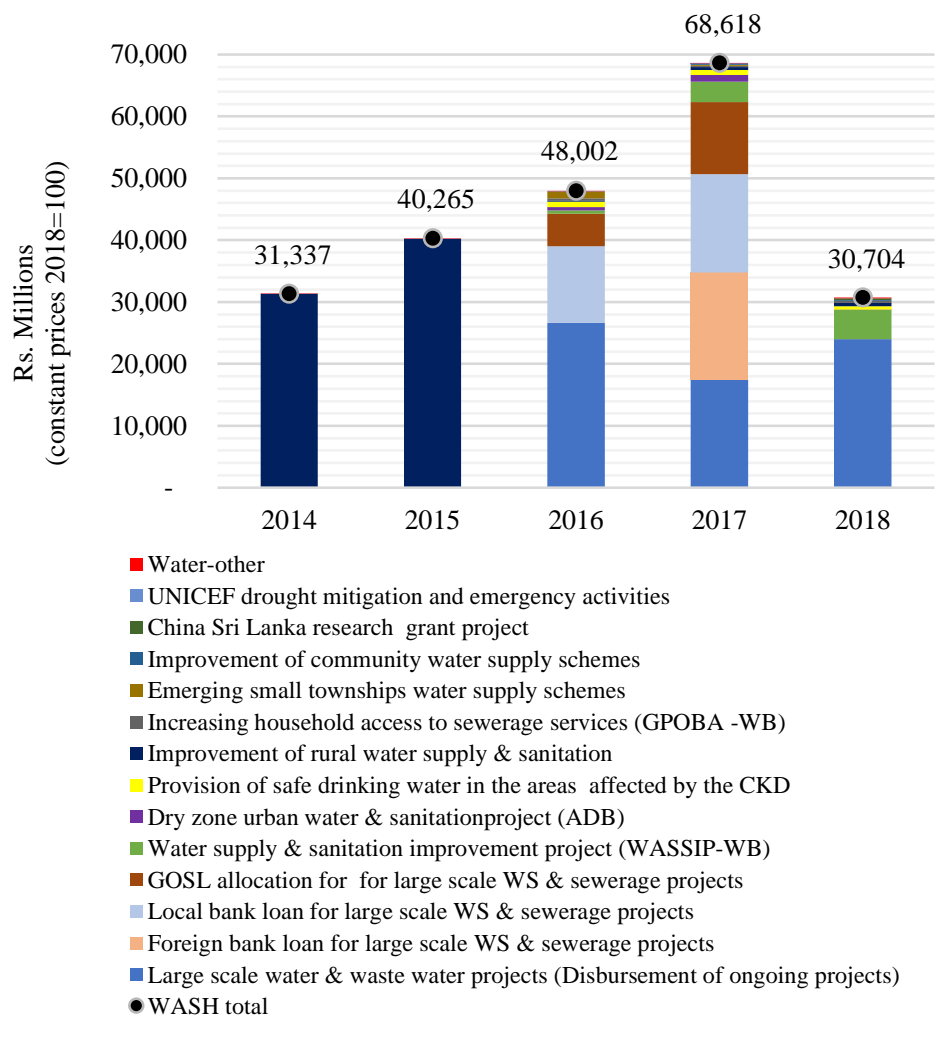

The government has financed around SL Rs 30-50 billion for WASH programs annually (Figure 32). During 2015-2018, about 18 large-scale water supply and sewerage projects were completed and seven new water supply projects and one sanitation project initiated. In 2017, investment in WASH programs was around SL Rs 68 billion, whereas 11 new water projects were initiated and six large-scale water supply projects completed. Further, in 2017 the government invested around 43 billion for large-scale water supply and sewerage projects with GOSL investments as well as 
foreign and local bank loans. Further, it is noteworthy that the GOSL has spent around 23 billion annually for the loan disbursement of ongoing projects.

Some of the key recent WASH programs include the WASSIP with support from the World Bank (4.8 billion in 2018, 426,000 beneficiaries in seven districts); the Dry Zone Urban Water and Sanitation Project with support from the ADB (to improve the urban water and sanitation services in the towns of North and North-Western regions); and the Global Partnership on Output-based Aid (GPOBA) Project supported by the World Bank (to expand residential sewerage connections in the greater Colombo area and to improve sanitation facilities). Some special programs have been in place with the aim of preventing $\mathrm{CKDu}$, such as providing safe drinking water to highly $\mathrm{CKDu}-$ prevalent districts, new water connections and pipe line extensions, and installation of reverse osmosis (RO) plants in villages and schools. Further, the China-Sri Lanka Research Grant is operated for development of technologies for rainwater harvesting testing of quality of water and to identify factors causing $\mathrm{CKDu}$.

\subsection{Provincial distribution of public expenditure for nutrition}

\subsubsection{Trends in public expenditure on nutrition by province}

The provincial expenditure on nutrition includes both centrally procured items that were distributed to and utilized in provinces and actual expenditure in the provinces. The Western Province spent the largest amount of nutrition resources among the nine provinces, which is not surprising given that the province hosts the largest population (Figure 33). On the contrary, the Western Province spent the least in terms of per capita expenditure on nutrition. It is noteworthy that the Northern and Eastern Provinces, both recovering from the aftermath of decades of civil war, marked the highest per capita expenditure on nutrition. This could be partially explained by the government's public policy that seeks to promote balanced regional growth by investing more funds in the provinces that need more resources. 
Figure 33: TPE on nutrition by province, 2014-2018

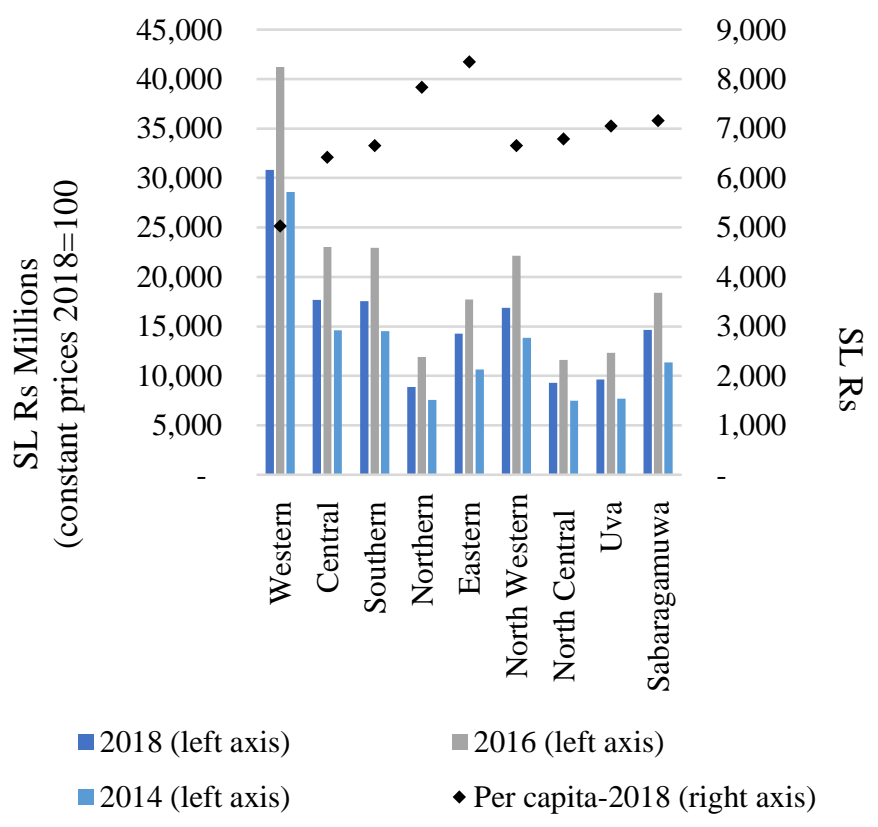

Box 5: Allocation of funds to the provinces

In 1987, the Finance Commission (FC) was established under the 13th Amendment to the Constitution of the GOSL with the objective of achieving balanced regional development in the country and facilitating the process of transfer of funds to the provinces for provincial development.

\section{Assessment of provincial needs}

The current practice seeks to address not only the service needs of individual provinces but also the imperatives of balanced provision as well as costs of provision across provinces. The procedure for assessment of provincial needs is based on the requests from provinces for the forthcoming financial year. The FC issues a set of guidelines for this purpose annually.

\section{Allocation of funds}

The grants are allocated to the provinces based on the recommendations from the FC. The FC analyzes the annual provincial needs submitted by each province considering the GOSL policies and provincial medium-term development plans. The FC calculates the amount of provincial allocations based on a formula developed in collaboration with the Department of Census and Statistics. In the allocation formula for capital, the following socioeconomic indicators are included:

- Population of each province

- Provincial per capita income

- Provincial GDP

- Persons per medical officer

- Candidates qualified for universities in science stream (province-wise percentage)

Source: FC Annual Report, 2017. 


\subsubsection{Public expenditure for targeted nutrition programs against nutritional status}

As discussed earlier in this report, there are very few targeted nutrition interventions implemented in Sri Lanka. The DNAP is implemented by the ND of the MoH, with the aim of improving the nutritional status of the vulnerable population. As shown in Figure 34, the DNAP targets the regions with higher prevalence of undernourished children. For instance, the Uva, Northern, and Eastern Provinces receive more funding to reduce undernutrition in these regions. However, the North-Western and North-Central Provinces where prevalence of malnutrition is relatively high do not receive much funding under this DNAP program. Further, the preschool meal program implemented by the MWCA has more coverage in the Northern, North-Central, and Eastern Provinces where the rates of stunting are also high (Figure 35). Although prevalence of stunting is highest in the Central Province, the proportion of beneficiaries of preschool program is relatively less.

Figure 34: Per capita public expenditure for the DNAP program, 2018

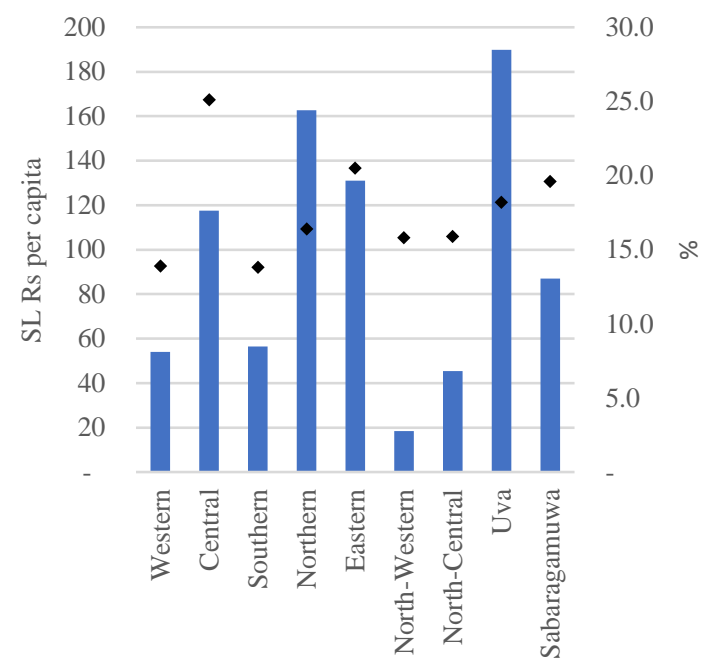

- Per capita financing for DNAP (left axis)

- \% of U5 stunted (right axis)
Figure 35: Percentage of preschool meal beneficiaries

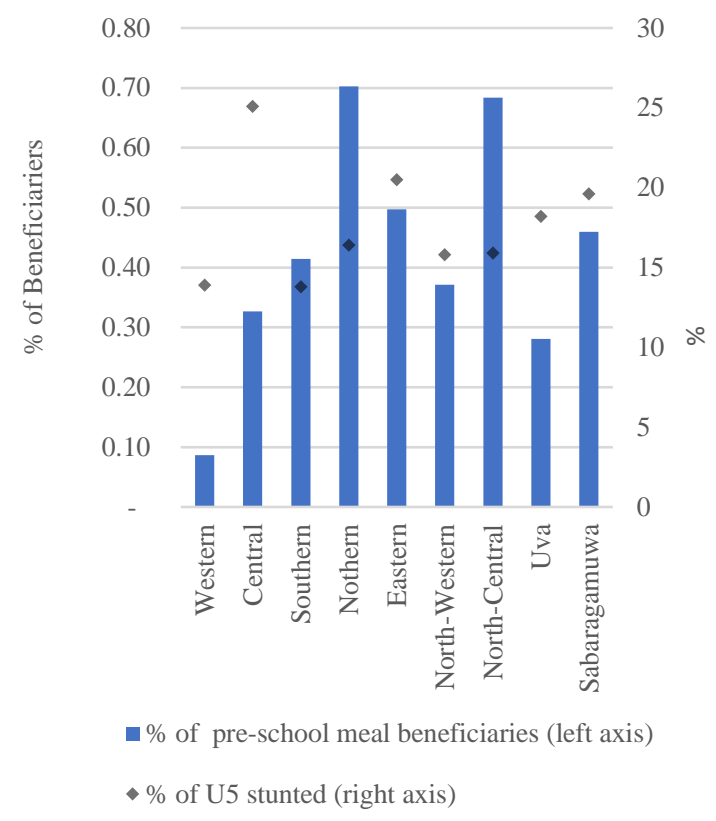

\subsubsection{Public expenditure for targeted versus universal cash assistance programs}

In the regions where poverty $\mathrm{HCI}$ is high, more people benefit from the targeted Samurdhi, the foremost social safety net program in the country (Figure 36). For instance, provinces with a higher poverty HCI have recorded higher coverage of Samurdhi, with around 11 percent of people from the Eastern Province followed by 8.9 percent of people from the Northern Province and 8.1 percent of people from the Sabaragamuwa Province receiving Samurdhi benefits. On the contrary, the Western Province has recorded the lowest coverage of Samurdhi where poverty HCI is also lowest. 
On the other hand, given that food allowance for pregnant mothers is a universal program, all the provinces get similar benefits whereas poor people do not get special benefits under this program.

Figure 36: Percentage of beneficiaries: Pregnant Mother's Food Allowance versus Samurdhi program

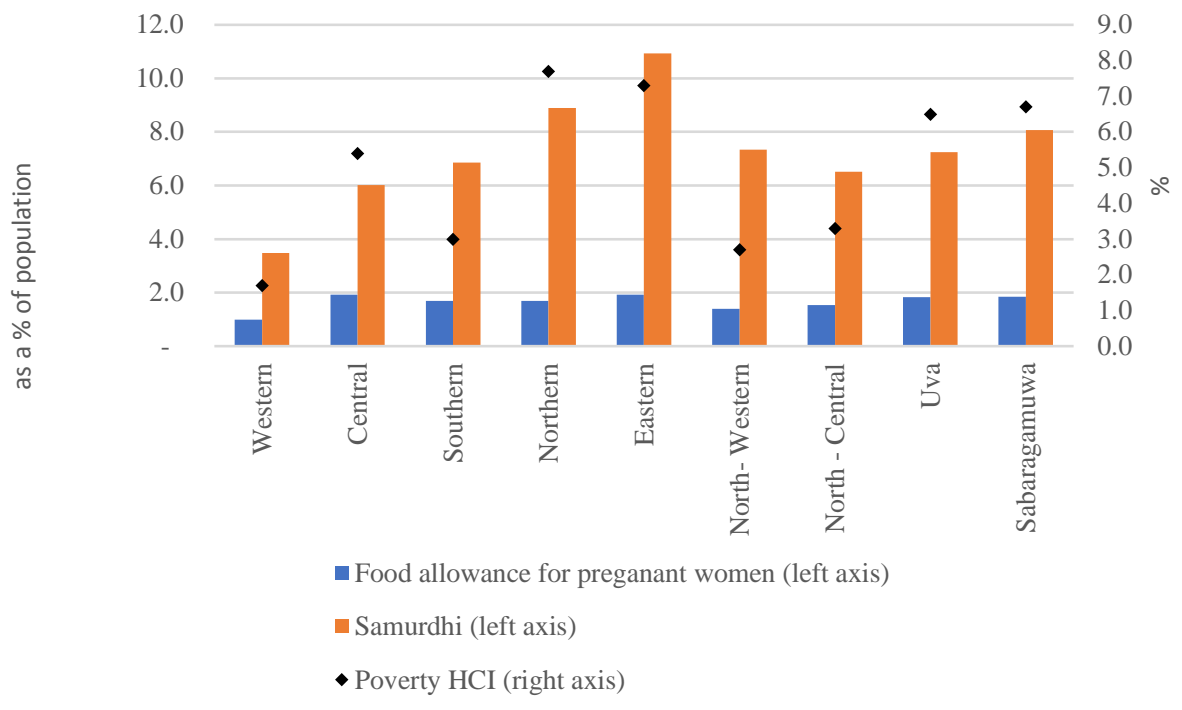




\section{SUMMARY AND THE WAY FORWARD}

\subsection{Key findings and limitations}

\section{The GOSL has invested modestly on nutrition programs and interventions}

Relative to other countries in the region, Sri Lanka has been spending a modest amount of government resources on nutrition. A 5 percent share of TPE on nutrition is higher than some countries such as Bhutan (3 percent, unweighted) but lower compared to countries such as Nepal and Bangladesh (respectively 23 percent and 9 percent, unweighted). Given the small TPE as a share of GDP (that is, less than 20 percent), the total investments in nutrition in Sri Lanka may be remarkably less compared to its peers. The overall expenditure on nutrition has sharply increased in 2015 due to the initiation of new programs (for example, FPNP) and scale-up of existing programs (for example, Samurdhi), which was followed by a gradual decline in subsequent years with a clear drop in 2018. The drop in nutrition expenditure was primarily driven by closure of some nutrition-sensitive programs (for example, water programs). 2018 has seen a sharp increase in expenditure on nutrition-specific programs, particularly due to island-wide scale-up of micronutrient supplementation (that is, folic acid, iron, calcium).

The relatively small share of nutrition-specific programs indicates the potential for further scaling up effective interventions

Sri Lanka's investments in nutrition are dominated by nutrition-sensitive interventions; only 10 percent of the total nutrition investments (or only 0.5 percent of TPE) are spent on nutritionspecific programs. Given that investments in nutrition-sensitive programs were not weighted, the current expenditure level of 5.2 percent of TPE on nutrition should be interpreted with caution. On the other hand, the relatively imbalanced composition of the current nutrition expenditure suggests a significant potential for further improvements of nutritional status.

Blanket provision of some nutrition programs appears costly and may not be efficient

For instance, the expansion of targeted food assistance for pregnant mothers to a universal program in 2015 added an extra SL Rs 5.6 billion, an increase by 1,250 percent. The amount of expenditure on this program is now almost equal to the total expenditure on nutrition-specific programs under the $\mathrm{MoH}$, which encompass all maternal and child nutrition interventions. This should be targeted in the poor areas.

Less than 2 percent of nutrition-specific investments is spent on targeted nutrition awarenessraising programs

Effective communication on maternal nutrition and IYCF and healthy diet is a critical element of a nutrition program. However, only 2 percent of the total nutrition-specific investment has been 
used for educational and promotive behavior change communication. This may be partly due to the nature of intervention where a large portion of resources comprise health personnel (for example, public health midwife). The assumption employed in allocating HR expenditure (that is, proportional allocation based on the amount of all other expenditures of a program) may have resulted in a smaller allocation of staff costs.

\subsection{Key messages}

From the previous section, it is evident that resources used for nutrition programs have not been distributed in a most efficient way, suggesting potential room for efficiency gains by optimizing resource allocation. Given this situation, the following provides some key messages that can be derived from this exercise.

The current nutrition programs need to be reviewed, in terms of both design and beneficiaries

The analysis shows that Sri Lanka has been providing a reasonably comprehensive set of programs for nutrition. However, a significant share of resources has been used by a small number of programs that may or may not be the most effective interventions in reducing malnutrition. A rigorous prioritization exercise would be warranted by investigating the effectiveness, costeffectiveness, and good practices of nutrition interventions. In relation to this, careful considerations need to be taken in determining the beneficiaries (that is, targeted versus blanket).

The current allocation of resources for nutrition-specific interventions deserves revisiting

The evidence of nutrition-specific interventions is generally more robust and they address the immediate determinants of malnutrition. While nutrition-sensitive programs have critical roles in addressing the underlying determinants of nutrition, the decision on investments may well be driven by other agendas. Conversely, investments in nutrition-specific programs can be directly guided by the nutrition agenda and hence would be more responsive to the real needs. Coverage of nutrition-specific programs is generally high (for example, 91 percent vitamin A supplementation at 3 years, ANC coverage over 90 percent). However, some programs have lesser coverage or coverage itself is not well understood. For instance, the current nutrition information system lacks data on SAM/MAM service coverage, management, and treatment outcomes. To address the information gaps, the minimum indicators on acute malnutrition need to be integrated into the appropriate database system. Given the high prevalence of wasting, services addressing prevention of SAM/MAM at the community level need to be scaled up.

\section{Mainstreaming nutrition in other sectors}

Despite the importance of nutrition-specific programs, the effects of those programs could be undermined if the underlying causes are not properly addressed. The difficulty in mobilizing resources for nutrition-sensitive programs rests with the fact that decisions are also guided by other 
agendas of the sectors. It is therefore important to mainstream nutrition in other sectors to have more voice in decision making. In strengthening the multisectoral engagement and coordination in nutrition, the MSAPN was developed in line with the NNP alongside other policies related to nutrition that need to be aligned with each other. In reviewing different policies and strategies, the need to tightening links between different strategies was noted. The multisectoral platform for scaling up nutrition should be aligned to support the concept that 'nutrition is in every sector and every sector is in nutrition' (SUN) and underline the extent of political commitment. In this regard, the NNP that is being revised is expected to place more emphasis on multisectoral coordination and partnerships, and all relevant health and non-health policies are expected to be coherent with NNP.

\section{Targeting of programs}

Generally, targeted programs are more cost-effective than blanket coverage as long as the targets are well selected. The selection of targets requires a prioritization exercise as described earlier, which, however, needs to accommodate considerations on negative side effects such as inequity. Nevertheless, weighted resource allocation has already been practiced by the government, though on a limited scale. There is a potential to gain some fiscal space by changing the supplementary feeding program, for pregnant and lactating women (Thriposha), to target at-risk pregnant women rather than all women. Recently, the $\mathrm{MoH}$ reviewed the design of this supplementary feeding program for pregnant and lactating women, which resulted in a change in targeting strategy from blanket to targeted provision. However, the policy dialogue needs to be continued to finalize and approve the modifications (and plan for areas where freed resources should be invested).

\section{Health promotion}

Albeit with limitations in estimating the expenditure discussed earlier, nutrition awareness-raising programs and educational and promotive activities may deserve more allocation, especially for those that are related to the first 1,000-day window, such as IYCF. Given the weak evidence of the traditional IEC approach in changing behaviors, social and behavior change communication could be scaled up along with interventions to provide a supportive environment and promote positive behaviors to enable the beneficiaries to adapt and maintain desirable behaviors.

\subsection{Challenges faced in tracking financial information}

In conducting the exercise, the team faced a number of difficulties in collecting, consolidating, and analyzing the data. This was somewhat anticipated given the multisectoral nature of nutrition, and it would be useful for planning if this exercise could be conducted routinely in more systematic modalities. The following provides some of the key challenges that are worth noting and some recommendations for potential improvement. 


\subsubsection{Key challenges}

\section{Multisectoral nature of nutrition was the biggest challenge for the exercise}

The major challenge was to collect information from all relevant sectors and consolidating on a single platform. This exercise was initiated with a workshop with representations from provinces and multiple line ministries. Following on the instructions given at the workshop, each institution was requested to extract and provide financial data for both nutrition-specific and nutritionsensitive programs. Most of the institutions provided the preliminary data sets, which were then followed up by meetings with relevant officials for clarification. However, in some cases, miscommunications complicated the data collection process, particularly in the non-health sectors. This was partly due to lack of consensus as to what constitutes a nutrition-specific or nutritionsensitive program. Communicating a clear definition for all sectors was problematic.

\section{Very limited data were available under budget line items for nutrition}

The budget document of the MoF was the starting point in identifying relevant data and other sources for this exercise. Sri Lanka uses an input-based budget line and it was not immediately feasible to isolate nutrition programs from those records, except for a few programs such as the school meal and Thriposha programs. Therefore, data collection had to be conducted manually with a combination of desk review and visits to each government institution. There was no consolidated database, and paper-based recording was still widely practiced, especially for older data. It was difficult to find comprehensive data sets over 10 years. Most of the institutions had started using computer-based databases or spreadsheets recently, but older data sets were kept on paper.

\section{Data gaps and inconsistent budget formats and record keeping}

In some cases, centrally procured items distributed to the regional level did not keep records on how those items were allocated to each province. Therefore, the amount of provincial allocation had to resort to assumptions. Some sectors, such as livestock and hill country, were affected by frequent organizational restructuring of ministries, both at the provincial and central levels. For those sectors, time series data were not available in a single ministry or department and had to be collected and consolidated from several departments/ministries to complete the data set. Further, unclear definitions and scope of programs made it difficult to identify what items were included in an expenditure item and what not, which was even more complicated with the different budget formats used by different provinces that made aggregation and comparison problematic. A similar issue was experienced in collecting off-budget information from DPs. Only a few organizations provided the expenditure data with varying formats. While the contributions of DPs in Sri Lanka are small, and on-budget data and some off-budget information were captured from the 
government side, the results are potentially slightly underestimated although the difference should be negligible.

\subsubsection{Recommendations}

\section{Standard coding and tagging}

Budget and expenditure of programs and funding sources can be reasonably traced if institutions at all levels (central, provincial, and below) use a standard coding system with program names. A budget tagging mechanism, whereby the line items are tagged for nutrition, would further improve resource tracking as has been practiced in Indonesia. This will also prevent potential double counting when reporting to the central level.

\section{Database for analysis}

Most of the current databases are not designed to generate instant reports and graphics. The monitoring and evaluation functions of the institutions could significantly improve if databases are upgraded to allow for more flexibility in performing analysis. Using common formats for data entry and following standardized good practices in data collection would ensure consistency and enable comparisons. Merging of data can be performed without difficulties and will reduce the risk of data misinterpretation and duplication and missing data. When processing expenditure data and generating summaries, it is recommended to keep a detailed and secure version for later analysis. It may be stored in an open file format that would not require any paid software to use and process data. 
ANNEX 1: KEY INTERVENTIONS FOR MALNUTRITION THROUGHOUT THE LIFE CYCLE

NUTRITION-SPECIFIC INTERVENTIONS

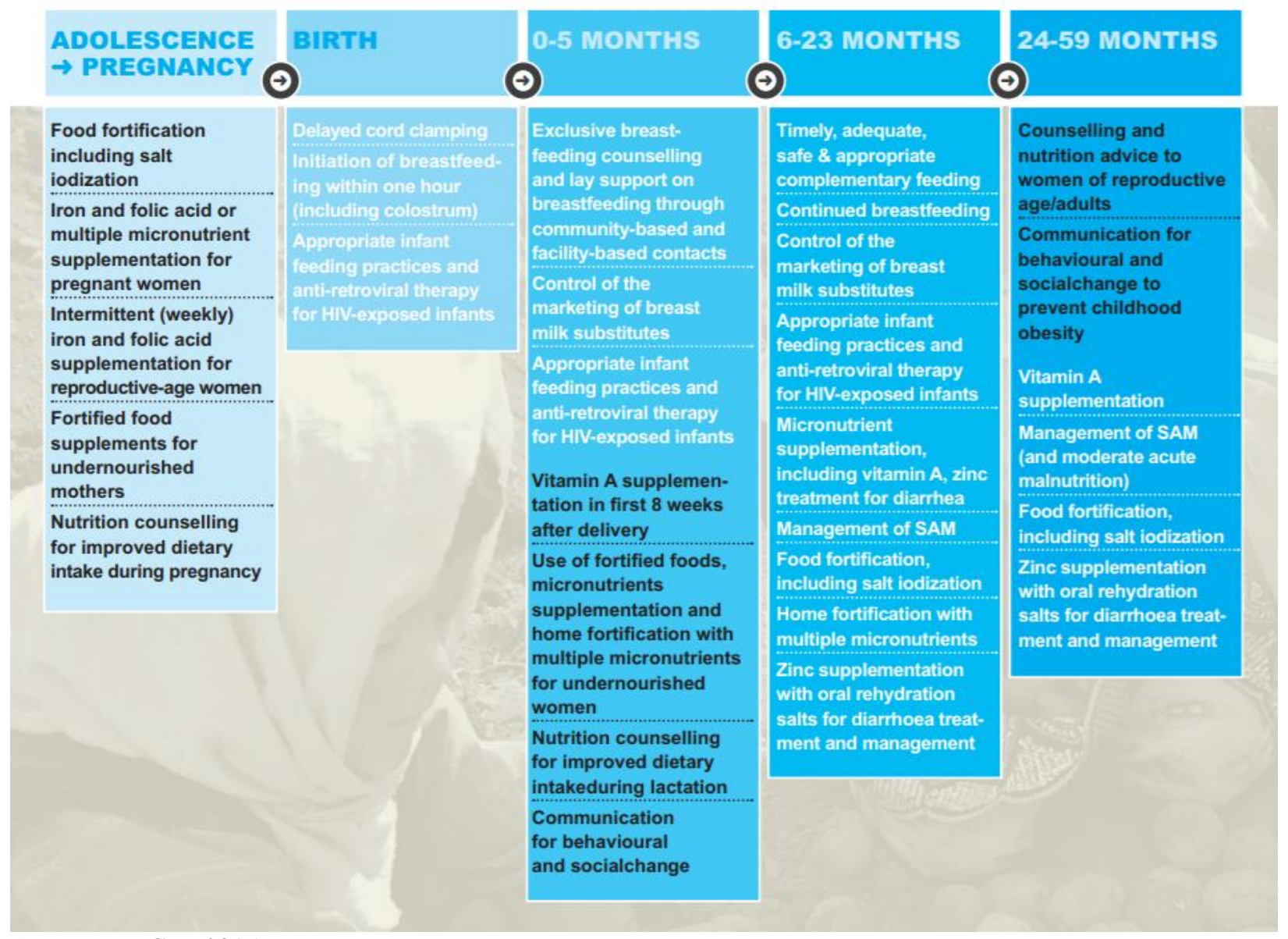

Source: UNICEF 2015. 
NUTRITION-SENSITIVE APPROACHES

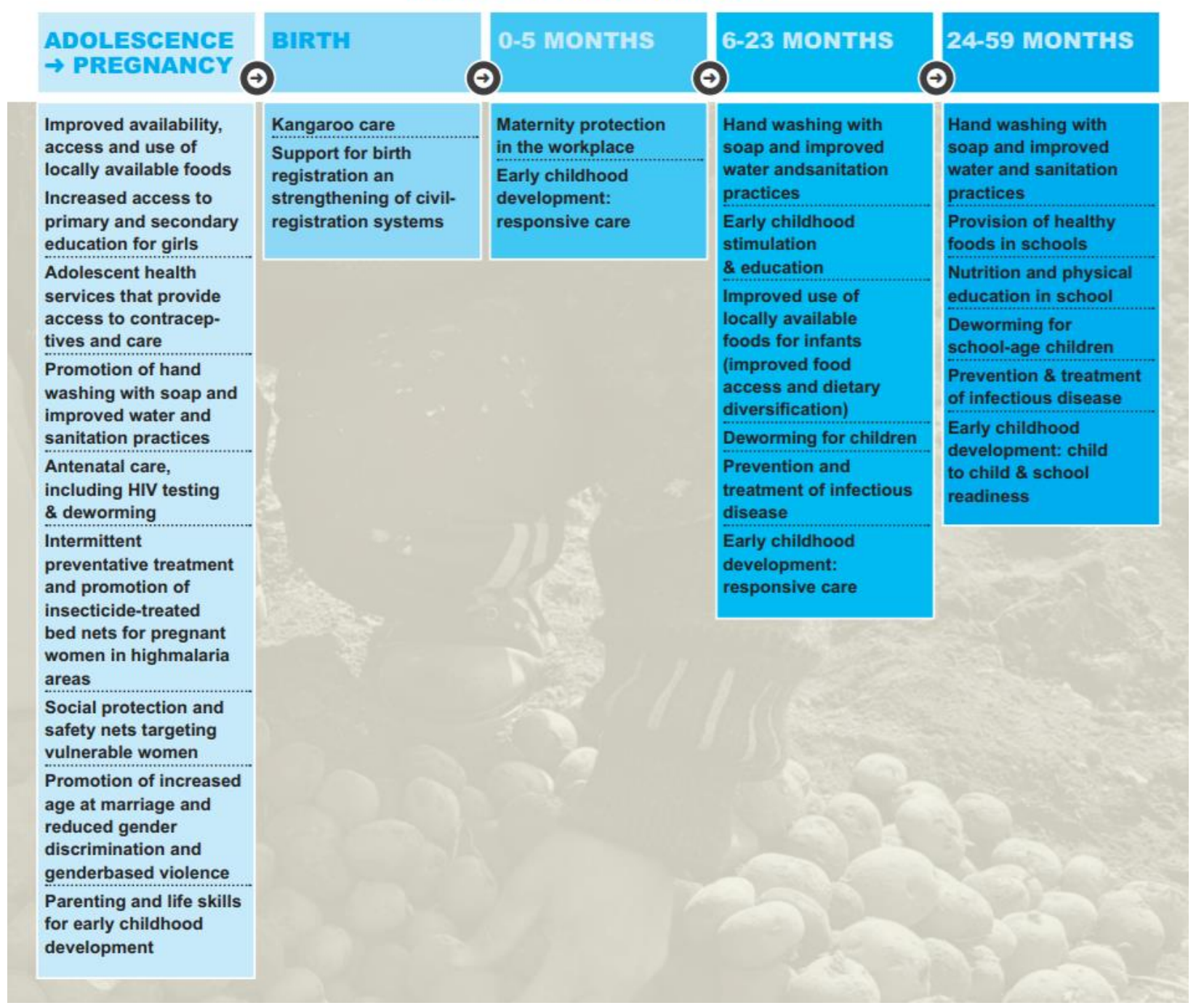

Source: UNICEF 2015. 


\section{ANNEX 2: GLOBAL EVIDENCE BASE FOR NUTRITION INTERVENTIONS}

\section{Nutrition-specific interventions and programs}

According to the Lancet Framework, nutrition-specific interventions target the immediate determinants of undernutrition: inadequate dietary intake and ill health. The 2013 Lancet Series recommended high-impact nutrition-specific interventions to achieve optimum maternal, fetal, and child nutrition and development, which are largely delivered through the health sector. The costs and effects of scaling up these interventions have been estimated across the life cycle addressing undernutrition and micronutrient deficiencies in women of reproductive age, pregnant women, neonates, infants, and children (Figure 37 and Table 5).

Figure 37: Conceptual framework

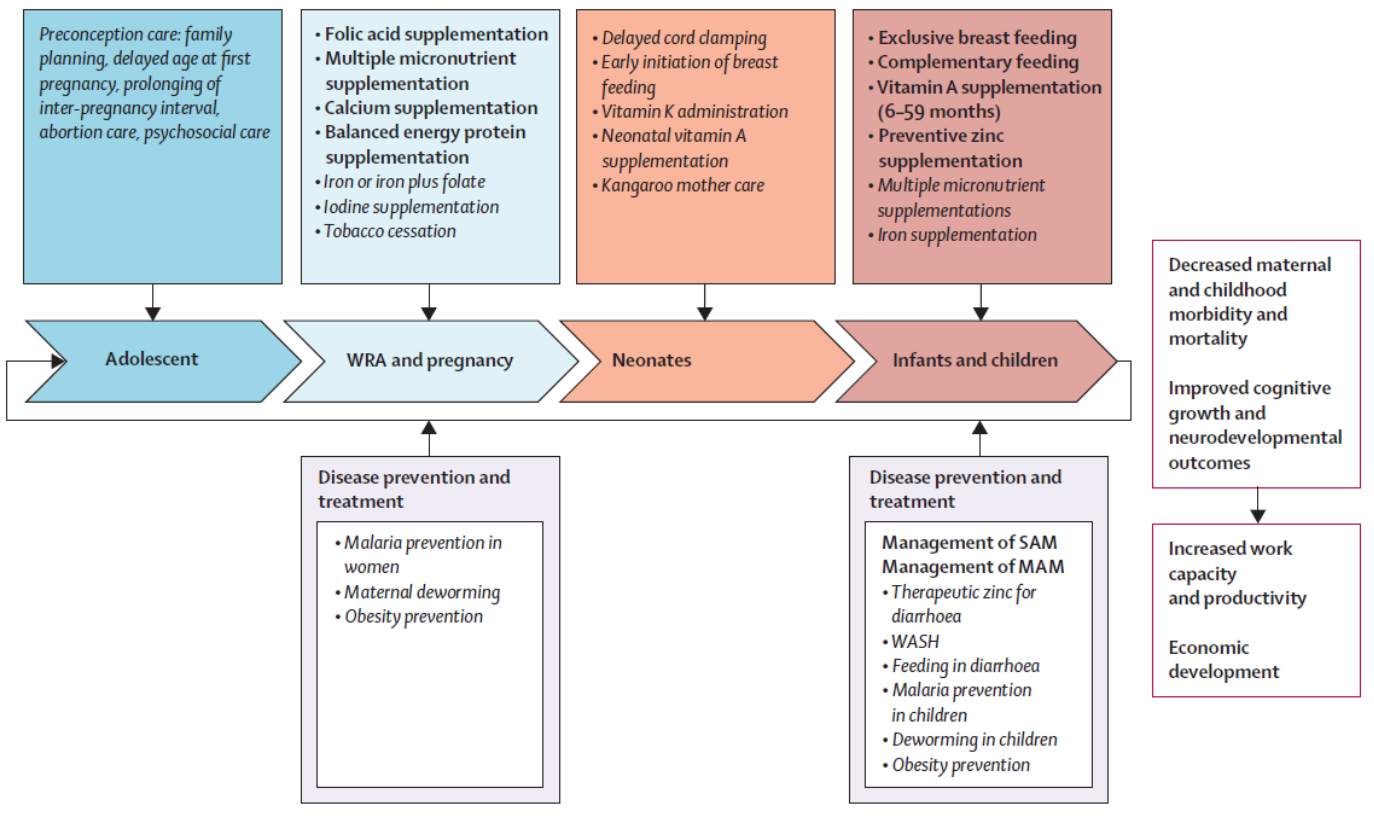

Delivery platforms: Community delivery platforms, integrated management of childhood illnesses, child health days, school-based delivery platforms, financial platforms, fortification strategies, nutrition in emergencies

Bold=Interventions modelled

Italics=0ther interventions reviewed

Source: Butta et al. 2013.

Globally, it is estimated that US\$9.6 billion per year is needed for scaling up the recommended 10 essential nutrition-specific interventions to reach 90 percent coverage in 34 countries (Table 5). If continued investment and sustainable delivery strategies are ensured, then the prevalence of stunting and severe wasting could be reduced by 20 percent and 60 percent, respectively, and around 33 million children prevented from suffering stunted growth. 
Table 5: Cost for scaling up nutrition-specific interventions per year globally

\begin{tabular}{|l|c|}
\multicolumn{1}{|c|}{ Nutrition-specific intervention } & $\begin{array}{c}\text { Cost for scaling up per year (US\$, } \\
\text { billions) }\end{array}$ \\
\hline Micronutrient interventions & 3.7 \\
\hline Educational interventions & 1.0 \\
\hline Management of SAM & 2.6 \\
\hline $\begin{array}{l}\text { Provision of food for pregnant women and children ages 6-23 months in } \\
\text { poor households }\end{array}$ & 2.3 \\
\hline
\end{tabular}

Source: Butta et al. 2013.

\section{IYCF in the first two years of life}

\section{Breastfeeding practices}

Breastfeeding is one of the fundamental elements that determine the development, survival, and health of children. The IYCF program includes promotion and support for early initiation of breastfeeding (newborns to be breastfed within one hour after birth), exclusive breastfeeding for the first six months, and continued breastfeeding until the age of two and beyond and ageappropriate complementary feeding from six months of age. Apart from preventing undernutrition, breastfeeding and adequate complementary feeding are also effective in preventing overweight and various kinds of diseases. Breastfeeding could prevent 823,000 annual deaths in children younger than five years and 20,000 maternal deaths from breast cancer every year if scaled up to a near-universal level (Victora et al. 2016).

Despite the numerous benefits and improved health-related outcomes, globally only about 41 percent of infants ages less than six months were exclusively breastfed in 2017, and the rate of continued breastfeeding at the age of two was 45 percent. ${ }^{10}$ Given the low rate of adequate breastfeeding, the WHO recommends the following breastfeeding counseling practices (WHO 2019):

- Breastfeeding counseling should be provided to all pregnant women and mothers with young children.

- Breastfeeding counseling should be provided in both the antenatal period and postnatally and up to 24 months or longer.

- Breastfeeding counseling should be provided at least six times and additionally as needed.

- Breastfeeding counseling should be provided through face-to-face counseling. It may, in addition, be provided through telephone or other remote modes of counseling.

\footnotetext{
${ }^{10}$ https://data.unicef.org/topic/nutrition/infant-and-young-child-feeding/.
} 
- Breastfeeding counseling should be provided as a continuum of care, by appropriately trained health care professionals and community-based lay and peer breastfeeding counselors.

- Breastfeeding counseling should anticipate and address important challenges and contexts for breastfeeding, in addition to establishing skills, competencies, and confidence among mothers.

- Protection, promotion, and support of breastfeeding, in accordance with international guidance, are essential in emergencies. Breastfeeding counseling should be an integral part of emergency.

\section{Complementary feeding practices}

Complementary feeding refers to the timely introduction of safe and nutrient-rich foods, in addition to breast milk, that are typically provided between 6 and 23 months of age. Breastfed children at 12-23 months of age receive on average 35-40 percent of total energy needs from breast milk and the remaining 60-65 percent from complementary foods (Dewey and Brown 2003). Box 6 provides the WHO recommended guiding principles for complementary feeding of the breastfed child (PAHO 2003) and for feeding non-breastfed children from 6 to 24 months of age (WHO 2005).

Box 6: WHO guiding principles for child feeding

Guiding principles for complementary feeding of the breastfed child:

1. Practice exclusive breastfeeding from birth to six months of age and introduce complementary foods at six months of age (180 days) while continuing to breastfeed.

2. Continue frequent, on-demand breastfeeding until two years of age or beyond.

3. Practice responsive feeding, applying the principles of psychosocial care.

4. Practice food hygiene and proper food handling.

5. Start at six months of age with small amounts of food and increase the quantity as the child gets older while maintaining frequent breastfeeding.

6. Gradually increase food consistency and variety as the infant gets older, adapting to the infant's requirements and abilities.

7. Increase the number of times that the child is fed complementary foods as he/she gets older.

8. Feed a variety of foods to ensure that nutrient needs are met.

9. Use fortified complementary foods or vitamin-mineral supplements for the infant, as needed.

10. Increase fluid intake during illness, including more frequent breastfeeding, and encourage the child to eat soft, varied, appetizing, and favorite foods. After illness, give food more often than usual and encourage child to eat more.

Guiding principles for feeding non-breastfed children of 6-24 months of age:

1. Ensure that energy needs are met. 
2. Gradually increase food consistency and variety as the infant gets older, adapting to the infant's requirements and abilities.

3. For the average healthy infant, provide meals four to five times per day, with additional nutritious snacks offered one or two times per day, as desired.

4. Feed a variety of foods to ensure that nutrient needs are met.

5. As needed, use fortified foods or vitamin-mineral supplements (preferably mixed with or fed with food) that contain iron.

6. Non-breastfed infants and young children need at least 400-600 $\mathrm{ml}$ per day of extra fluids in a temperate climate and 800-1,200 $\mathrm{ml}$ per day in hot climate.

7. Practice good hygiene and proper food handling.

8. Practice responsive feeding, applying the principles of psychosocial care.

9. Increase fluid intake during illness and encourage the child to eat soft, varied, appetizing, and favorite foods. After illness, give food more often than usual and encourage child to eat more.

Source: WHO 2019.

Delays in initiating feeding of solid foods to later than the recommended six months may cause deficiencies of zinc, protein, iron, and vitamins B and D that could lead to suppression of growth and feeding problems (Butte, Lopez-Alarcon, and Garza 2002). Iron deficiency, anemia, and rickets are also found to be more prevalent among infants who are fed solid foods later than six months of age (Butte, Lopez-Alarcon, and Garza 2002).

\section{Micronutrient supplementation programs for young children}

Micronutrient deficiency, also known as 'hidden hunger', is a chronic lack of vitamins and minerals, which can lead to mental impairment, poor health and productivity, or even death. Micronutrient deficiencies in children, including deficiencies of vitamin A, iron, and zinc, are major risk factors that contribute to the disease burden in childhood.

Vitamin A is an essential micronutrient that helps in maintaining healthy vision, rapid growth, and development of a child and to combat severe infections such as measles and diarrhea, which are leading causes of mortality in children below the age of five. Studies from LMICs suggest that providing vitamin A supplements to children 6-59 months of age is associated with a reduced risk of mortality, incidence of diarrheal diseases, and other infections (Ching et al. 2000; Imdad et al. 2010).

Iron is an important micronutrient for a child's brain development and for transportation of oxygen to the body tissues. Globally, IDA is a major public health concern. Daily iron supplementation is recommended in infants above 6 months of age, preschool-age children, and school-age children up to 12 years of age living in settings where anemia is highly prevalent (WHO 2016a). Zinc supplementation is given for managing the diarrhea among children under five years of age along with ORS. Diarrhea is one of the direct causes of malnutrition in children under five years. Studies 
show that zinc supplementation could help reduce the duration and severity of diarrhea. Therefore, zinc supplementation is considered as an important intervention in preventing acute malnutrition.

\section{Treatment and management of infants and young children with MAM/SAM}

As per the WHO guidelines, children with MAM/SAM should receive supplementary/therapeutic feeding and care either as inpatients (if there are medical complications) or as outpatients in their communities (if there are no medical complications). Figure 38 shows the differences in definition of MAM and SAM.

Figure 38: MAM versus SAM

\section{Acute malnutrition}

Severe acute malnutrition (SAM)

- Severe wasting (WHZ<-3), MUAC $<115 \mathrm{~mm}$, bilateral oedema

- Children with severe wasting are up to 11 times more likely to die
Moderate acute malnutrition (MAM)

- Moderate wasting $(\mathrm{WHZ} \geq-3 \& \mathrm{WHZ}<-2)$ and a MUAC $\geq 115$ and $<125 \mathrm{~mm}$

- Children with moderate wasting are up to 3 times more likely to die

Source: Bernardette 2019.

Note $:$ MUAC $=$ Mid-upper arm circumference; $\mathrm{WHZ}=$ Weight-for-height $\mathrm{Z}$ score .

Both MAM and SAM have serious consequences, contributing to increased morbidity and mortality, impaired intellectual development, suboptimal adult work capacity, and increased risk of disease in young children. Since the United Nations (UN) agencies issued their first-ever joint statement on community-based management of wasting and other forms of acute malnutrition, the total number of children receiving care has grown from just over 1 million in 2009 to almost 10 million in 2018. This collective success has been primarily driven by the efforts of national health systems which, with the support of UNICEF and other UN agencies, civil society organizations, and academic partners, have adopted solutions to simplify the way wasted children are found, treated, and cared for. Guidelines on management of wasted and severely wasted children are provided by the WHO (2013).

\section{Interventions targeting adolescent nutrition}

Adolescence is a period of rapid physical, social, and development changes (Story, NeumarkSztainer, and French 2002). The accelerated growth rate during puberty increases the need for energy and nutrients to sustain healthy development. At the same time, adolescents are increasingly exposed to influences on their eating behaviors (Banna et al. 2016) and have increasing autonomy over their food choices (Basset, Chapman, and Beagan 2007) and use of 
leisure time. As a result, adolescence is a nutritionally vulnerable time during which both dietary excess and insufficiency can be common. Eating and physical activity behaviors established in adolescence are known to continue into adulthood and may contribute to nutrition-related problems that have consequences for their long-term health (Kelder et al. 1994; Singh et al. 2008).

It is suggested that adolescents avoid foods that are high in fat (saturated and trans fat); foods with added sodium and sugars (including sweetened beverages); and fast foods high in energy, fat, and sodium and low in nutrient density (WHO 2018). Multidimensional programs that integrate traditional health education approaches within broader mental health promotion strategies appear to have promising outcomes in improved adolescent nutrition practices (WHO 2018). Evidence also suggests that regular physical activity is fundamental for energy balance, weight control, prevention of obesity (WHO 2007, 2014c), development of musculoskeletal tissues and enhancement of bone health, the cardiovascular system and neuromuscular awareness, and reduction of symptoms of anxiety and depression (WHO 2014b). Another strategy which is crucial for the health and well-being of women, children, and adolescents is to prevent unintended pregnancies and reduce adolescent childbearing through universal access to sexual and reproductive health care.

\section{Women's nutrition}

A woman who is healthy at the time of conception gives birth to a healthy child. Therefore, the nutritional status of women at the time of conception and during pregnancy plays a vital role in determining the health of the mother and ensuring healthy fetal growth and development. Evidence shows that maternal anemia, particularly during pregnancy, is an important contributor to both maternal mortality (23 percent of total deaths) and morbidity. Maternal iron deficiency is associated with LBW, which is a common predictor of wasting and the concurrence of wasting and stunting in the region (Torlesse and Augayo 2018). Calcium deficiency is also known to increase the risk of pre-eclampsia, currently the second leading cause of maternal mortality (19 percent of total deaths). Therefore, addressing these deficiencies could substantially reduce the risk of maternal deaths. Further, maternal overweight and obesity have also shown to be associated with maternal morbidity, preterm birth, increased infant mortality, and increase in the risk of childhood obesity that continues into adolescence and early adulthood, heightening the transgenerational transmission of obesity. Table 6 provides the list of nutrition interventions recommended by the WHO. 
Table 6: WHO recommended nutrition interventions in ANC

\begin{tabular}{|c|c|c|}
\hline & Intervention & Recommendation \\
\hline \multirow[t]{3}{*}{$\begin{array}{l}\text { Dietary } \\
\text { interventions }\end{array}$} & $\begin{array}{l}\text { Counseling about healthy eating and keeping physically active during } \\
\text { pregnancy }\end{array}$ & Recommended \\
\hline & $\begin{array}{l}\text { In undernourished populations, nutrition education on increasing daily } \\
\text { energy and protein intake }\end{array}$ & $\begin{array}{l}\text { Context-specific } \\
\text { recommendation }\end{array}$ \\
\hline & $\begin{array}{l}\text { In undernourished populations, balanced energy and protein dietary } \\
\text { supplementation }\end{array}$ & $\begin{array}{l}\text { Context-specific } \\
\text { recommendation }\end{array}$ \\
\hline \multirow{2}{*}{$\begin{array}{l}\text { Iron and folic } \\
\text { acid } \\
\text { supplements }\end{array}$} & $\begin{array}{l}\text { Daily oral iron and folic acid supplementation with } 30-60 \mathrm{mg} \text { of } \\
\text { elemental iron and } 400 \mu \mathrm{g}(0.4 \mathrm{mg}) \text { of folic acid }\end{array}$ & Recommended \\
\hline & $\begin{array}{l}\text { Intermittent oral iron and folic acid supplementation with } 120 \mathrm{mg} \text { of } \\
\text { elemental iron and } 2,800 \mu \mathrm{g}(2.8 \mathrm{mg}) \text { of folic acid once weekly }\end{array}$ & $\begin{array}{l}\text { Context-specific } \\
\text { recommendation }\end{array}$ \\
\hline $\begin{array}{l}\text { Calcium } \\
\text { supplements }\end{array}$ & $\begin{array}{l}\text { In populations with low dietary calcium intake, daily calcium } \\
\text { supplementation }(1.5-2.0 \mathrm{~g} \text { oral elemental calcium })\end{array}$ & $\begin{array}{l}\text { Context-specific } \\
\text { recommendation }\end{array}$ \\
\hline $\begin{array}{l}\text { Vitamin A } \\
\text { supplements }\end{array}$ & $\begin{array}{l}\text { Vitamin A supplementation is only recommended for pregnant } \\
\text { women in areas where vitamin A deficiency is a severe public health } \\
\text { problem. }\end{array}$ & $\begin{array}{l}\text { Context-specific } \\
\text { recommendation }\end{array}$ \\
\hline $\begin{array}{l}\text { Zinc } \\
\text { supplements }\end{array}$ & $\begin{array}{l}\text { Zinc supplementation for pregnant women is only recommended in } \\
\text { the context of rigorous research. }\end{array}$ & $\begin{array}{l}\text { Context-specific } \\
\text { recommendation }\end{array}$ \\
\hline $\begin{array}{l}\text { Restricting } \\
\text { caffeine intake }\end{array}$ & $\begin{array}{l}\text { For pregnant women with high daily caffeine intake (more than } 300 \\
\text { mg per day), lowering daily caffeine intake during pregnancy }\end{array}$ & $\begin{array}{l}\text { Context-specific } \\
\text { recommendation }\end{array}$ \\
\hline
\end{tabular}

Source: WHO 2016b.

While most of the interventions in Table 6 are recommended in specific contexts, daily iron and folic acid supplementation and dietary counseling are recommended universally. Due to increased metabolic demands to meet fetal requirements for growth and development, pregnant women are more vulnerable to mineral deficiencies. A Cochrane systematic review assessed the benefits and harms of iron supplementation in healthy pregnant women. It found that women taking daily iron supplements were less likely to have LBW babies compared with controls, and daily iron supplementation reduced the risk of maternal anemia at term by 70 percent and iron deficiency at term by 57 percent but had no significant effect on the risk of infections during pregnancy (PeñaRosas et al. 2012). In the preconception period, women at the reproductive age are more prone to increased risk of anemia because of chronic iron depletion during the menstrual cycle. It is estimated that worldwide 30.2 percent women of reproductive age are anemic (WHO 2011). The WHO recommends an intermittent iron and folic acid supplementation for menstruating women. A Cochrane systematic review showed that women who were taking intermittent iron supplements either alone or in combination with other micronutrients had significantly higher hemoglobin and ferritin concentrations and were less likely to develop anemia than those not receiving the supplement (Fernández-Gaxiola and De-Regil 2011). Another systematic review and metaanalysis by Salam et al. (2016) that evaluated the effectiveness of iron, folic acid, vitamin A, vitamin $\mathrm{D}$, vitamin $\mathrm{C}$, calcium, zinc, and $\mathrm{MMN}$ supplementation for adolescents suggested improved concentration of serum hemoglobin, iron, ferritin, and zinc. 


\section{Fortified food supplements}

Cereals are the major source of energy and other nutrients for most modern societies worldwide. Wheat, maize, and rice represent the most important cereal crops; if they are fortified appropriately and implemented, it is an efficient, simple, and inexpensive strategy for supplying vitamins and minerals to the diets of large segments of the population. This supplement can be fortified with various micronutrients and vitamins such as iron, folic acid, vitamin $\mathrm{A}$, vitamin $\mathrm{D}$, zinc, calcium, retinol, iodine, copper, and so on. However, the direct benefits of such fortified supplements do not have strong evidence (WHO 2016c). Iodization of salt is another intervention that is widely practiced to prevent iodine deficiency disorders. A systematic review has shown to reduce the risk of goiter, cretinism, low cognitive function, and iodine deficiency (Aburto et al. 2014).

\section{Nutrition-sensitive interventions and programs}

This section covers interventions from sectors that have evidence base on nutritional outcomes including health, agriculture, social services and protection, early childhood development, education, and WASH. The programs reviewed in this section generally have several objectives such as raising income, food security, women's empowerment, and nutrition.

\section{Agriculture programs}

The growth in the agriculture sector has been shown to be associated with a reduction in undernutrition. Hoddinott, Rosegrant, and Torero (2013) demonstrated that an extra investment of US\$8 billion per year globally would reduce the number of hungry people by 210 million and reduce the number of underweight children by 10 million by 2050 . Evidence also suggests that targeted agricultural programs are more successful when they incorporate strong behavior change communications strategies and a gender equity focus, especially for women engagement and empowerment (Hoddinott, Rosegrant, and Torero 2013). 
Box 7: Pathways by which agriculture can affect nutrition outcomes

- A source of food. Agriculture increases household availability and access to food from own production.

- A source of income. Agriculture increases income from wages earned by agricultural workers or through the marketing of agriculture commodities produced.

- Food prices. Agricultural policies (national and global) affect a range of supply and demand factors that establish the price of marketed food and non-food crops; this price, in turn, affects the income of net seller households, the purchasing power of net buyers, and the budget choices of both.

- Women's social status and empowerment. Women's participation in agriculture can affect their access to, or control over, resources and assets and increase their decision-making power regarding intrahousehold allocation of food, health, and care.

- Women's time. Women's participation in agriculture can affect their time allocation and the balance between time spent in income-generating activities and time allocated to household management and maintenance, caregiving, and leisure.

- Women's own health and nutritional status. Women's participation in agriculture can affect their health (for example, through exposure to agriculture-associated diseases) and nutritional requirements (for example, through increased energy expenditure); their health and nutritional status can, in turn, affect their agricultural productivity and hence their income from agriculture.

Source: World Bank 2007; Gillespie, Harris, and Kadiyala 2012.

\section{Home gardens and homestead food production programs}

An intervention that has been promoted in a number of LMICs by the agriculture sector is home garden and homestead food production programs. ${ }^{11}$ Although several studies have investigated the effects of homestead food production programs on maternal or child nutritional status (anthropometry or micronutrient status), evidence is limited. A meta-analysis pooling studies from four countries that examined the effects of agricultural interventions on nutritional status of children has shown that vitamin A status as measured by serum retinol concentration had a small difference between the intervention and control arms $(0.08 \mu \mathrm{mol} / \mathrm{L})$ (Masset et al. 2012). A cluster randomized effectiveness study that examined the effects of the introduction of $\beta$ carotene-rich orange sweet potato in rural Uganda showed a 9.5 percent point reduction in the prevalence of low serum retinol $(<1.05 \mu \mathrm{mol} / \mathrm{L})$ among children ages 3-5 years at baseline (Hotz et al. 2012). Another study conducted in a resource poor area of Mozambique investigated the effects of introduction of orange-fleshed sweet potato in an integrated agriculture and nutrition intervention that aimed to increase vitamin A intake and serum retinol concentrations in young children. The quasi-experimental intervention study followed households of 741 children (mean age 13 months at baseline) through two agricultural cycles and found that vitamin A intake was significantly higher among the intervention arm (median 426 versus $56 \mu \mathrm{g}$ retinol activity equivalent). Another impact pathway-focused assessment of a homestead food production system in Cambodia did not

\footnotetext{
${ }^{11}$ The important distinction between home gardening and homestead food production is that the latter involves rearing of small livestock, for example, chickens, which are an important source of nutrient-rich animal source foods.
} 
show any effects on child anthropometry or anemia despite effects on improved household production.

\section{Biofortification}

Another unique nutrition-sensitive intervention in the agriculture sector is biofortification, which focuses on breeding of staple crops that are rich in essential micronutrients. All biofortified crops have favorable agronomic qualities, including equal or higher yields than common varieties, and greater disease resistance and drought tolerance. The advantage of this approach is well documented (Ruel, Alderman, and Maternal and Child Nutrition Study Group 2013). However, biofortification alone does not achieve high concentration of micronutrients that are needed for treating severe deficiency cases or to fulfil the high nutritional requirements.

Box 8: Three milestones to be achieved for a successful biofortification program

1. Breeding objectives (minimum target concentration for each micronutrient) must be met.

2. Retention and bioavailability of micronutrients must be satisfactory so that intake leads to expected improvements in status.

3. Farmer adoption rates and intakes by target populations must be adequate.

HarvestPlus is a program that has led a global effort to breed and disseminate staple food biofortified with vitamin A, zinc, and iron in seven crops including cassava, maize, sweet potato, bean, pearl millet, rice, and wheat. In 2017, a biofortified high-iron pearl millet program demonstrated functional cognitive improvements that could profoundly affect women and teens' daily lives, including their ability to succeed at school and work. In India, adolescents who consumed biofortified pearl millet twice daily as bhakri (a local flatbread) or shev (a savory snack) for six months significantly improved their learning and mental abilities related to perception, attention, and memory (HarvestPlus 2019). Another two effectiveness trials in Uganda and Mozambique (milestone three), which assessed the effects of rolling out orange sweet potato, showed a favorable adoption by farmers and significant increases in vitamin A intake in both countries. Iron-biofortified rice and beans were also associated with improved iron status.

\section{Social protection programs}

Social protection - a set of policies and programs aimed at preventing or protecting all people against poverty, vulnerability, and social exclusion throughout their life courses, with a particular emphasis toward vulnerable groups (UNICEF 2019) — provides a unique opportunity to improve maternal and child nutrition outcomes.

\section{Cash transfer}

Among the nutrition-sensitive interventions, cash transfer programs have gained attention worldwide partly due to the scale at which they are expanding and partly due to their proven impact 
on poverty, inequality, and food insecurity. A UNICEF mapping exercise of social protection broadly suggests that 108 countries (out of 136 countries surveyed) either had an active social protection policy or strategy document in place or were planning such a document (UNICEF 2019). The rate of expansion is remarkable. In 1997, only two countries had introduced conditional cash transfer (CCT) programs, while by 2015 the number had grown to 64 and, even more rapidly, the number of countries in Africa with unconditional cash transfers doubled from 20 to 40 between 2010 and 2015. In LMICs, the share of government expenditures devoted to social protection has been growing more rapidly than investments in other sectors (Alderman 2015).

The impacts of social protection, in particular cash transfers, on intermediate nutrition outcomes are well established. Cash transfers not only raise the living standards of beneficiary households but also enable parents and caregivers to invest more in their children. The most direct effect of a cash transfer is the increased level of resources in the beneficiary household, which, assuming equitable intra-household distribution, improves the standard of living of all members of the household, including children. Evidence shows that food consumption and diet diversification are a major focus of expenditure when families living in poverty receive social transfers (cash and food transfers) (UNICEF 2019). Cash transfers therefore promote realization of Articles 26 and 27 of the Convention on the Rights of the Child (CRC) on the rights to social security and an adequate standard of living. However, the impacts of cash transfers go far beyond the direct revenue effect on beneficiaries' level of consumption. They also have indirect knock-on effects on a wide range of other rights, including those to food security, adequate nutrition, and access to basic social services, such as education and health. Social protection has been shown to have a significant impact both on the usage of health services and on mitigating the financial impact of a health crisis in a household, as well as on uptake of health services (UNICEF 2019).

Where the empirical evidence is less clear is on the overall effects of cash transfers on final nutrition outcomes, such as stunting and wasting rates. This is in large part because comparative analysis of the nutritional impact of different programs, in different countries, is hindered by differences in the nature of the programs. Evidence on the nutrition impacts of cash transfer programs is available for programs in several countries, some of which have conditionalities, and others are unconditional. In some programs, the transfers are accompanied by direct nutrition interventions, such as the distribution of foods fortified with micronutrients, as in the Mexican program Oportunidades, or the provision of micronutrient supplements, as in Nicaragua's Red de Protección Social. Adding to the complexity, the different studies measure nutrition impacts in different age ranges (from 0-5 months up to 0-59 months), giving results that are therefore not strictly comparable.

Evidence on cash transfer programs' impact on nutrition is often derived from experimental or quasi-experimental impact evaluations. Comparing evidence from evaluations of six programs in 
middle-income countries, ${ }^{12}$ focusing on the impact of cash transfers on stunting, shows that most but not all programs have helped reduce stunting. Programs in Mexico, Nicaragua, Colombia, and South Africa have had a substantial positive and statistically significant impact on stunting, although this has not been the case in Honduras and Brazil. Programs are more likely to reduce stunting when they target households with very young children (under two years old) and transfer amounts are quite large. Comparative studies (Leroy et al. 2010; Manley, Gitter, and Slavchevska 2011) show that cash transfers tend to have larger impacts on consumption expenditure, including food expenditure, on beneficiaries' poverty rates, and on the quality or diversity of food consumed. ${ }^{13}$ Many also have impacts on child nutrition, but this is not always the case.

While evidence shows benefits of both conditional and unconditional transfers, evidence on the added value of condition is mixed (UNICEF 2019). CCTs aim to incentivize households to invest in health, nutrition, and education of their children (enhancing human capital) by providing cash conditional to the utilization of certain services. Most CCTs target transfers to women on the premise that it will lead to greater investments in nutritional status of children at each household level. CCTs in Latin America have shown positive effects on poverty reduction, household food consumption, and diversifying diet (Leroy et al. 2010; Manley, Gitter, and Slavchevska 2012). The review conducted by Gaarder, Glassman, and Todd (2010) found that CCTs were associated with increased use of preventive and curative health and nutrition services in almost all studies analyzed. Studies from Mexico, Brazil, and Nicaragua (Adato et al. 2000; Adato and Hoddinott 2010; Skoufifias and McClafferty 2001) have indicated improvements in women's control over additional resources, enhanced self-esteem, heightened knowledge and awareness of health and nutrition, and increased opportunities for women to strengthen their social networks.

Unconditional transfers, on the other hand, are given either as cash or in kind with so-called soft conditions, which may facilitate behavior change communications or social marketing to encourage health-seeking behavior in households. A randomized trial from Burkina Faso showed that clinic visits have increased in cash programs provided with health conditionality, whereas it did not in unconditional cash transfer (Akresh, De Walque, and Kazianga 2012). This implies that unconditional transfer programs may be less effective in facilitating behavior change.

It is noteworthy, however, that one of the cash transfer programs with significant impacts on stunting, the South African Child Support Grant, is unconditional. This program shows that cash transfers can have a substantial impact on child nutrition from their income effect alone (Agüero, Carter, and Woolard 2007). A meta-analysis of the nutritional impacts of 17 cash transfer programs, including 5 without any conditionality, found that programs with conditionalities do no

\footnotetext{
$\mathbf{1 2}$ The six programs examined were Child Support Grant in South Africa; 'Oportunidades' (ex-PROGRESA) in Mexico; 'Red de Protección Social' (Social Protection Net) in Nicaragua; 'Familias en Acción' (Families in Action) in Colombia; 'Programa de Asignación Familiar' (Family Allowance Program) in Honduras; and 'Bolsa Alimentação' (Food Grant) in Brazil, which was subsequently integrated into the larger 'Bolsa Família' program.

${ }^{13}$ A notable exception is the program in Honduras, where the transfer amount was particularly low.
} 
better at improving nutritional status than do programs without (Manley, Gitter, and Slavchevska 2011). The challenges of generating evidence, which varies by context, and the seemingly limited impact of cash transfers on stunting and wasting indicate that nutritional outcomes require more than just food or income and that there are supply-side and behavioral factors that need to be addressed (Alderman et al. 2015).

\section{Box 9: Pathways by which social protection can affect nutrition outcomes}

The transfer of additional resources to the household improves food security, leading to improvements in food intake, in terms of both quantity and quality, as well as the household's financial access to health services (in a country such as Sri Lanka, where OOP health expenditure is high). The impact on food/nutrient intake should in principle be particularly important, given the weight of food expenditure in total household consumption expenditure, especially among the poor. This is significant in Sri Lanka as food constitutes around one-third of the expenses of the average household in the urban and rural sectors and half of the total expenses of the average family in the estate sector. Family incomes, the expenditure level, and the level of indebtedness have a large impact on their dietary levels. In Sri Lanka, a person classified as 'non-poor' consumes, on average, almost double the kilocalories that a person classified as 'poor' consumes (according to the Household Income and Expenditure Survey 2016 data). Marked differences on daily calorie consumption also exist among districts.

Evidence from impact evaluations suggests that households generally use the additional resources coming from cash transfers to meet their most urgent needs, in particular to buy food, and this suggests that all members of the household, including those who are most vulnerable such as young children and pregnant women, benefit. Conditionality may add to the income effect of cash transfers, for example, by requiring participation in informal education sessions on feeding, hygiene, and care practices, as shown in the figure below, but evidence is inconclusive. More recent approaches, such as 'cash plus,' are using complementary inputs to get the presumed benefits of conditionality, without having its punitive effect.

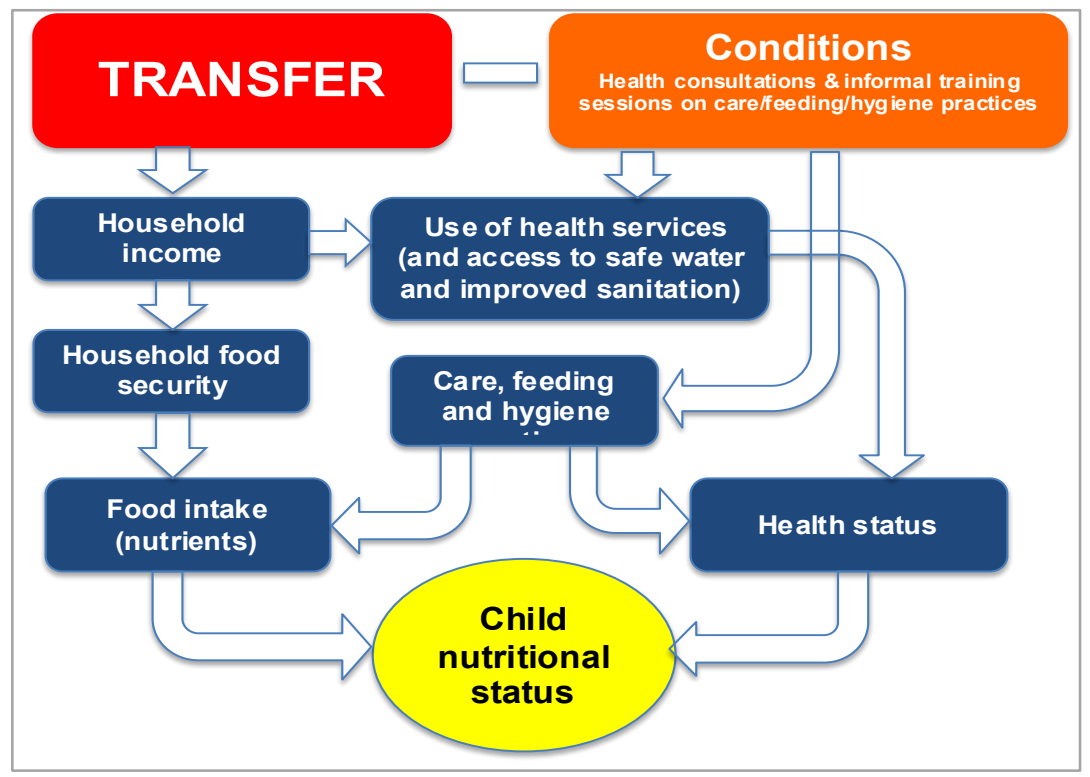

Source: Adapted from UNICEF nutrition conceptual framework (see UNICEF 1990). 


\section{Social safety nets}

Social safety net programs transfer funds to low-income households. The programs often aim to raise the income levels of vulnerable population to enhance resilience against loss of assets in times of crises. Transfers can be in the form of cash or in kind (food). Approximately 1.75 billion people in LMICs receive cash support (DFID 2011) and the coverage varies from country to country. For instance, Ethiopia's Productive Safety Net Program reached 10 percent of the country's population (World Bank 2012), while transfer programs in Brazil and Mexico reached 25 percent and in Ecuador 40 percent (Fiszbein et al. 2009).

\section{School feeding programs}

Another type of conditional transfer program is the school feeding program. Although the relationship between the program and the nutritional status of the targeted children is less evident, the program can reduce hunger and stimulate learning of children at school and thus have been widely implemented in nearly every country in the world (Bundy, Drake, and Burbano 2012). A meta-analysis conducted by Kristjansson et al. (2007) suggested no significant anthropometric effects in school children, and hence major improvements in height cannot be expected in school children through this program. Conversely, school meals had a small effect on weight gain that can have either a positive (in underweight) or a negative (in obese) impact.

Sometimes the school meal programs can benefit the other members of a child's family, when children are allowed to take the food back home (Afridi 2010). A few randomized control studies in Uganda and Burkina Faso have shown increased weights among preschool boys (under five years) whose siblings received either school meal or take home ration compared to the control group (Kazianga, De Walque, and Alderman 2009). If designed according to needs, school feeding programs also have the potential to improve micronutrient status. A review of randomized studies of iron-rich school meals (fortified or provision of animal-source foods) demonstrated improved iron status of adolescent girls, irrespective of the initial status (Adelman, Gilligan, and Lehrer 2008).

\section{In-kind household food distribution}

Due to the associated high cost, in-kind household food distributions have become less popular in the past decades. This type of program is primarily used during an emergency response or in places where the logistics of cash transfers are constrained. Sometimes these kinds of programs also provide micronutrient fortified foods (for example, corn soy or wheat soy blend) to mothers and young children in addition to general family rations. In Haiti, for instance, such rations were provided to all mothers and children within the first 1,000 days that showed greater effects on child growth than did targeting of underweight children under five (Ruel et al. 2008). Another similar program which provided iron-fortified micronutrient powders reduced anemia prevalence by half 
in as short a time as two months (Menon et al. 2007). However, these in-kind food transfer programs can sometimes have unintended effects on overweight and obesity when the energy contribution of the food basket exceeds the energy gap in the targeted population (Leroy et al. 2010, 2013).

\section{Transfer programs in emergencies}

These types of programs usually combine nutritionally enhanced complementary foods with family rations or cash for pregnant and lactating women and their young children. If the transfers are provided as targeted programs, they can aid in preventing major deteriorations in child undernutrition during disasters or other emergency situations (Giles and Satriawan 2010; Yamano, Alderman, and Christiaensen 2005).

\section{Nurturing care}

Recently, the Lancet Series on Early Childhood Development published new evidence that supports the concept of 'nurturing care' as a stable environment that is sensitive to children's health and nutritional needs, with interactions that are responsive, emotionally supportive, and developmentally stimulating. 'Nurturing care'—defined as health, nutrition, security and safety, responsive caregiving, and early learning — should be provided by parent and family interactions and supported by an environment that enables these interactions. Holistic approach involving families through service providers across many sectors - for example, health, nutrition, education, water and sanitation, social protection-is therefore critical to enable young children to thrive.

Figure 39: Supporting families for nurturing care and home visiting resource package
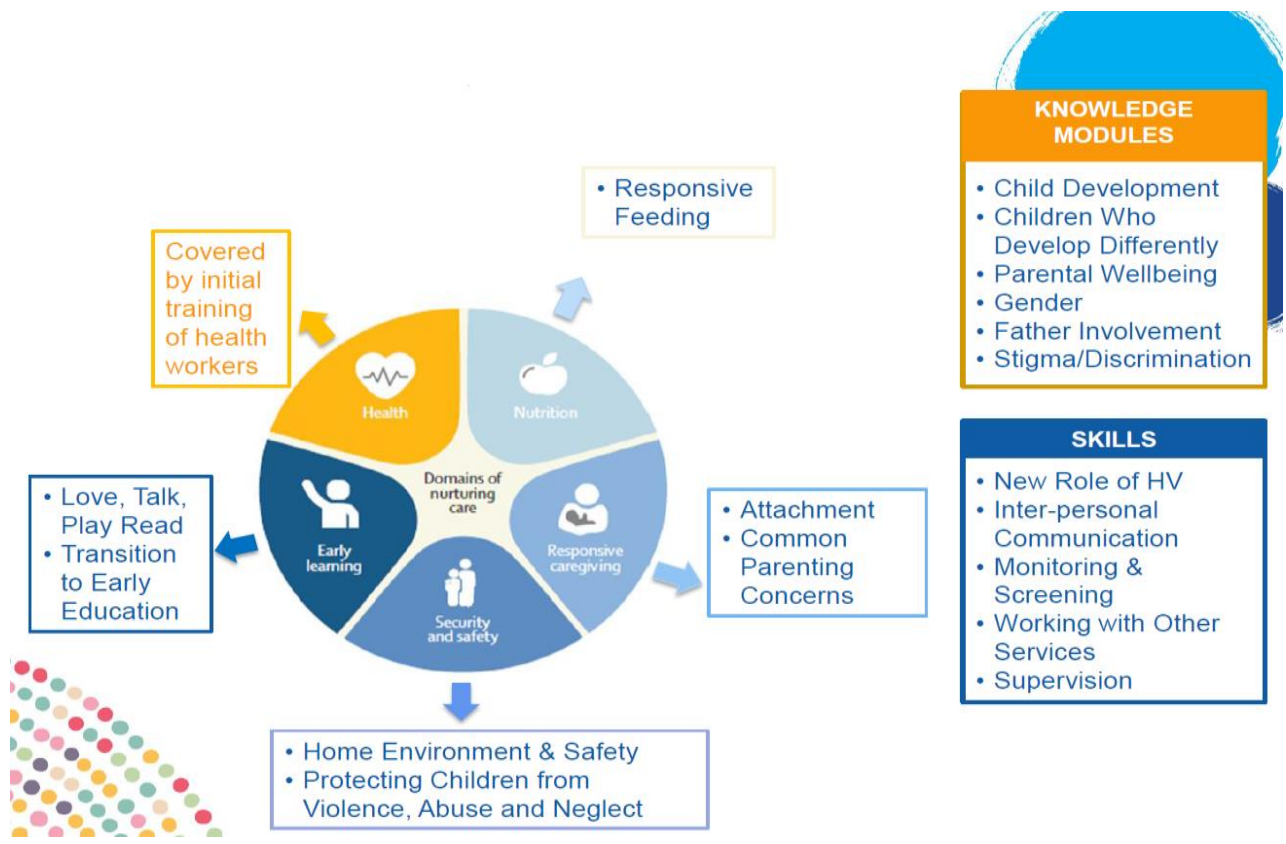

\begin{tabular}{|l|}
\hline \multicolumn{1}{|c|}{ SKILLS } \\
\hline - New Role of HV \\
- Inter-personal \\
Communication \\
- Monitoring \& \\
Screening \\
- Working with Other \\
Services \\
- Supervision \\
\hline
\end{tabular}

Source: UNICEF and ISSA 2016. 
The nurturing care framework was developed by the WHO, UNICEF, and the World Bank, in collaboration with the Partnership for Maternal, Newborn and Child Health, the Early Childhood Development Action Network to guide the program designs and implementation.

A program in Jamaica that provided both child stimulation and food supplementation for stunted children ages between 9 and 24 months showed improvements in cognitive development (Grantham-McGregor et al. 1991). A program from Bangladesh, which included stimulation and home visits in addition to standard nutrition and health care for severely malnourished children, has demonstrated better development outcomes and weight-for-age Z score (WAZ) (Nahar et al. 2009). Likewise, another study from Bangladesh that included responsive parenting (including feeding) to an informal nutrition and child development education program showed improvements in feeding and parenting, behavioral changes, child self-feeding, and development outcomes (Aboud and Akhter 2011). Another intervention from Jamaica that provided zinc supplementation and responsive stimulation intervention in underweight children showed synergistic effects on child development compared to the control groups (Gardner et al. 2005). Reducing maternal depression is another way that could address risk factors that are common to both nutrition and child development (Black et al. 2009; Surkan et al. 2011). Early childhood development programs can have various focuses and forms, and hence the potential contributions to nutrition depend on what activities are included.

\section{School education}

The level of school education is a strong predictor of nutritional status of the next generation. The impact of schooling on nutritional improvement can take a number of causal pathways such as by (a) providing information on health and nutrition directly to the individuals and communities; (b) assisting caregivers in acquiring information and nutrition knowledge through teaching numeracy and literacy to their children; (c) exposing individuals to new environments that could enhance receptiveness to modern medicine; (d) imparting self-confidence that can enhance women's role in decision making and interactions with health care professionals; and (e) providing women with the opportunity to form social networks, which can be of particular importance in isolated rural areas (Ruel, Alderman, and Maternal and Child Nutrition Study Group 2013).

\section{Water, sanitation, and hygiene}

Poor WASH can increase the risk of infection, which could lead to a vicious cycle of poor health, poor absorption of nutrients, and reduced immune system. A major direct cause of undernutrition in addition to inadequate diet is disease (Black et al. 2008; UNICEF 1990). Good hygiene practices, safe water, and sanitation are crucial for maintaining good nutritional status primarily by reducing infection and diseases. 
WASH programs can potentially contribute to nutritional improvements in various pathways that include

(a) Reduction of diarrheal diseases due to reduced fecal contacts with improved environment (Checkley et al. 2004; Esrey 1996; Fink et al. 2011) — handwashing with soap can reduce the risk of diarrhea by 40 percent (Freeman et al. 2014);

(b) Reduction of enteric infections due to reduced fecal contacts with improved environment (Lin et al. 2013);

(c) Reduced exposure and infection with protozoa and helminths due to improved environment (Barreto et al. 2010; Goto, Mascie-Taylor, Lunn 2009; Moraes et al. 2004; Ziegelbauer et al. 2012); and

(d) Reduction in time spent fetching water and caring for sick children and time and costs of seeking treatment (Pickering and Davis 2012).

However, findings from recent randomized controlled studies in three countries (Bangladesh, Kenya, and Zimbabwe) suggested a different story. In Bangladesh, water, sanitation, and hygiene interventions implemented individually or combined did not provide favorable evidence of improvements in growth, although diarrheal diseases reduced (Luby et al. 2018). The trial in Kenya found limited improvements of growth with WASH interventions at one year post intervention but no effects at two years and no effects on diarrheal diseases (Stewart et al. 2018). Similarly, the study in Zimbabwe did not demonstrate any effect of WASH on diarrheal diseases or growth (Humphrey et al. 2019). Multiple interpretations of the negative results from the trials are possible. However, one that likely stands out is that the WASH intervention alone was not sufficient to reduce fecal contamination. 
ANNEX 3: PROGRAM LEVEL EXPENDITURE FOR NUTRITION INTERVENTIONS, 2018

\begin{tabular}{|c|c|c|c|}
\hline Ministry & Implementing agencies & Program/Activity & $\begin{array}{l}\text { Expenditure, } 2018 \\
\text { (SL Rs, millions) }\end{array}$ \\
\hline \multirow[t]{18}{*}{$\mathrm{MoH}$} & \multirow[t]{3}{*}{ FHB } & $\begin{array}{l}\text { Micronutrient supplementation (iron, folic acid, vitamin } \mathrm{C} \text {, and calcium) for } \\
\text { pregnant women and lactating mothers }\end{array}$ & 954.6 \\
\hline & & Vitamin A mega dose for children (6 months to 5 years) & 36.0 \\
\hline & & MMN supplementation (6-18 months ) & $\begin{array}{c}194.7 \\
(2017)\end{array}$ \\
\hline & \multirow{2}{*}{ Hospitals } & Multivitamin drops, iron, folic acid for preterm and LBW children & 13.8 \\
\hline & & Management of SAM (BP 100) & 38.2 \\
\hline & $\mathrm{MoH}$ & $\begin{array}{l}\text { Thriposha for pregnant and lactating mothers (for } 6 \text { months post-delivery) and } \\
\text { undernourished children } 6-59 \text { months }\end{array}$ & $2,358.3$ \\
\hline & Hospitals & Zinc supplementation for children with diarrhea & 4.8 \\
\hline & FHB & Deworming treatment & 58.5 \\
\hline & FHB/ND/HPB/Regional & Promote optimal maternal nutrition and IYCF practices & 17.3 \\
\hline & FHB/ND/Regional & Capacity building of relevant health staff in maternal nutrition and IYCF counseling & 17.5 \\
\hline & FHB/HPB & IEC material - breastfeeding, IYCF & 12.6 \\
\hline & FHB & $\begin{array}{l}\text { Printing of growth monitoring materials - child health development record, } \\
\text { pregnancy records }\end{array}$ & 16.8 \\
\hline & FHB/ND/Regional & Health awareness programs - FP, NCDs, healthy life styles & 11.0 \\
\hline & FHB/MoE & School health program & 20.0 \\
\hline & ND/Estate and urban health & DNAP and Estate nutrition programs & 17.6 \\
\hline & \multirow[t]{2}{*}{ FHB } & Recommended instruments for MCH nutrition clinics & 9.9 \\
\hline & & Equipment for school health program & 23.5 \\
\hline & & Total - MoH & $3,619.0$ \\
\hline \multirow[t]{6}{*}{ MWCA } & \multirow[t]{3}{*}{ Children's Secretariat } & Morning meal/fresh milk for preschool children (2-5 years) & 242.0 \\
\hline & & Food allowance for pregnant mothers & $5,526.4$ \\
\hline & & Poshana Manpetha - Food and Nutrition Program & 2.0 \\
\hline & Women Development & Suva Diviyata Poshanaya 'Nutrition for healthy life' & $\begin{array}{c}1.03 \\
(2016)\end{array}$ \\
\hline & $\begin{array}{l}\text { Department of Probation } \\
\text { and Child Care services }\end{array}$ & Assistance for twins & 2.0 \\
\hline & & Total - MWCA & $5,772.0$ \\
\hline \multirow[t]{3}{*}{$\mathrm{MoE}$} & \multirow[t]{2}{*}{ SHN } & School meal program & $5,456.3$ \\
\hline & & Glass of milk for school children & 458.4 \\
\hline & WFP/Regional & WFP - School Meal Program & 22.5 \\
\hline
\end{tabular}




\begin{tabular}{|c|c|c|c|}
\hline Ministry & Implementing agencies & Program/Activity & $\begin{array}{l}\text { Expenditure, } 2018 \\
\text { (SL Rs, millions) }\end{array}$ \\
\hline & \multirow[t]{3}{*}{$\mathrm{MoE}$} & School Health Promotion Program & 7.2 \\
\hline & & School WASH & 344.2 \\
\hline & & Total - MoE & $6,289.0$ \\
\hline MPISE & Samurdhi Development & Samurdhi welfare & $39,239.0$ \\
\hline \multirow[t]{21}{*}{ MoA } & MoA & FPNP & 918.0 \\
\hline & \multirow[t]{3}{*}{ MoA/Regional } & Home gardening promotion and apiculture control project & 29.8 \\
\hline & & Food crop production and improvement & 147.3 \\
\hline & & Establishment of fruit village & 9.6 \\
\hline & \multirow[t]{3}{*}{ Regional } & Promotion of alternative crops & 15.8 \\
\hline & & Encourage the production and use of organic fertilizer & 11.8 \\
\hline & & Commercial farming and agrobusiness development & 20.5 \\
\hline & MoA/Regional & Farm mechanization program & $\begin{array}{c}65.1 \\
(2017)\end{array}$ \\
\hline & \multirow{2}{*}{ Regional } & Good Agricultural Practices & 7.3 \\
\hline & & Post-harvest technology development projects & 5.9 \\
\hline & \multirow[t]{2}{*}{ MoA } & Fertilizer subsidy & $26,879.0$ \\
\hline & & E-agriculture - agricultural database & 14.0 \\
\hline & MoA/Regional & 'Gamdora' - gathering information of farming crops & 4.0 \\
\hline & \multirow[t]{2}{*}{ Regional } & Research and technical development program & 3.7 \\
\hline & & Agriculture exhibition and community awareness & 11.6 \\
\hline & MoA/Regional & Hela Bojun' sales centers - changing food consumption patterns & 14.8 \\
\hline & Regional & Supply of equipment, machinery, and so on & 65.1 \\
\hline & MoA/Regional & Minor irrigation and renovation of small tanks & $2,098.0$ \\
\hline & Regional & Infrastructure facility improvement - stores and so on & 29.5 \\
\hline & Regional & Construction of training centers & 66.2 \\
\hline & & Total - MoA & $30,352.0$ \\
\hline \multirow[t]{9}{*}{ MLRD } & \multirow[t]{8}{*}{ MLRD/Regional } & Establishment of Animal Breeder Farms & 113.2 \\
\hline & & DAPH livestock program & 324.6 \\
\hline & & National food production program & 96.5 \\
\hline & & Facilitation and Promotion of Liquid Milk Consumption & 79.6 \\
\hline & & Development of Small and Medium Scale Poultry Farming System & 33.5 \\
\hline & & Swine Industry Development & 7.0 \\
\hline & & Farmer training and promotion & 13.5 \\
\hline & & Provision of farm equipment & 17.2 \\
\hline & DAPH & Construction - milk stalls, food demonstration unit & 0.8 \\
\hline
\end{tabular}




\begin{tabular}{|c|c|c|c|}
\hline Ministry & Implementing agencies & Program/Activity & $\begin{array}{l}\text { Expenditure, } 2018 \\
\text { (SL Rs, millions) }\end{array}$ \\
\hline & & Total - MLRD & 686.0 \\
\hline \multirow[t]{13}{*}{ MFARD } & \multirow{2}{*}{ NAQDA } & National Food Production Program & 221.1 \\
\hline & & Develop Inland Fisheries-Stocking of Fish Fingerlings, enhancing breeding capacity & 237.5 \\
\hline & \multirow[t]{5}{*}{ FSDD } & Assistance for introducing new technology & 8.3 \\
\hline & & Fishery community empowerment & 115.0 \\
\hline & & Coastal rehabilitation and resources management program & 75.3 \\
\hline & & Improvement of fishery villages in 10 costal districts & 218.6 \\
\hline & & $\begin{array}{l}\text { Establishment of integrated inland fishery villages 'Wawak Sahitha Gamak } \\
\text { Program' }\end{array}$ & 239.9 \\
\hline & \multirow[t]{3}{*}{ DFAR } & DFAR & 251.0 \\
\hline & & Supply of boats and assistance for fishery sector & 298.1 \\
\hline & & Promoting value added fish production and enhance marketing & 0.2 \\
\hline & \multirow{3}{*}{ CFC } & Infrastructure facilities for aquaculture, sales centers & 180.2 \\
\hline & & Development and Rehabilitation of Fishery Harbors & $1,010.9$ \\
\hline & & Total - MFARD & $2,856.0$ \\
\hline \multirow[t]{5}{*}{ MHC } & MHC & Tikiri Shakthi - nutritional bar & 43.4 \\
\hline & $\begin{array}{l}\text { MHC } \\
\text { MCPWS }\end{array}$ & Others (Nutrition and Food Program/Home Gardening) & 2.4 \\
\hline & \multirow[t]{3}{*}{ MHC } & Upgrade Child Development Centers & 8.6 \\
\hline & & WASH - estate sector & 42.8 \\
\hline & & Total - MHC & 97.0 \\
\hline \multirow[t]{12}{*}{ MCPWS } & MCPWS & Provision of safe drinking water for the areas affected by the chronic kidney disease & 553.2 \\
\hline & MCPWS/NWSDB & Improvement of Rural Water Supply and Sanitation & 533.7 \\
\hline & \multirow[t]{3}{*}{ MCPWS } & All Island Sanitation Programs & 26.9 \\
\hline & & WASSIP (World Bank) & $4,767.0$ \\
\hline & & China Sri Lanka Research Grant Project & 248.0 \\
\hline & \multirow[t]{2}{*}{ NWSDB } & Dry Zone Urban Water and Sanitation Project (ADB) & 49.9 \\
\hline & & Large-scale water and waste water projects (disbursement of ongoing projects) & $23,982.4$ \\
\hline & DNCWS & Improvement of Community Water Supply Schemes & 157.2 \\
\hline & \multirow[t]{4}{*}{ NWSDB } & Increasing household access to sewerage services (GPOBA -World Bank) & 315.1 \\
\hline & & GOSL Allocation for Large Scale Water Supply and Sewerage Projects & $\begin{array}{c}1,1119.1 \\
(2017)\end{array}$ \\
\hline & & Local Bank Loan for Large Scale Water Supply and Sewerage Projects & $\begin{array}{c}15,254.7 \\
(2017)\end{array}$ \\
\hline & & Foreign Bank Loan for Large Scale Water Supply and Sewerage Projects & $16,631.1$ \\
\hline
\end{tabular}




\begin{tabular}{|c|c|c|c|}
\hline \multirow[t]{6}{*}{ Ministry } & Implementing agencies & Program/Activity & $\begin{array}{l}\text { Expenditure, } 2018 \\
\text { (SL Rs, millions) }\end{array}$ \\
\hline & & & $(2017)$ \\
\hline & & Emerging Small Townships Water Supply Schemes & $\begin{array}{c}130.3 \\
(2017) \\
\end{array}$ \\
\hline & & UNICEF Drought Mitigation and Emergency Activities & $\begin{array}{l}56.36 \\
(2017)\end{array}$ \\
\hline & & Provincial & 70.4 \\
\hline & & Total - MCPWS & $30,704.0$ \\
\hline
\end{tabular}

Note: HR costs not added. 


\section{REFERENCES}

Aboud, F. E., and S. Akhter. 2011. "A Cluster-randomized Evaluation of a Responsive Stimulation and Feeding Intervention in Bangladesh." Pediatrics 127: e1191-e1197.

Aburto, N., M. Abudou, V. Candeias, and T. Wu. 2014. Effect and Safety of Salt Iodization to Prevent Iodine Deficiency Disorders: A Systematic Review with Meta-analyses. WHO eLibrary of Evidence for Nutrition Actions (eLENA). Geneva: WHO.

Adato, M., B. De la Brière, D. Mindek, and A. Quisumbing. 2000. The Impact of PROGRESA on Women's Status and Intrahousehold Relations. Final Report. Washington, DC: International Food Policy Research Institute.

Adato, M., and J. Hoddinott. 2010. Conditional Cash Transfers in Latin America. Baltimore: Johns Hopkins University Press.

Adelman, S., D. O. Gilligan, and K. Lehrer. 2008. "How Effective Are Food for Education Programs? A Critical Assessment of the Evidence from Developing Countries." IFPRI Food Policy Review 9. Washington, DC: International Food Policy Research Institute.

Afridi, F. 2010. "Child Welfare Programs and Child Nutrition: Evidence from a Mandated School Meal Program in India." J Dev Econ. 92: 152-65.

Agüero, J., M. Carter, and I. Woolard. 2010. "The Impact of Unconditional Cash Transfers on Nutrition: The South African Child Support Grant." International Poverty Centre Working Paper 37: 1-28.

Akresh, R., D. De Walque, and H. Kazianga. 2012. "Alternative Cash Transfer Delivery Mechanisms: Impacts on Routine Preventative Health Clinic Visits in Burkina Faso." Policy Research Working Paper 5958, World Bank, Washington, DC.

Alderman, H. H. 2015. Leveraging Social Protection Programs for Improved Nutrition: Summary of Evidence Prepared for the Global Forum on Nutrition-sensitive Social Protection Programs. Global Forum on Nutrition-Sensitive Social Protection Programs, September 10-11, 2015. Washington, DC: World Bank Group.

Bangladesh Finance Division and UNICEF (United Nations Children's Fund). 2019. Bangladesh Public Expenditure Review on Nutrition. Dhaka: Ministry of Finance and UNICEF.

Banna, J. C., O. V. Buchthal, T. Delormier, H. M. Creed-Kanashiro, and M. E. Penny. 2016. "Influences on Eating: A Qualitative Study of Adolescents in a Periurban Area in Lima, Peru." BMC Public Health 16 (1): 40. 
Barreto, M. L., B. Genser, A. Strina, M. G. Teixeira, A. M. O. Assis, R. F. Rego, C. A. Teles, M. S. Prado, S. M. A. Matos, N. M. Alcântara-Neves, and S. Cairncross. 2010. "Impact of a Citywide Sanitation Program in Northeast Brazil on Intestinal Parasites Infection in Young Children.” Environmental Health Perspectives 118 (11): 1637-1642.

Basset, R., G. E. Chapman, and B. L. Beagan. 2007. "Autonomy and Control: The Co-construction of Adolescent Food Choice." Appetite 50: 325 -332.

Bernardette, Cichon. 2019. Action Against Hunger UK and No Wasted Lives, Transforming Nutrition Course. Brighton: Institute of Development Studies. Sussex University.

Bhutta, Z. A., T. Ahmed, R. E. Black, S. Cousens, K. Dewey, E. Giugliani, B. A. Haider, B. Kirkwood, S. S. Morris, H. P. Sachdev, M. Shekar, and Maternal and Child Undernutrition Study Group. 2008. "What Works? Interventions for Maternal and Child Undernutrition and Survival." The Lancet 371 (9610): 417-440.

Bhutta, Z. A., J. K. Das, A. Rizvi, M. F. Gaffey, N.Walker, S. Horton, P. Webb, A. Lartey, R. E. Black, and the Maternal and Child Nutrition Study Group. 2013. "Evidence-based interventions for improvement of maternal and child nutrition: what can be done and at what cost?" The lancet 382(9890): 452-477.

Black, R. E., L. H. Allen, Z. A. Bhutta, L. E. Caulfield, M. de Onis, M. Ezzati, C. Mathers, and J. Rivera. 2008. "Maternal and Child Undernutrition: Global and Regional Exposures and Health Consequences." The Lancet 371 (9608): 243-260.

Black, M., A. H. Baqui, K. Zaman, S. El Arifeen, and R. E. Black. 2009. "Maternal Depressive Symptoms and Infant Growth in Rural Bangladesh.” Am J Clin Nutr. 89: S951-57.

Black, R. E., C. G. Victora, S. P. Walker, Z. A. Bhutta, P. Christian, M. De Onis, M. Ezzati, S. Grantham-McGregor, J. Katz, and R. Martorell. 2013. "Maternal and Child Undernutrition and Overweight in Low-income and Middle-income Countries." The Lancet 382 (9890): $427-451$.

Bundy, D., L. Drake, and C. Burbano. 2012. "School Food, Politics, and Child Health." Public Health Nutr 16 (6): 1012-1019.

Butte, N.F., M. G. Lopez-Alarcon, and C. Garza. 2002. Nutrient Adequacy of Exclusive Breastfeeding for the Term Infant during the First Six Months of Life. Geneva: WHO.

CBSL (Central Bank of Sri Lanka). 2019. Annual Report 2018. Colombo: CBSL.

Checkley, W., R. H. Gilman, R. E. Black, L. D. Epstein, L. Cabrera, C. R. Sterling, and L. H. Moulton. 2004. "Effect of Water and Sanitation on Childhood Health in a Poor Peruvian Peri-urban Community." The Lancet 363 (9403): 112-118. 
Ching, P., M. Birmingham, T. Goodman, R. Sutter, and B. Loevinsohn. 2000. "Childhood Mortality Impact and Costs of Integrating Vitamin A Supplementation into Immunization Campaigns." American Journal of Public Health 90: 1526-1529.

DCS (Department of Census and Statistics). 2009. Sri Lanka Demographic and Health Survey 2006. Battaramulla: Department of Census and Statistics and Ministry of Health, Nutrition and Indigenous Medicine.

- 2017. Sri Lanka Demographic and Health Survey 2016. Battaramulla: Department of Census and Statistics and Ministry of Health, Nutrition and Indigenous Medicine.

Dewey, K. G. and K. H. Brown. 2003. "Update on Technical issues concerning Complementary Feeding of Young Children in Developing Countries and Implications for Intervention Programs." Food and Nutrition Bulletin 24 (1): 5-28.

DFID (U.K. Department for International Development). 2011. Cash Transfer Evidence Paper. London: Department for International Development Policy Division.

Esrey, S. A. 1996. "Water, Waste, and Well-Being: A Multi-country Study." American Journal of Epidemiology 143 (6): 608-623.

Fernández-Gaxiola, A. C., and L. M. De-Regil 2011. "Intermittent Iron Supplementation for Reducing Anaemia and Its Associated Impairments in Menstruating Women." Cochrane Database of Systematic Reviews 12: CD009218.

FHB (Family Health Bureau). 2018. STOP STUNTING: The Power of Maternal Nutrition.

Fiszbein, A, N. Schady, F. H. Ferreira, M. Grosh, N. Kelleher, P. Olinto, and E. Skoufias. 2009. Conditional Cash Transfers for Attacking Present and Future Poverty. World Bank Policy Research Report, Washington, DC: World Bank.

Fracassi, P., C. Picanyol, W. Knechtel, M. D’Alimonte, A. Gary, A. Pomeroy-Stevens, and R. Watts. 2017. Budget Analysis for Nutrition: Guidance Note for Countries (update 2017).

Freeman, M. C., M. E. Stocks, O. Cumming, A. Jeandron, J. P. T. Higgins, J. Wolf, A. PrussUstun, S. Bonjour, P. R. Hunter, L. Fewtrell, and V. Curtis. 2014. "Hygiene and Health: Systematic Review of Handwashing Practices Worldwide and Update of Health Effects." Tropical Medicine and International Health 19 (8): 906-916.

Gaarder, M. M., A. Glassman, and J. E. Todd. 2010. "Conditional Cash Transfers and Health: Unpacking the Causal Chain.” J Dev Effect 2: 6-50.

Galasso, E., and A. Wagstaff. 2018. The Aggregate Income Losses from Childhood Stunting and the Returns to a Nutrition Intervention Aimed at Reducing Stunting. Washington, DC: World Bank. 
Gardner, J. M. M., C. A. Powell, H. Baker-Henningham, S. P. Walker, T. J. Cole, and S. M. Grantham-McGregor. 2005. "Zinc Supplementation and Psychosocial Stimulation: Effects on the Development of Undernourished Jamaican Children." Am J Clin Nutr. 82:399-405.

Giles, J., and E. Satriawan. 2010. "Protecting Child Nutritional Status in the Aftermath of a Financial Crisis: Evidence from Indonesia.” Policy Research Working Paper 5471, World Bank, Washington, DC.

Gillespie, S., J. Harris., and S. Kadiyala. 2012. "The Agriculture-nutrition Disconnect in India: What Do We Know?” IFPRI Discussion Paper 01187, International Food Policy Research Institute, Washington, DC.

GOSL (Government of Sri Lanka). 2013. Vision 2016: Sri Lanka, A Nourished Nation: Multisector Action Plan for Nutrition. Colombo: National Nutrition Secretariat.

- 2019. Multi-sector Action Plan for Nutrition 2018-2025, (Draft). Colombo: National Nutrition Secretariat.

Goto, R., C. G. N. Mascie-Taylor, and P. G. Lunn. 2009. "Impact of Anti-Giardia and Antihelmintic Treatment on Infant Growth and Intestinal Permeability in Rural Bangladesh: A Randomised Double-Blind Controlled Study." Transactions of the Royal Society of Tropical Medicine and Hygiene 103 (5): 520-529.

Grantham-McGregor, S. M., C. A. Powell, S. P. Walker, and J. H. Himes. 1991. "Nutritional Supplementation, Psychosocial Stimulation, and Mental Development of Stunted Children: the Jamaican Study." Lancet 338: 1-5.

Fink, G., I. Günther, and K. Hill. 2011. "The Effect of Water and Sanitation on Child Health: Evidence from the Demographic and Health Surveys 1986-2007.” International Journal of Epidemiology 40 (5): 1196-1204.

HarvestPlus. 2019. 2018. Annual Report. Washington, DC: HarvestPlus.

Headey, D., and J. Hoddinott. 2015. "Understanding the Rapid Reduction of Undernutrition in Nepal 2001-2011.” PLOS ONE 10 (12): e0145738.

Hoddinott, J., M. Rosegrant, and M. Torero. 2013. "Investments to Reduce Hunger and Undernutrition." In Copenhagen Consensus 2012, edited by B. Lomborg. Cambridge: Cambridge University Press.

Hotz, C., L. Cornelia, A. de Brauw, P. Eozenou, D. Gilligan, M. Moursi, B. Munhaua, P. Jaarsveld, A. Carriquiry, and J. V. Meenakshi. 2012. “A Large-scale Intervention to Introduce Orange Sweet Potato in Rural Mozambique Increases Vitamin A Intakes among Children and Women." British Journal of Nutrition 108: 163-76. 
Humphrey, J. H., M. N. Mbuya, R. Ntozini, L. H. Moulton, R. J. Stoltzfus, N. V. Tavengwa, K. Mutasa, F. Majo, B. Mutasa, and G. Mangwadu. 2019. "Independent and Combined Effects of Improved Water, Sanitation, and Hygiene, and Improved Complementary Feeding, on Child Stunting and Anaemia in Rural Zimbabwe: A Cluster-randomised Trial." The Lancet Global Health 7 (1): e132-e147.

Imdad, A., K. Herzer, E. Mayo-Wilson, M. Y. Yakoob, and Z. A. Bhutta. 2010. "Vitamin A Supplementation for Preventing Morbidity and Mortality in Children from 6 Months to 5 Years of Age." Cochrane Database of Systematic Reviews 12: CD008524.

Kazianga, H., D. De Walque, and H. Alderman. 2009. "Educational and Health Impact of Two School Feeding Schemes: Evidence from a Randomized Trial in Rural Burkina Faso." World Bank Policy Research Working Paper 4976, World Bank, Washington, DC.

Kelder, S. H., C. L. Perry, K. I. Klepp, and L. L. Lytle. 1994. "Longitudinal Tracking of Adolescent Smoking, Physical Activity, and Food Choice Behaviors." American Journal of Public Health 84 (7): 1121-1126.

Kristjansson, E. A., V. Robinson, M. Petticrew, B. MacDonald, J. Krasevec, L. Janzen, T. Greenhalgh, G. A. Wells, J. MacGowan, A. P. Farmer and B. Shea. 2007. "School Feeding for Improving the Physical and Psychosocial Health of Disadvantaged Elementary School Children." Cochrane Database Syst Rev. 1: CD004676.

Leroy, J. L., P. Gadsden, S. Rodríguez-Ramírez, and T. González de Cossiío. 2010. "Cash and Inkind Transfers in Poor Rural Communities in Mexico Increase Household Fruit, Vegetable, and Micronutrient Consumption But Also Lead to Excess Energy Consumption." Journal of Nutrition 140: 612-617.

Leroy, J. L., P. Gadsden, T. G. De Cossío, and P. Gertler. 2013. "Cash and In-kind Transfers Lead to Excess Weight Gain in a Population of Women with a High Prevalence of Overweight in Rural Mexico.” Journal of Nutrition 143: 378-383.

Lin, A., B. F. Arnold, S. Afreen, R. Goto, T. M. N. Huda, R. Haque, R. Raqib, L. Unicomb, T. Ahmed, J. M. Colford Jr, and S. P. Luby. 2013. "Household Environmental Conditions Are Associated with Enteropathy and Impaired Growth in Rural Bangladesh." American Journal of Tropical Medicine and Hygiene 89 (1): 130-137.

Luby, S. P., M. Rahman, B. F. Arnold, L. Unicomb, S. Ashraf, P. J. Winch, C. P. Stewart, F. Begum, F. Hussain, and J. Benjamin-Chung. 2018. "Effects of Water Quality, Sanitation, Handwashing, and Nutritional Interventions on Diarrhoea and Child Growth In Rural Bangladesh: A Cluster Randomised Controlled Trial." The Lancet Global Health 6 (3): e302-e315. 
Manley J., S. Gitter, and V. Slavchevska. 2011. "How Effective Are Cash Transfer Programs at Improving Nutritional Status?” Working Paper 2010-2018, Department of Economics, Towson University, Maryland, the United States.

- 2012. How Effective Are Cash Transfer Programmes at Improving Nutritional Status? A Rapid Evidence Assessment of Programmes' Effects on Anthropometric Outcomes. London EPPI Centre, Social Research Science Unit, Institute of Education, London: University of London.

Masset, E., L. Haddad, A. Cornelius, and J. Isaza-Castro. 2012. "Effectiveness of Agricultural Interventions That Aim to Improve Nutritional Status of Children: Systematic Review." BMJ 344: d8222.

Menon, P., M. T. Ruel, C. U. Loechl, M. Arimond, J. P. Habicht, G. Pelto and L. Michaud. 2007. "Micronutrient Sprinkles Reduce Anemia among 9- to 24-mo-old Children When Delivered through an Integrated Health and Nutrition Program in Rural Haiti." Journal of Nutrition 137: 1023-30.

MFARD (Ministry of Fisheries and Aquatic Resources Development). 2016. Ministry of Fisheries and Aquatic Resources Development Annual Report 2016. Colombo: Ministry of Fisheries and Aquatic Resources Development, Sri Lanka.

MCPWS (Ministry of City Planning, Water Supply, and Higher Education). 2018. Ministry of City Planning, Water Supply and Higher Education, Performance Report 2018. Colombo: Ministry of City Planning, Water Supply and Higher Education, Sri Lanka.

MoE (Ministry of Education). 2017. Nutrition Program Implemented for School Children: Ministry of Education Circular 10/2017. Colombo: Ministry of Education, Sri Lanka.

MoH (Ministry of Health, Nutrition and Indigenous Medicine). 2010. National Nutrition Policy $(N N P)$ 2010. Colombo: Ministry of Health, Nutrition and Indigenous Medicine, Sri Lanka.

Moraes, L. R. S., J. A. Cancio, and S. Cairncross. 2004. "Impact of Drainage and Sewerage on Intestinal Nematode Infections in Poor Urban Areas in Salvador, Brazil." Transactions of the Royal Society of Tropical Medicine and Hygiene 98 (4): 197-204.

MRI (Medical Research Institute). 2013. National Nutrition and Micronutrient Survey 2012. Colombo: Ministry of Health, Sri Lanka.

Nahar, B., J. D. Hamadani, T. Ahmed, F. Tofail, A. Rahman, S. N. Huda, and S. M. GranthamMcGregor. 2009. "Effects of Psychosocial Stimulation on Growth and Development of Severely Malnourished Children in a Nutrition Unit in Bangladesh.” Eur J Clin Nutr. 63: 725-31. 
PAHO (Pan American Health Organization). 2003. Guiding principles for complementary feeding of the breastfed child. Washington, DC: PAHO.

Peña-Rosas, J. P., L. M. De-Regil, T. Dowswell, and F. E. Viteri. 2012. "Daily Oral Iron Supplementation during Pregnancy." Cochrane Database of Systematic Reviews 12: CD004736.

Pickering, A. J., and J. Davis. 2012. "Freshwater Availability and Water Fetching Distance Affect Child Health in Sub-Saharan Africa." Environmental Science and Technology 46 (4): 2391-2397.

Ruel, M., H. Alderman, and Maternal and Child Nutrition Study Group. 2013. "Nutrition-Sensitive Interventions and Programmes: How Can They Help to Accelerate Progress in Improving Maternal and Child Nutrition?" Lancet 382: 536-551.

Ruel, M. T., P. Menon, J. P. Habicht, C. Loechl, G. Bergeron, G. Pelto, M. Arimond, J. Maluccio, L. Michaud and B. Hankebo. 2008. "Age-based Preventive Targeting of Food Assistance and Behaviour Change Communication for Reduction of Childhood Undernutrition in Haiti: A Cluster Randomized Trial.” Lancet 371: 588-595.

Salam, R. A., M. Hooda, J. K. Das, A. Arshad, Z. S. Lassi, P. Middleton, and Z. A. Bhutta. 2016. "Interventions to Improve Adolescent Nutrition: A Systematic Review and MetaAnalysis.” Journal of Adolescent Health 59: S29eS39.

Singh, A. S., C. Mulder, J. W. R. Twisk, W. Van Mechelen, and W. J. M. Chinapaw. 2008. "Tracking of Childhood Overweight into Adulthood: A Systematic Review of the Literature." Obesity Reviews 9 (5): 474-488.

Skoufifias, E., and B. McClafferty. 2001. "Is PROGRES A working? Summary of the Results of an Evaluation by IFPRI." Food Consumption and Nutrition Division Discussion Paper 118, International Food Policy Research Institute, Washington, DC.

Stewart, C. P., A. J. Pickering, H. N. Dentz, B. F. Arnold, C. D. Arnold, J. Benjamin-Chung, T. Clasen, K. G. Dewey, L. C. Fernald, and C. Null. 2018. "Effects of Water Quality, Sanitation, Handwashing, and Nutritional Interventions on Diarrhoea and Child Growth in Rural Kenya: A Cluster-Randomised Controlled Trial." The Lancet Global Health 6 (3): e316-e329.

Story, M., D. Neumark-Sztainer, and S. French. 2002. "Individual and Environmental Influences on Adolescent Eating Behaviors." Journal of American Dietary Association 102(3): S40S51. 
Surkan, P.J., C. E. Kennedy, K. M. Hurley, and M. M. Black. 2011. "Maternal Depression and Early Childhood Growth in Developing Countries: Systematic Review and Meta-analysis." WHO Bull 89: 608-15.

Torlesse, H., and V. M. Aguayo. 2018. "Aiming Higher for Maternal and Child Nutrition in South Asia.” Maternal and Child Nutrition 14 (Suppl 4): e12739.

UNICEF (United Nations Children's Fund). 1990. "Strategy for Improved Nutrition of Children and Women in Developing Countries." New York: UNICEF.

—. 2015. "UNICEF's Approach to Scaling Up Nutrition for Mothers and Their Children." Discussion Paper, Program Division, UNICEF, New York.

- 2019. UNICEF's Global Social Protection Programme Framework. New York: UNICEF.

UNICEF (United Nations Children's Fund) and ISSA (International Step by Step Association). 2016. Supporting Families for Nurturing Care. https://www.issa.nl/home_visiting.

UNICEF, WHO, and World Bank. 2019. UNICEF-WHO-World Bank Joint Child Malnutrition Estimates. New York, Geneva, Washington, DC: UNICEF, WHO, World Bank.

Victora, C.G., R. Bahl, A. J. D. Barros, G. V. A. França, S. Horton, J. Krasevec, S. Murch, M. J. Sankar, N. Walker, and N. C. Rollins. 2016. "Breastfeeding in the 21st Century: Epidemiology, Mechanisms, and Lifelong Effect.” Lancet 387: 475-490.

Walker, S. P., S. M. Chang, C. A. Powell, E. Simonoff, and S. M. Grantham-McGregor. 2007. "Early Childhood Stunting Is Associated with Poor Psychological Functioning in Late Adolescence and Effects Are Reduced by Psychosocial Stimulation.” Journal of Nutrition 137 (11): 2464-2469.

WFP (World Food Programme). 2017. National Strategic Review of Food Security and Nutrition: $\begin{array}{llll}\text { Towards Zero Hunger } & 2017 .\end{array}$ https://www.wfp.org/publications/Sri_Lanka_Food_Security_Review.

WHO (World Health Organization). 2007. Promoting Physical Activity in Schools: An Important Element of a Health-promoting School. Geneva: WHO.

- 2011. Haemoglobin Concentrations for the Diagnosis of Anaemia and Assessment of Severity: Vitamin and Mineral Nutrition Information System. Geneva: WHO.

- 2013. Guideline: Updates on the Management of Severe Acute Malnutrition in Infants And Children. Geneva: WHO.

- 2014a. Global Nutrition Targets 2025: Stunting Policy Brief (WHO/NMH/NHD/14.3). Geneva: WHO. 
. 2014b. Global Status Report on Noncommunicable Diseases 2014. Geneva: WHO.

- 2016a. WHO Guideline: Daily Iron Supplementation in Infants and Children. Geneva: WHO.

-2016b. WHO Guideline: Fortification of Maize Flour and Corn Meal with Vitamins and Minerals. Geneva: WHO.

- 2016c. WHO Recommendations on Antenatal Care for a Positive Pregnancy Experience. Geneva: WHO.

- 2018. Guideline: Implementing Effective Actions for Improving Adolescent Nutrition. Geneva: WHO.

- 2019. Essential Nutrition Actions: Mainstreaming Nutrition through the Life-course. Geneva: WHO.

2020. Global Health Expenditure Database. https://apps.who.int/nha/database/Home/Index/en.

World Bank. 2007. From Agriculture to Nutrition: Pathways, Synergies and Outcomes. Washington, DC: World Bank.

- 2012. Managing Risk, Promoting Growth: Developing Systems for Social Protection in Africa: The World Bank's Africa Social Protection Strategy 2012-2022. Washington, DC: World Bank.

—. 2017a. Sri Lanka Health Financing System Assessment. Washington, DC: World Bank. . 2017b. Multisectoral Nutrition Assessment in Sri Lanka's Estate Sector. Washington, DC: World Bank.

. 2017c. Getting to Work: Unlocking Women's Potential in Sri Lanka's Labor Force. Washington, DC: World Bank.

. 2018. Improving Nutrition Outcomes for Children in Sri Lanka's Estate Sector: The Positive Deviance Approach. Washington, DC: World Bank.

—. 2019a. World Development Indicator. https://databank.worldbank.org/source/worlddevelopment-indicators.

- 2019b. Assessing Public Financing for Improving Nutrition Outcomes and Human Capital in Bhutan: What Gets Measured Gets Managed. Washington, DC: World Bank.

- 2019c. Assessing Public Financing for Nutrition in Nepal (2011-2017). Washington, DC: World Bank. 
Yamano, T., H. Alderman, and L. Christiaensen. 2005. "Child Growth, Shocks, and Food Aid in Rural Ethiopia.” Am J Agric Econ. 87:273-288.

Ziegelbauer, K., B. Speich, D. Mausezahl, R. Bos, J. Keiser, and J. Utzinger. 2012. "Effect of Sanitation on Soil-Transmitted Helminth Infection: Systematic Review and Metaanalysis.” PLoS Medicine 9 (1): e1001162. 
